31 Collection Focus dirigée par Alain Cortat

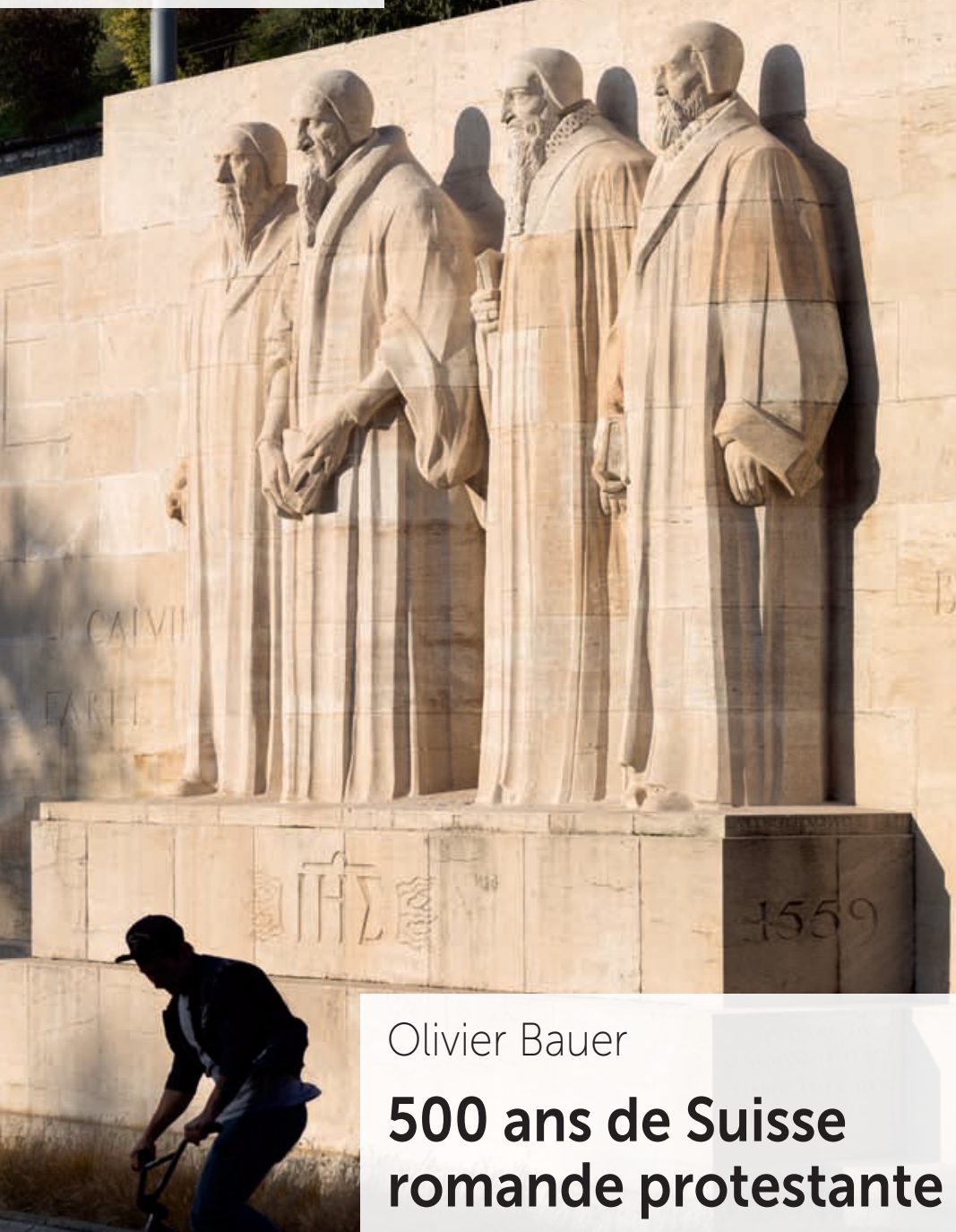





\section{ANS DE SUISSE ROMANDE PROTESTANTE}




\section{Collection Focus}

Focus est une collection qui présente des synthèses sur des thématiques de sciences humaines et sociales, ainsi que sur des sujets d'actualité. Elle vise un large public et s'adresse en premier lieu à des personnes qui souhaitent découvrir un domaine et en comprendre les principaux enjeux. Elle permet de s'informer de l'état d'une question et de saisir les différentes approches ou les différents points de vue exprimés sur un sujet particulier.

Des extraits de documents, des chronologies et des cartes complètent le texte. Une bibliographie sélective permet d'orienter le lecteur qui souhaite approfondir un thème.

La collection Focus est dirigée par Alain Cortat. 
Olivier Bauer

\section{ANS de SuISSE romande PROTESTANTE}

ÉDitions Livreo-AlPHIL 
(C) Éditions Livreo-Alphil, 2020

Case postale 5

2002 Neuchâtel 2

Suisse

Éditions Livreo-Alphil est une marque des Éditions Alphil.

www.alphil.ch

Alphil Distribution

commande@alphil.ch

ISBN papier 978-2-88950-041-3

ISBN PDF 978-2-88950-045-1

ISBN E-pub 978-2-88950-046-8

DOI : 10.33055/ALPHIL.00031

Publié avec le soutien du Fonds national suisse de la recherche scientifique.

Les Éditions Alphil bénéficient d'un soutien structurel de l'Office fédéral de la culture pour les années 2016-2020.

Illustration de couverture: KEYSTONE/Gaetan Bally

Couverture, maquette et réalisation: Nusbaumer-graphistes sàrl, www.nusbaumer.ch

Ce livre est sous licence:

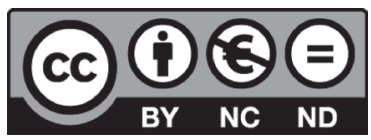

Ce texte est sous licence Creative Commons : elle vous oblige, si vous utilisez cet écrit, à en citer l'auteur, la source et l'éditeur original, sans modifications du texte ou de l'extrait et sans utilisation commerciale.

Responsable d'édition: François Lapeyronie 


\section{INTRODUCTION}

\section{La Suisse romande PRotestante}

Peut-on faire l'histoire de quelque chose qui n'existe pas? Peut-on faire l'histoire de 500 ans d'une Suisse romande protestante, quand «la Suisse» n'existe pas pendant la plus grande partie de cette histoire, qu'elle n'est pratiquement pas «romande» et qu'il reste à définir ce que signifie être «protestant-e»? On peut certainement, mais il faut prendre quelques précautions.

\section{La SuisSe N'existe Pas !}

Lorsqu'à l'hiver 1527, Berne envoie Guillaume Farel prêcher l'évangile à Aigle, la Suisse n'existe pas. Ce qui existe ce sont treize cantons - Ort, «lieu» en allemand - qui se sont confédérés, mettant une partie de leur existence en commun - Schwyz, Unterwald et Uri (fondateurs en 1291), Lucerne (depuis 1332), Zurich (1351), Glaris et Zoug (1352), Berne (1353), Fribourg et Soleure (1481), Bâle et Schaffhouse (1501) et Appenzell (1513) - et envoyant des délégués dans des Diètes qui prennent des décisions à la majorité.

À cette confédération, il faut ajouter des bailliages, c'està-dire des territoires qui dépendent d'un ou de plusieurs cantons - par exemple l'Argovie et le Tessin actuels ou certains territoires, conquis lors des guerres de Bourgogne, qui font aujourd'hui partie du canton de Vaud -, et des alliés, comme la République de Genève (dès 1477), les dizains du Valais et le Valais assujetti (dès 1528), la Principauté épiscopale de Bâle, dont le prince-évêque est installé à Porrentruy (dès 1579), la 
Principauté de Neuchâtel et de Valangin (dès 1598), ainsi que les Grisons, Mulhouse et Saint-Gall.

\section{LA SuISSE RoMAnde N'EXISTe Pas!}

Même s'il existe une entité géographique et politique qui ressemble à une «Suisse», celle-ci n'est pas romande. Jusqu'à l'intégration du canton bilingue de Fribourg et à l'envahissement par Berne de quelques villages près du lac Léman, la Suisse est uniquement germanophone. Et elle le reste jusqu'à ce que la France impose et la République helvétique et le bilinguisme français allemand (1798). Et qu'elle compte des francophones ne change rien! La Suisse parle allemand, et Fribourg doit en faire sa langue officielle dès 1483.

$\mathrm{Au} \mathrm{XVI}^{\mathrm{e}}$ siècle, ce qui se rapproche le plus d'une Suisse romande est le Welschland, qui désigne exclusivement le Pays de Vaud, sujet bernois depuis 1536. Il faut attendre le XVIII ${ }^{\mathrm{e}}$ siècle pour que l'expression «Suisse romande» apparaisse sous la plume de l'historien vaudois Abraham Rochat qui rédige, entre 1723 et 1725, une Histoire de la Suisse romande, celle du Pays de Vaud, de l'État de Neuchâtel, des Évêchés de Bâle, de Genève et de Sion. Mais depuis le $\mathrm{Xv}^{\mathrm{e}}$ siècle, on utilise l'adjectif «romand» ou «roman» tantôt par opposition aux «Alémaniques» pour désigner les Suisses qui parlent la langue française, tantôt par opposition à la langue française pour désigner les patois franco-provençaux parlés en Suisse romande.

\section{LA SuISSE Romande PROTESTANTE N'EXISTE PAS !}

Ce que l'on appelle la «Suisse romande» n'a jamais été protestante. D'abord parce que certaines de ses parties - Fribourg, le Valais, le Jura - sont restées majoritairement catholiques; ensuite parce que même les territoires protestants ne l'ont pas toujours et uniformément été.

De manière générale, «protestantes » désigne les personnes et les Églises qui se revendiquent de la Réforme - ou de la 
Réformation, selon l'usage suisse - du XvI ${ }^{\mathrm{e}}$ siècle. Celle-ci a été initiée par Martin Luther qui, le 31 octobre 1517, aurait cloué sur la porte du château de Wittenberg une affiche où figuraient 95 thèses; il y dénonçait la vente par l'Église catholique romaine des indulgences, censées permettre à celles et ceux qui les achetaient de réduire le temps passé au purgatoire. Comme il n'existe pas d'autorité qui accorde ou refuse le label «protestant», chaque personne et chaque Église reste libre de se déclarer protestante. Ce qui explique que les formes protestantes sont nombreuses et variées: luthériennes, réformées, évangéliques ou pentecôtistes.

Les dénominateurs communs des protestantismes, c'est d'abord le fait d'être chrétien·ne, c'est-à-dire de croire que Jésus révèle quel Dieu est Dieu; c'est ensuite d'être convaincu·e que Dieu révèle sa volonté directement à chaque être humain (principe du témoignage intérieur du Saint-Esprit); c'est encore de refuser tous les intermédiaires qui se placent ou que l'on met entre Dieu et les êtres humains: les personnes - Marie et les saints, le pape et les prêtres - comme les artefacts - l'eucharistie, les pèlerinages ou les icônes; c'est enfin compter plus sur l'amour de Dieu que sur ses propres efforts (principe de la grâce seule), faire confiance à Dieu pour accepter chaque être humain tel qu'il est (principe de la foi seule), accorder une valeur particulière à la Bible (principe de l'Écriture seule).

\section{De Quelle Suisse romande Protestante EST-IL QUESTION?}

Comme souvent en Suisse, il convient de répondre: «Cela dépend!» Essayons donc de résumer simplement une situation compliquée.

\section{À la Réforme}

$\mathrm{Au} \mathrm{XVI}^{\mathrm{e}}$ siècle, la Suisse romande comprend, dans l'ordre de leur passage à la Réforme, la partie francophone du canton de Berne - les quatre mandements, soit Aigle, Bex, Ollon 
et les Ormonts, ainsi que les bailliages francophones qu'il administre en commun avec le canton de Fribourg, à savoir Grandson, Orbe-Échallens et Morat -, la partie méridionale de la Principauté épiscopale de Bâle - l'Erguël, la Montagne de Diesse, La Neuveville et la Prévôté de Moutier-Grandval -, les deux Comtés de Neuchâtel et Valangin, la République de Genève, le Pays de Vaud - que nous préférons traiter hors du canton de Berne, bien qu'il en fasse partie - et le Valais assujetti-le Bas-Valais -, un territoire francophone qui, sans passer à la Réforme, compte cependant une population protestante. Quant à la population francophone du canton de Fribourg - y compris celle de la Gruyère, prise à la Savoie en 1536 -, elle est presque exclusivement catholique, excepté dans le bailliage commun de Morat.

D'un point de vue confessionnel, la «Suisse romande protestante » est réformée: Berne, les territoires protestants de la Principauté de Bâle et le Pays de Vaud ont adopté la théologie du Zurichois Huldrich Zwingli (1484-1531), Genève celle du Français Jean Calvin (1509-1564) et Neuchâtel un mélange des deux; ces Églises réformées forment des Églises d'État. La Suisse romande est aussi anabaptiste ou mennonite, une manière d'être protestant·e que les Églises réformées persécutent, mais qui se montre incroyablement résiliente; les anabaptistes ont comme particularité de refuser les baptêmes d'enfants, d'être non violents et de refuser de prêter serment, y compris aux autorités politiques.

\section{Sous l'Ancien Régime}

Sous l'Ancien Régime, pendant presque deux cents ans, la situation politique de la Suisse romande reste stable, pour ne pas dire figée. La Suisse romande est formée de la partie francophone du canton de Fribourg, des bailliages communs à Berne et à Fribourg, de la République de Genève, du Pays de Vaud, de la partie francophone de la Principauté épiscopale de Bâle, de la Principauté de Neuchâtel et de la Seigneurie de Valangin et du Valais assujetti. 
La situation religieuse de ces territoires évolue lentement, mais évolue quand même. Au XVII ${ }^{\mathrm{e}}$ siècle, une première ligne de fracture apparaît à l'intérieur du protestantisme, entre des réformé·e·s qui se réclament d'une orthodoxie stricte et d'autres qui mettent en cause certains dogmes: la prédestination - Dieu aurait prédestiné chaque être humain, avant même sa naissance et indépendamment de ses actes, soit au salut, soit à la perdition - ou l'inerrance de la Bible - elle ne pourrait pas se tromper, car directement inspirée par Dieu.

Mais il faut attendre la toute fin du $\mathrm{XVII}^{\mathrm{e}}$ siècle et le $\mathrm{XVIII}^{\mathrm{e}}$ siècle pour que d'autres formes de protestantisme soient tolérées en Suisse romande protestante: les piétistes, disciples du luthérien Philip Jakob Spener (1635-1705), qui insistent sur la régénération des individus; les quiétistes qui prônent une passivité propre à laisser Dieu agir dans l'être humain ; les Frères moraves, dont le comte Nikolaus Ludwig von Zinzendorf (1700-1760) fut l'évêque, qui cherchent l'unité des chrétien·ne·s. Ces courants oscillent entre deux attitudes : rester dans les Églises réformées pour les transformer de l'intérieur ou créer de nouvelles communautés pour pouvoir vivre leur foi ; c'est souvent la seconde qu'ils choisissent ou qui leur est imposée. On trouve aussi en Suisse romande deux des trois communautés amish de Suisse qui subsistent après 1750: à la Chaux d'Abel (Jura) et dans le Val-de-Ruz (Neuchâtel).

\section{Dans la Suisse moderne}

La Révolution française, les guerres napoléoniennes et le Congrès de Vienne en 1815 vont profondément transformer le visage de la Suisse. Politiquement, d'une part, avec l'indépendance accordée aux bailliages - dont évidemment le Pays de Vaud -, l'annexion temporaire de certains territoires à la France - dans le Jura, le Valais ainsi qu'à Genève - ou encore l'imposition d'une éphémère République helvétique. Géographiquement, d'autre part, avec l'attribution à la Suisse de nouveaux territoires et la création de nouveaux cantons. 
De toute cette période compliquée va émerger ce que l'on appelle la Suisse moderne, un État fédéral dans ses frontières actuelles.

Sur le plan religieux, la France va imposer à la Suisse la liberté de croyances et de conscience; en 1848, la Confédération helvétique va l'inscrire dans sa constitution et l'imposer aux cantons. Pour la Suisse romande protestante, cela implique d' accueillir - souvent avec réticence - les catholiques mais aussi d'autres communautés protestantes, issues du mouvement du Réveil : des dissidents qui forment des Églises qualifiées d'évangélique à Genève, de libre dans le canton de Vaud ou d'indépendante dans le canton de Neuchâtel; des assemblées darbystes, en référence au nom du fondateur, l'Anglais John Nelson Darby (1800-1882); dès 1883, l'Armée du salut, longtemps contestée, dont le droit à l'existence doit être reconnu par le Tribunal fédéral.

Aux $\mathrm{Xx}^{\mathrm{e}}$ et $\mathrm{XXI}^{\mathrm{e}}$ siècles, ce sont les frontières intérieures de la Suisse qui bougent, avec la création d'un canton du Jura, séparé de Berne en 1978, sans que l'on sache encore en 2019 si ce sera avec ou sans Moutier. Mais c'est aussi le protestantisme qui se transforme radicalement; la Suisse romande protestante connaît une forte baisse du protestantisme réformé et un fort développement des protestantismes évangéliques, pentecôtistes et néo-pentecôtistes; elle voit aussi l'apparition d'Églises protestantes «issues de l'immigration» où les protestant $\cdot e \cdot s^{1}$ se réunissent en fonction de leur origine ou de la langue parlée.

\footnotetext{
${ }^{1}$ Pour rendre justice au «protestantisme suisse romand» qui compte au moins autant de femmes que d'hommes (et peut-être même plus), nous avons choisi d'utiliser une écriture inclusive.
} 


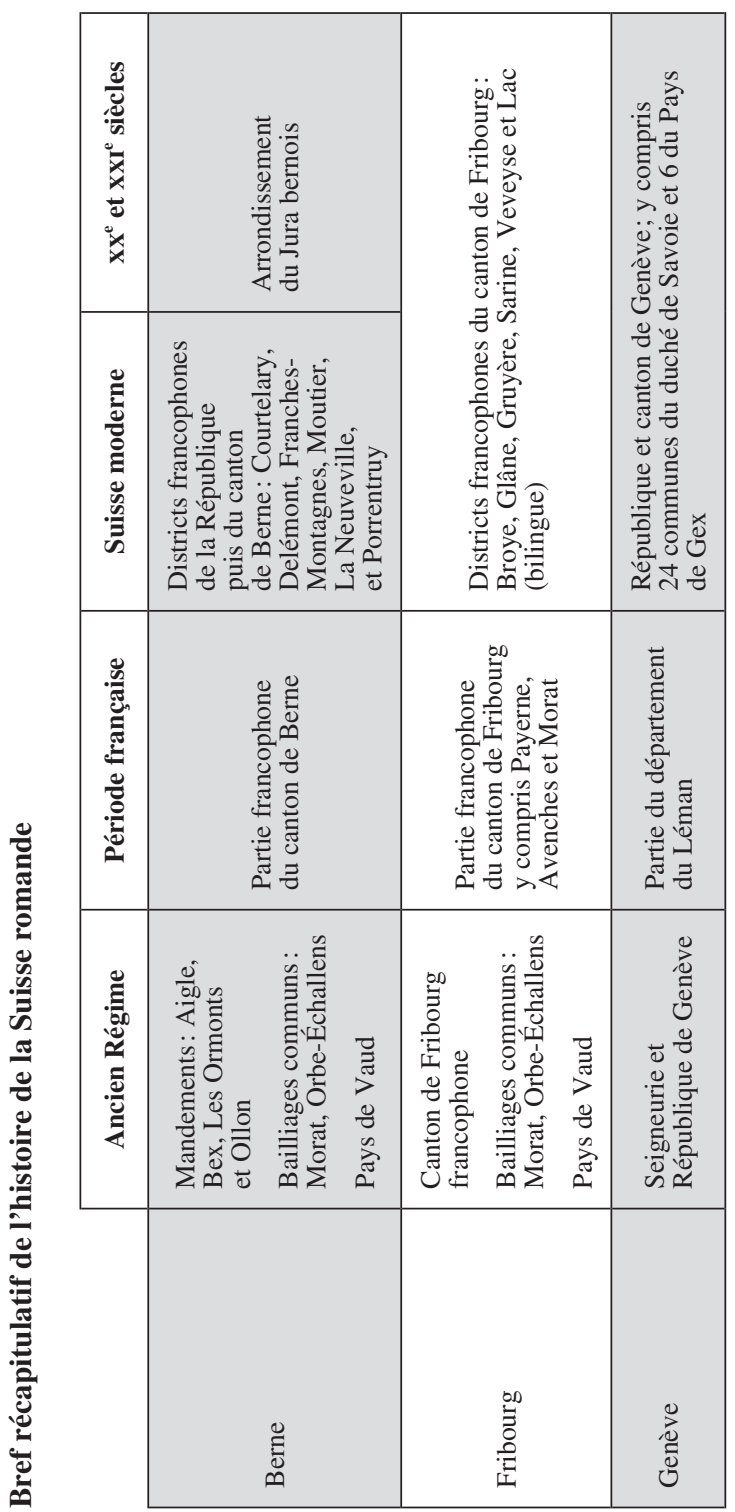




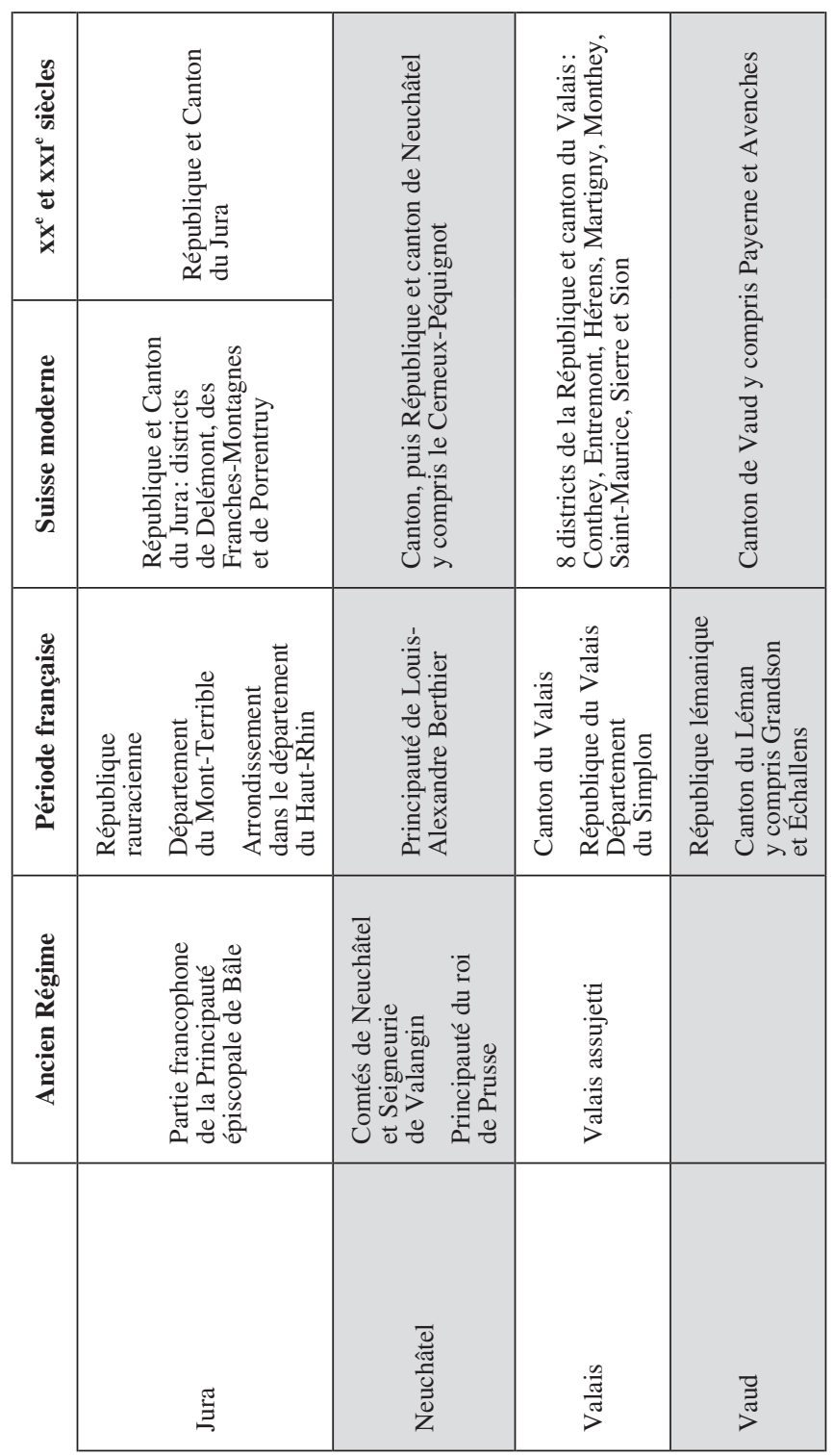




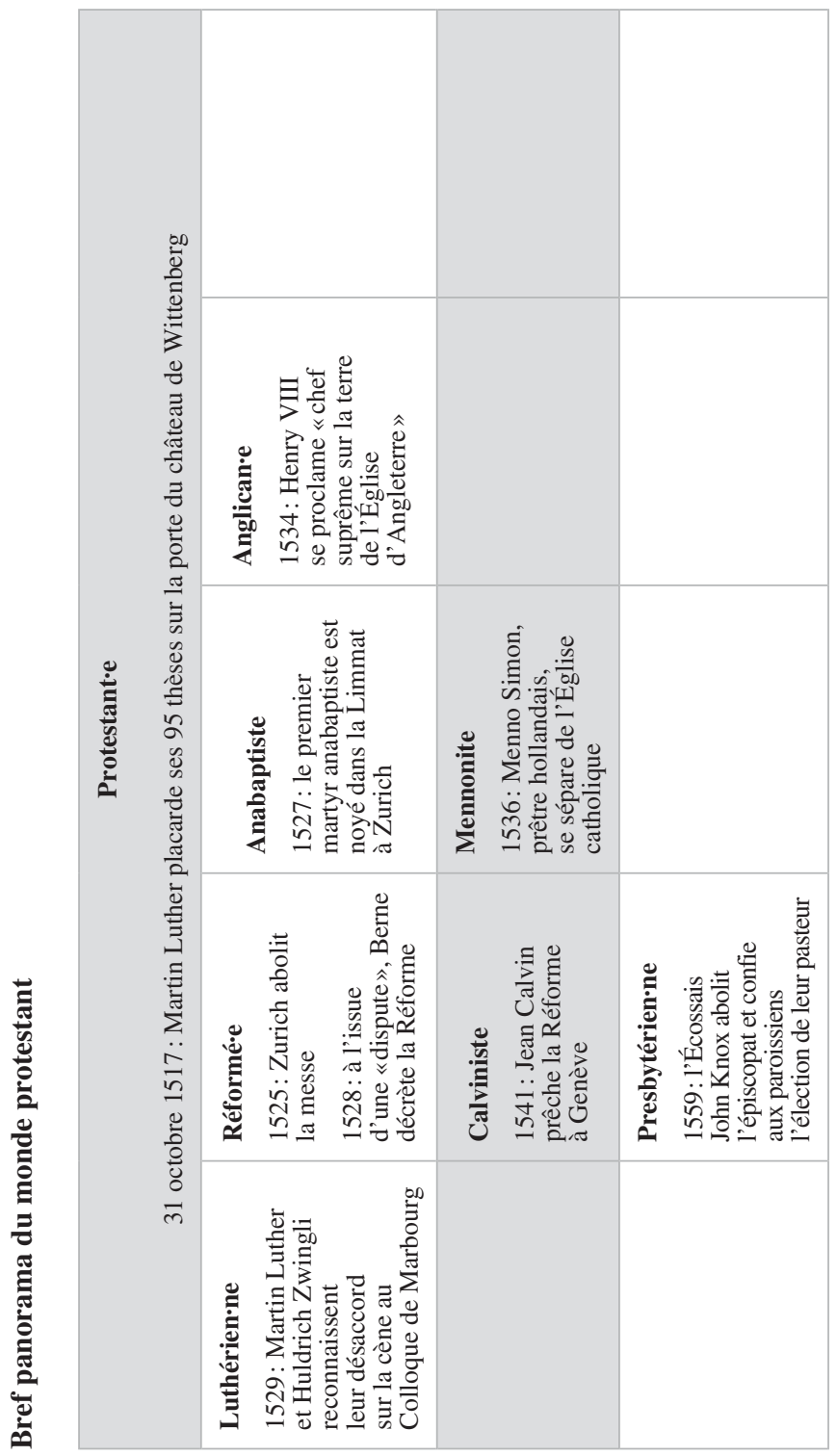


Olivier Bauer

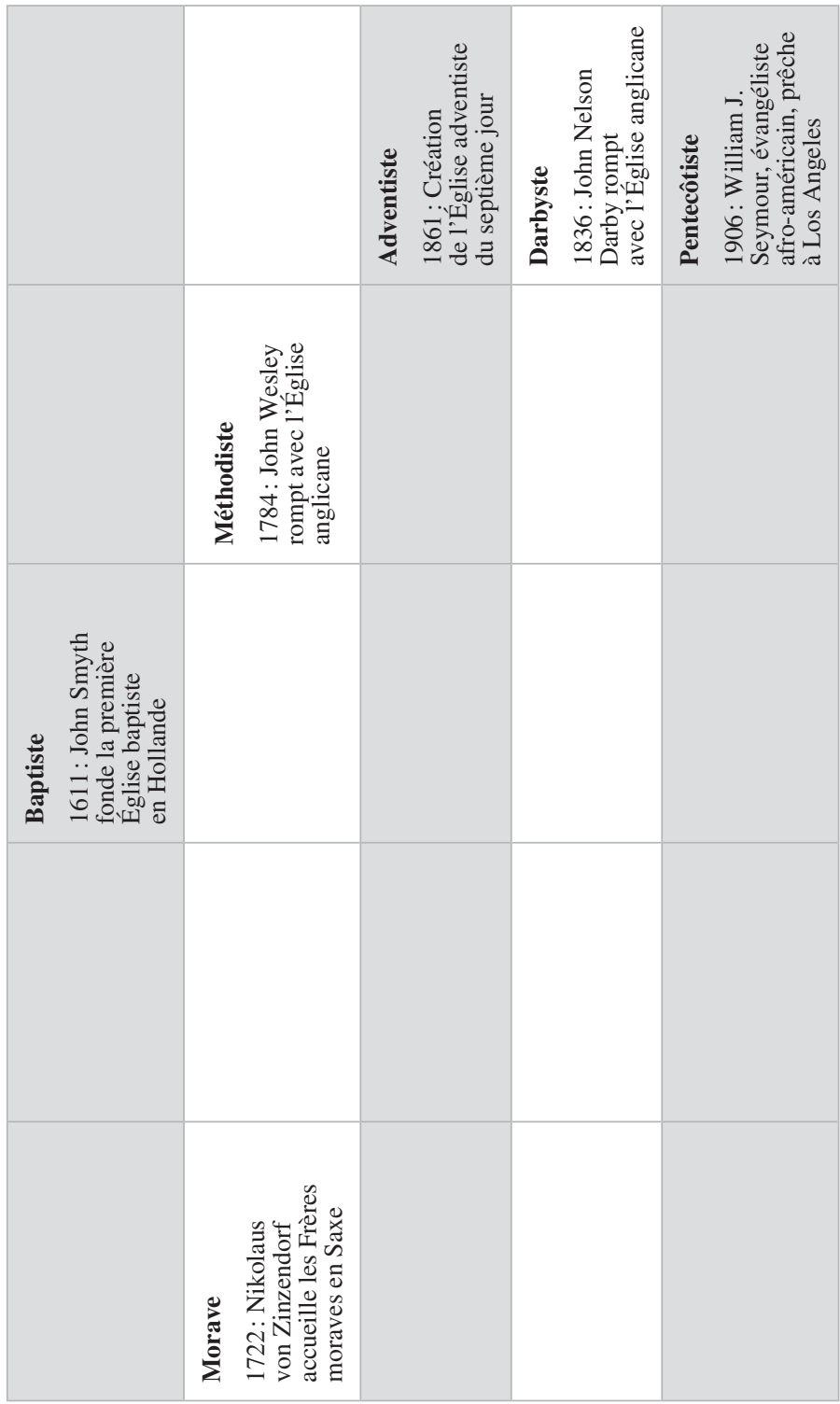




\section{ORIENTATION BIBLIOGRAPHIQUE}

AndRey G., La Suisse romande: une histoire à nulle autre pareille, Fleurier: Éditions du Belvédère, 2012.

Dictionnaire historique de la Suisse, http://www.hls-dhs-dss.ch/f/home.

ReYmond B., Le protestantisme en Suisse romande: portraits et effets d'une influence, Genève: Labor et Fides, 1999.

Vischer L., Schenker L., Dellsperger R., Histoire du christianisme en Suisse: une perspective æecuménique, Genève \& Fribourg (Suisse): Labor et Fides \& Saint-Paul, 2000. 


\section{1 \\ XVI ${ }^{\mathrm{e}}$ SIÈCLE : LA RÉFORME PROTESTANTE}

Le 30 novembre 1526, un certain Maître Ursinus - «Ursinus », c'est-à-dire «Ourson», peut-être pour exprimer ce qu'il doit à Berne dont l'ours est le totem -, régent - autrement dit un instituteur -, célèbre un culte clandestin à Aigle (Vaud) devant quelques sympathisants. Maître Ursinus n'est autre que Guillaume Farel, un prédicant originaire de Gap dans le Dauphiné, un évangéliste qui s'est déjà fait connaître à Montbéliard - il y a prêché au marché sur un étal appelé la «pierre à poissons» - et à Strasbourg, où il a rencontré le réformateur Martin Bucer, un agitateur que sa véhémence a fait expulser de Bâle, un propagandiste que sa virulence a fait jeter dans l'Aleine à Montbéliard. Sans le savoir, en l'ayant sûrement rêvé, le 30 novembre 1526, Guillaume Farel inaugure la Réforme protestante en Suisse romande.

En une dizaine d'années, elle va s'étendre, soutenue ou imposée par l'influence politique et la puissance militaire de la ville de Berne, promue par la détermination des prédicant·e.s, des pasteurs et des théologien.ne·s, souvent français.es, choisie - et parfois refusée - par des femmes et des hommes souhaitant des changements religieux et sociaux; une cinquantaine d'années plus tard, la Réforme est en quelque sorte «achevée», quand les pasteurs de Suisse romande - ceux de Berne d'abord en 1564, puis ceux de Genève en 1566 et enfin ceux de Neuchâtel en 1568 - ont adopté la même confession de foi que toute la Suisse protestante, la Confession helvétique postérieure, rédigée par Heinrich Bullinger (1504-1575). 
Examinons maintenant les principaux temps de la Réforme de la Suisse romande, en en suivant chronologiquement la diffusion dans les diverses régions suisses romandes.

\section{i. I DAns le CANTON de Berne...}

C'est à Aigle durant l'hiver 1526-1527, que commence la Réforme protestante - on précise parfois Réforme réformée pour la distinguer de la Réforme luthérienne ou de la Réforme radicale - en Suisse romande. À Berne, donc, puisque Aigle est un «mandement», c'est-à-dire une possession bernoise depuis la fin $\mathrm{du} \mathrm{Xv}^{\mathrm{e}}$ siècle. Berne y délègue Guillaume Farel (1489-1565), un théologien français - natif de Gap dans le Dauphiné, il parle et comprend le dialecte franco-provençal local -, comme instituteur avec le droit de prêcher l'évangile; sans grand succès, puisque le clergé local reste attaché à Rome. Pour que la Réforme prenne en Suisse romande, il faut un geste politique, il faut que Berne organise une Dispute - à partir du 7 février 1528 - et que la ville passe officiellement à la Réforme avec tous les territoires sur lesquels elle exerce son autorité. Guillaume Farel est alors chargé de traduire en français le livre bernois de liturgie, l'Agendbüchli. Sa traduction paraît en 1533 ; elle est la première liturgie francophone suisse romande.

Si la situation dans les quatre mandements est simple - on doit y croire comme Berne croit -, il en va autrement dans les territoires que Berne administre en commun avec Fribourg depuis les guerres de Bourgogne - les régions de Grandson (Vaud), de Morat (Fribourg) ainsi que celle d'Orbe et Échallens (Vaud) - puisqu'ils dépendent de deux cantons aux confessions différentes; la Réforme ne peut y être imposée, elle doit être acceptée. En 1530, Berne et Fribourg concluent un accord qui permet la cohabitation des catholiques et des protestant·e.s, mais qui ne résout pas tous les problèmes. Il règle, d'une part, la manière de coexister quand toute une population ne partage pas la même confession; le principe du simultaneum permet que les églises paroissiales soient utilisées 
par les deux confessions; chacune dispose d'un temps d'utilisation et parfois d'un espace qui lui est réservé - en général le chœur pour les catholiques et la nef pour les protestant·e.s; chacune doit respecter les aménagements de l'autre partie, ce qui implique que les protestant.e.s acceptent les autels et les ornements de la partie catholique et que les catholiques acceptent parfois de s'en passer. Il fixe, d'autre part, la procédure à suivre pour qu'un village puisse changer de confession: c'est l'instauration du «plus », un système de vote majoritaire (50\% plus un) sur le maintien de la messe ou sa suppression; l'accord est inégal, puisque la suppression de la messe est définitive, alors que le choix de la maintenir peut toujours être remis en question par un autre vote.

\section{LE «PLUS »}

Si ce sont les autorités civiles qui, dans la plupart des territoires suisses ont imposé ou refusé la Réforme, il est des endroits où c'est la population elle-même qui a pris sa décision, parfois contre sa souveraine ou son souverain. En Suisse romande, c'est le cas dans la Principauté épiscopale de Bâle qui dépendait du prince-évêque, réfugié à Porrentruy mais sur lequel s'exerçait l'influence bernoise, dans le Comté de Neuchâtel dont Jeanne de Hochberg était la suzeraine et dans les bailliages communs, ces territoires placés sous l'administration commune de Fribourg la catholique et de Berne la protestante.

En 1529, les cantons suisses parviennent à un accord. Les habitants d'une localité peuvent demander un «plus», c'està-dire un scrutin majoritaire, pour décider de leur avenir religieux. On organise alors un vote pour ou contre l'abolition de la messe. Processus démocratique, mais jusqu'à un certain point. Car si la majorité se prononce pour l'abolition de la messe, le territoire passe aussitôt et définitivement à la Réforme; si elle se prononce en faveur de la messe, le territoire demeure certes catholique mais avec la possibilité 
d'organiser un nouveau vote, en temps plus opportun. Dans ces conditions, on comprend que ce sont les protestants qui demandent les «plus». Autre point de friction, la composition du corps électoral. Seuls les hommes sont admis à voter, mais lesquels? Les bourgeois? Les étrangers qui possèdent un bien dans la localité? Et qu'en est-il des prêtres et des religieux? Des réponses à ces questions dépend souvent l'issue du vote.

Malgré toutes ses limites, le «plus» fonctionne. Preuve en est que le résultat n'est pas toujours identique. Ainsi, le premier «plus», tenu à Saint-Imier en juillet 1529 a pour résultat le maintien de la messe. Diesse (Berne), La Neuveville (Berne) et Moutier (Jura) ne choisissent la Réforme que lors d'une deuxième tentative. Neuchâtel abolit la messe le 4 novembre 1530 par 18 voix de majorité, mais en 1542 , Cressier (Neuchâtel) et Le Landeron (Neuchâtel) votent pour son maintien. Si à Grandson (Vaud), le 26 octobre 1531, on compte 54 votes pour la Réforme et 44 contre, une année plus tard, Concise (Vaud) vote pour le maintien de la messe à 60 voix contre 26. C'est à Assens (Vaud) en 1678 qu'a lieu le dernier «plus»: la messe l'emporte avec 95 votes contre 81.

Dans les bailliages communs à Fribourg et à Berne, la communauté villageoise prévaut parfois sur la loyauté confessionnelle. Ainsi, en 1602 à Assens (Vaud), quatre protestants refusent l'organisation d'un «plus»; c'est sans doute qu'ils veulent poursuivre la coexistence entre catholiques et protestants, alors qu'un passage à la Réforme signifierait l'expulsion d'une partie de leurs concitoyens. En 1619, à Penthéréaz (Vaud), ils sont même six protestants qui votent avec six catholiques pour le maintien de la messe (voir la liste de quelques «plus» et leurs résultats en fin de chapitre).

Source principale: Grosse C., «Coexister après la Réforme: simultaneum et négociation des frontières confessionnelles dans le bailliage d'Orbe-Échallens», in Butticaz S., Grosse C., ARnold M. (éd.), Unité et diversité des Réformes: du XVI siècle à nos jours, Genève: Labor et Fides, 2017, p. 107-149. 
Au début de 1530, les populations de la région de Morat (Fribourg), une ville dont Guillaume Farel est pasteur, passent à la Réforme ; cinq paroisses y sont créées : Morat, Chiêtres, Ferenbalm, Merlach et Môtier; les pasteurs sont rattachés à la Classe de Nidau (Berne). En 1531, Guillaume Farel prêche dans l'église d'Orbe (Vaud) ou du moins tente d'y prêcher, car il subit cris et insultes, est jeté à terre et n'est mis à l'abri que grâce à l'intervention du bailli. Mais le bilan n'est pas entièrement négatif, puisqu'il y recrute Pierre Viret (1511-1571), natif du lieu, unique réformateur originaire de Suisse romande. En août 1531 à Grandson (Vaud), c'est l'iconoclasme réformé qui remet en cause les accords passés; cet iconoclasme est sciemment pensé puisqu'il vise à déclencher une procédure judiciaire durant laquelle les protestant $\cdot e \cdot s$ pourront faire valoir leurs plaintes. Son entreprise réussit: le 21 novembre 1531, la population vote en faveur du passage à la Réforme. Tout le bailliage va progressivement faire le même choix: Fiez la même année, Yvonand en 1533, Concise en 1537 après un premier refus en 1532, Orbe en 1554. Le passage à la Réforme a souvent des conséquences immédiates : les images sont retirées des églises et les prêtres sont expulsés.

\section{i.2 Pendant ce temps-là, dans la Principauté ÉPISCOPALE DE BÂLE...}

C'est à Bienne, et donc à Berne dont elle dépend, que le sud de la Principauté épiscopale de Bâle doit son passage à la Réforme. Car, en 1528, la ville, déjà travaillée par les idées protestantes - en particulier grâce à Thomas Wyttenbach (1472-1526) qui a été le professeur d'Huldrich Zwingli -, l'adopte officiellement, même si elle conserve certains anciens usages comme le maintien de jours fériés catholiques ou les cloches qui sonnent l'Ave Maria.

Pour des raisons tant politiques que religieuses, Bienne cherche à imposer la Réforme dans les régions où elle détient un pouvoir ou exerce une influence; elles sont au nombre de quatre: l'Erguël (autour de Saint-Imier), La Neuveville, 


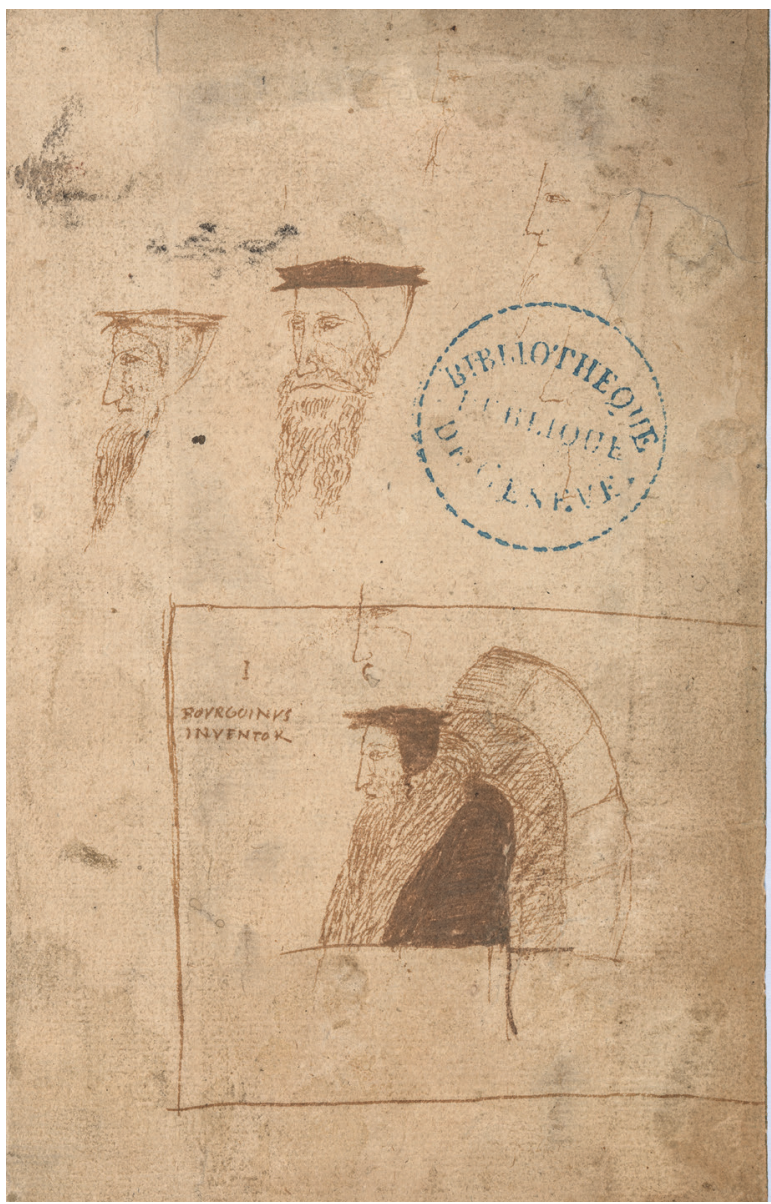

Jacques Bourgoing, Jean Calvin enseignant

Fac-similé, Genève, 1563 (?) / XxI ${ }^{\mathrm{e}}$ siècle

(C) Bibliothèque de Genève

L'étudiant Jacques Bourgoing - «Bourguinus» en latin a croqué sur le vif son maître Jean Calvin. Par respect ou par ennui, nul ne le sait. Il s'agit du seul portrait réalisé du vivant du réformateur qui nous soit parvenu. 
la Montagne de Diesse (Diesse, Lamboing, Nods et Prêles) et la Prévôté de Moutier-Grandval. Et c'est l'inévitable Guillaume Farel qui s'en charge; il prêche plusieurs fois à La Neuveville entre 1529 et 1530 ; il connaît du succès à Tavannes mais au prix d'un malentendu: les habitants pensent que la Réforme leur permettra de profiter de la table et des biens des ecclésiastiques; il échoue à Bellelay où il affronte une puissante abbaye.

La Réforme en Erguël commence le lundi de Pâques 1529, au moment où Bienne convoque les prêtres du Vallon pour tenter de les convertir; en juillet, elle organise un «plus» à Saint-Imier mais la majorité choisit le maintien de la messe; le 11 novembre, elle impose à la ville un prédicant. Un processus est enclenché ; les villages de l'Erguël passent à la Réforme les uns après les autres. Seul Saint-Imier résiste encore un peu; le 8 janvier 1530, la ville envoie des députés à Bienne pour demander à rester catholique mais au printemps 1530, c'est une délégation de la ville de Bienne qui parcourt l'Erguël pour faire voter les paroisses; à Saint-Imier, les autels sont détruits et les images sont brûlées; quant aux reliques, aux archives et au trésor du chapitre, ils sont envoyés à Porrentruy où s'est réfugié le prince-évêque que la Réforme a chassé de Bâle en 1528 .

Sur la Montagne de Diesse, c'est le curé Jacques Boivin, natif de Diesse, qui le premier adopte la Réforme, une conversion qui ne l'empêche pas de continuer à célébrer la messe dans une maison qu'il a aménagée en chapelle. Mais, cette demimesure ne satisfait pas les paroissien·ne·s: le 6 août 1529, ils votent contre la Réforme et le 26 décembre, sous la conduite de leur maire, une cinquantaine d'entre eux interrompent Jacques Boivin en pleine prédication et l'obligent à célébrer la messe. Il faut attendre mars 1530 pour que l'assemblée de la paroisse de Diesse se prononce en faveur de la Réforme; les images sont soigneusement ôtées de l'Église et Jacques Boivin est officiellement nommé pasteur. Mais certaines choses et certaines personnes sont longues à changer: pendant 
trente-six ans, Jacques Boivin célèbre à Diesse et la messe et le culte tout à la fois; il finit par être démis de ses fonctions par le Sénat de Berne.

À La Neuveville, on relève la même opposition entre les prêtres et les paroissien·ne·s. Au printemps 1530, alors que le prêtre, Jean Bosset adopte la Réforme, les habitants préfèrent rester catholiques; et quand les Bernois exigent que la chapelle Sainte-Catherine soit débarrassée de ses ornements, quand ils imposent que Jean Bosset puisse $\mathrm{y}$ prêcher et y célébrer la cène, les autorités font de la résistance: elles destituent le pasteur et le remplacent par Jean de Mette. Mais celui-ci passe lui aussi à la Réforme. Finalement, en décembre 1530, La Neuveville vote la suppression de la messe. Et vers 1540, une communauté anabaptiste s'y établit.

La Prévôté de Moutier-Grandval est encore catholique et les Bernois sont pressés. Dès janvier 1531, ils font procéder aux votes; Court, Malleray et Sornetan choisissent la Réforme, mais Moutier reste catholique. Berne y organise un second vote, le 12 mars 1531 ; la suppression de la messe est décidée à l'unanimité, à l'exception des territoires situés au nord du village de Roches, dans les gorges de la Birse, entre Moutier et Delémont, qui restent catholiques. Dès 1535, la prévôté compte une autre minorité religieuse, quand quelques familles anabaptistes venues d'Alsace s'installent autour de Moutier.

Même acquis à la Réforme, ces territoires méridionaux de la Principauté épiscopale restent sous l'autorité politique du prince-évêque. Ce qui ne présente pas que des inconvénients: La Neuveville parvient par exemple à obtenir de l'abbaye de Bellelay qu'elle rétribue son pasteur comme elle rétribuait son curé. Théologiquement pourtant, ils sont clairement dans la sphère d'influence bernoise, avec quelques différences et quelques nuances: les paroisses de Bienne et de La Neuveville sont totalement indépendantes; jusqu'en 1594, la Classe d'Erguël dépend de Bienne qui s'est approprié les droits auparavant détenus par les chanoines de la collégiale de Saint-Imier; quant aux pasteurs 


\section{LA PERSÉCUTION DES ANABAPTISTES}

Partie intégrante de la Réforme protestante, le mouvement anabaptiste se caractérise par un triple refus du baptême des enfants, du service militaire et du serment à l'État: ce qui a paru insupportable aux réformateurs et aux réformé·e·s, ce qui a semblé légitimer à leurs yeux une persécution systématique.

Tout commence très tôt. En 1528, huit anabaptistes se rendent à Berne, pour faire valoir leur théologie au cours de la Dispute qui se tient dans la ville. Mal leur en prend. Ils sont aussitôt emprisonnés et détenus jusqu'à la fin de la Dispute. On daigne cependant les laisser parler le 22 janvier, une journée pendant laquelle les discussions officielles sont suspendues... La suite de l'histoire est une longue liste de persécutions et de vexations. Genève semble tolérer les anabaptistes, à condition qu'ils restent discrets; elle les maintient sous la menace de voir leurs biens confisqués et d'être expulsés. Pierre Viret s'attaque à l'anabaptisme lors de la Dispute de Lausanne en 1536. Au XVIII siècle, la population neuchâteloise renâcle à tolérer les mennonites (autre nom des anabaptistes) et déplore leur théologie. Mais elle jalouse surtout la qualité de leurs exploitations agricoles et les dispense de service militaire contre le paiement d'une taxe.

Cependant, c'est incontestablement Berne qui se montre la plus sévère. En 1529, la ville organise le premier procès d'anabaptistes; en 1538, elle affirme que tous les moyens sont bons pour obliger les anabaptistes à se rétracter, y compris la torture, et que les chefs doivent être exécutés. La «Chambre des anabaptistes », créée en 1659, fait preuve d'une certaine ouverture quand elle reconnaît que les anabaptistes sont eux aussi des protestant·e.s, qu'elle décrète illégitime de les exécuter en raison de leurs croyances, inhumain de les condamner aux galères - celles du roi de Sicile et de la République de Gênes - et injuste de vouloir les faire changer de convictions; mais, parce 
qu'elle estime que les opinions des anabaptistes nuisent aux autorités, elle propose de les exiler. En 1702, Berne organise une troupe de Täuferjäger, des chasseurs d'anabaptistes, et promet des récompenses à qui en capturera. Lorsque Christoph von Graffenried (1661-1743) fonde, en 1710, la New Bern, une colonie en Caroline du Nord, il envisage même d'y déporter les anabaptistes. Mais ce n'est pas nécessaire, car ils partent d'eux-mêmes: entre 1717 et 1756, quatre mille mennonites s'installent en Amérique du Nord. C'est en 1815, dans l'Acte de Réunion de l'Évêché de Bâle et du canton de Berne, que ce dernier accorde enfin aux anabaptistes la protection de la loi et tolère leur culte.

Et pourtant, malgré les persécutions et les menaces, les anabaptistes font preuve d'une incroyable résilience et d'une incontestable ténacité. En 1528, ils sont au Büttenberg, près de Bienne; vers 1535, quelques familles s'installent autour de Moutier (Berne); en 1663, leur présence est attestée dans le vallon de Saint-Imier (Berne), au lieu-dit «Le Pont des Anabaptistes » et dans la combe de Péry; dès 1702, ils peuvent s'installer dans le Val-de-Ruz et dans les Montagnes neuchâteloises, quand le roi de Prusse en devient le nouveau souverain; et à partir de 1711 sur les terres jurassiennes des princes-évêques de Bâle. Tous ces lieux ont pour points communs d'être reculés, inhabités et peu propices à l'agriculture. Mais les anabaptistes y vivent et y survivent - en autarcie, autour de leur ferme, de leur chapelle et de leur école - et mettent les terres en valeur.

Le 17 novembre 2017, durant la Nuit des religions, le conseiller d'État bernois Christoph Neuhaus demande pardon aux mennonites. Deux ans plus tard, la Conférence mennonite accepte de pardonner.

Pour connaître l'histoire des anabaptistes dans le Jura: Ummel C., UMmel C.-L., «L'Église anabaptiste en Pays neuchâtelois», Mennonitica Helvetica, ${ }^{\circ}$ 17, 1994. 
de la Prévôté de Moutier-Grandval - ils sont quatre - et de la Montagne de Diesse, ils sont rattachés à Berne, par l'intermédiaire de la Classe de Nidau. Mais Berne surveille de près toutes ses Églises jurassiennes; chaque année, elle y envoie, en visite d'Église, un magistrat et un pasteur pour vérifier l'orthodoxie doctrinale et le respect des usages bernois: la présence des fonts baptismaux dans les églises, l'usage des oblats (pain sans levain) pour la cène, la célébration des fêtes de Noël, de Pâques, de l'Ascension et de Pentecôte, etc.

La plus ou moins grande dépendance vis-à-vis de Berne permet une plus ou moins grande liberté, notamment en matière liturgique: si la Montagne de Diesse et la Prévôté de Moutier-Grandval suivent la liturgie bernoise - celle que Guillaume Farel a traduite en français -, l'Erguël et La Neuveville préfèrent la liturgie genevoise, publiée par Jean Calvin en 1542.

Durant ce temps de Réforme, tous les pasteurs sont d'anciens prêtres ou viennent encore d'ailleurs; il faut attendre 1591 pour que Georges Rivet, le fils du pasteur de La Neuveville, soit consacré par la Classe de Bienne après avoir été formé par son père et avoir réussi l'examen de consécration. Mais il n'avait pas attendu pour annoncer l'évangile; pendant sa jeunesse, il avait, avec l'aval du Conseil de La Neuveville, monté une troupe de théâtre pour jouer des histoires bibliques dont il écrivait lui-même les textes en vers.

\section{i.3 Pendant ce temps-là, dans le Comté} de Neuchâtel et la Seigneurie de Valangin...

Guillaume Farel, encore lui, arrive à Neuchâtel en 1529; bien qu'il soit mandaté par Berne, il est chassé de Valangin à coups de pierres et ne peut prêcher que dans les rues, dans les cimetières ou chez des particuliers; il ne demeure que deux semaines sur place avant de repartir, pour Morat. Mais il revient à Neuchâtel en juillet 1530, avec son compatriote 
Antoine Froment (1508 ou 1509-1581). Il obtient le droit de prêcher dans l'une des dix-neuf chapelles de la collégiale, mais seulement quelques après-midis et en semaine. Les partisans de la Réforme reçoivent aussi la chapelle de l'Hôpital pour célébrer leur culte; ils la «nettoient» aussitôt, c'est-à-dire qu'ils ôtent toutes les images et toutes les statues. Mais ils en attendent davantage; ils veulent que les Bernois imposent un «plus». Ceux-ci restent prudents, ils veulent être sûrs d'obtenir la majorité.

Mais les choses se précipitent. Le dimanche 23 octobre 1530 , Guillaume Farel prêche à la collégiale; ses auditeurs s'échauffent; ils brisent des statues, leur coupent le nez et crèvent les yeux d'une image de la Vierge; le même soir, des soldats neuchâtelois de retour d'une expédition à Genève - peut-être frustrés de n'avoir pas pu se battre - mettent à sac la collégiale ; le lendemain, les bourgeois achèvent méthodiquement l'ouvrage: ils abattent le crucifix, renversent les autels, dispersent la vaisselle liturgique et mangent les hosties. Les partisans de la Réforme commettent le même iconoclasme à Dombresson, à Saint-Blaise, à Valangin ainsi que dans l'abbaye de FontaineAndré, entre Neuchâtel et Hauterive.

Le «plus » peut maintenant avoir lieu. Le 4 novembre, les bourgeois de Neuchâtel votent l'abolition de la messe à une majorité de 18 voix, sans que l'on sache exactement quel a été le nombre de votants. La majorité l'ayant décidé, la ville de Neuchâtel devient donc protestante; l'ensemble du comté aussi, sauf Le Landeron et Cressier - ils sont alliés de Soleure, ville catholique - qui restent catholiques; les changements ne sont pas toujours radicaux ni exclusifs; ainsi la messe continue-t-elle d'être célébrée aux Verrières même après que le village, frontalier avec la France - ceci expliquant peut-être cela -, a adopté la Réforme, probablement jusque vers 1536 .

Dans le Comté de Neuchâtel, la Réforme se fait contre des suzerains, les Orléans-Longueville qui sont et restent catholiques. Dans la Seigneurie de Valangin, sous la double pression 
de la ville de Neuchâtel et du village de Dombresson, passé à la Réforme avec Saint-Imier dont il dépend, elle est conduite par le comte catholique René de Challant. Celui-ci, malgré les réticences de sa mère, Guillemette de Vergy, qui réside à Valangin, accepte en 1536 que sa Seigneurie, qui inclut le Val-de-Ruz et les Montagnes neuchâteloises, passe elle aussi à la Réforme.

Pour un temps, Neuchâtel devient le centre de la Réforme francophone. Guillaume Farel y fait venir Pierre Viret, Antoine Froment et Antoine Marcourt (vers 1485-1561), ce dernier devenant pasteur de Neuchâtel quand Farel repart. Le Lyonnais Pierre de Vingle (1495-1536) y fonde une imprimerie, d'où sortent, en 1534, les Placards - ces textes polémiques rédigés par Antoine Marcourt sont affichés jusque sur la porte de la chambre du roi de France, François $1^{\text {er }}$ et, en 1535, la «Bible d'Olivétan », la première traduction réformée en français. C'est aussi à Neuchâtel qu'en 1544, sera publié, à mille cinq cents exemplaires, le premier ouvrage anabaptiste jamais paru en français, la traduction par Pierre Pelot - il est installé à La Neuveville d'où il s'occupe de ses coreligionnaires à Cressier et à Cornaux - d'un texte en allemand intitulé Vor des christlichen Tauf der Gläubigen.

Après le temps de la Réforme vient celui de l'organisation. En 1535, les douze pasteurs du Comté de Neuchâtel se constituent en une Vénérable Classe: dirigée par un doyen, se réunissant à un rythme hebdomadaire, elle gouverne l'Église de Neuchâtel, et accueille, parfois, les maîtres d'école, une fonction qui comprend une dimension pastorale et qui sert de préparation à ce ministère. Conduits par Guillaume Farel, qui est revenu à Neuchâtel après avoir été expulsé en 1538 d'une Genève pourtant protestante, les pasteurs cherchent à s'arroger des pouvoirs que les autorités civiles leur refusent ou réduisent; ils veulent participer aux consistoires seigneuriaux, ils veulent le pouvoir d'excommunier. Mais les magistrats tiennent à leurs prérogatives, y compris en matière religieuse ou théologique; ils veulent la responsabilité 
d'avaliser tout changement portant sur le culte et la liturgie, de fixer de nouvelles fêtes religieuses (en 1568, la fête de Noël est supprimée) et le pouvoir d'excommunier ou, plus exactement, de suspendre temporairement de la cène. En échange, ils mettent des cures à la disposition des pasteurs et enjoignent aux communautés locales de pourvoir à leurs besoins matériels. Deux fois par an, les pasteurs perçoivent une pension, payée en nature, en blé ou en vin et se plaignent souvent de recevoir les produits de pire qualité. En 1562, la Classe obtient toutefois deux pouvoirs : celui de nommer des Anciens appelés à surveiller le respect de la discipline et celui de désigner les pasteurs, alors qu'ils étaient, depuis 1546, choisis par les Conseils et les paroissien.ne.s; elle demande encore qu'un maître d'école soit nommé dans chaque paroisse et qu'il soit membre de la Classe.

Le mardi 20 décembre 1558, alors qu'il a déjà 69 ans, Guillaume Farel épouse Marie Torel, une jeune réfugiée française âgée de 18 ans; il meurt à Neuchâtel sept ans plus tard, le 13 septembre 1565. En 1576, les Vénérables Classes de Neuchâtel et de Valangin fusionnent et lorsqu'en 1592, les Orléans-Longueville ajoutent à leur titre de prince de Neuchâtel celui de prince de Valangin - on parle de réunion «à la directe»-, les deux Églises n'en forment plus qu'une.

Quand les persécutions touchent les protestant·e.s français·e.s, Comté et Seigneurie font preuve de solidarité; ils envoient des soldats au secours des coreligionnaires français; ils accueillent des réfugiés qui doivent fuir le Royaume de France: en septembre 1548 arrive à Neuchâtel une femme de Langres - on ne connaît pas son prénom - dont le mari a été exécuté, qui a été elle-même condamnée à mort et qui a pu s'enfuir avec ses trois enfants; la «veuve Michaud» s'y installe, se met à instruire «les filles»; son fils, Grégoire reçoit une bourse du bailli de Lausanne, fait des études de théologie, devient membre de la Classe de Lausanne; il est élu ministre «en l'église» de Lignières en 1576 et devient même bourgeois de Neuchâtel en 1583. 


\section{Marie Dentière}

Il n'y a pas que des réformateurs en Suisse romande, il y a aussi des réformatrices. La plus célèbre d'entre elles est Marie d'Ennetières - ou Dentière, comme elle avait choisi de se nommer - (1495-1561). Née à Tournai en Belgique dans une famille de commerçants, elle entre au couvent de Saint-Nicolas-des-Prés, dont elle devient prieure.

Au début des années 1520, elle se convertit au luthéranisme, quitte son couvent et s'installe à Strasbourg. En 1526, elle épouse le pasteur Simon Robert; le couple s'installe en Suisse à Bex, puis à Aigle (Vaud), où Simon est pasteur jusqu'à sa mort en 1532. Marie Dentière épouse alors un autre pasteur, Antoine Froment, bien plus jeune qu'elle. En 1535, elle le rejoint à Genève ; il y exerce le ministère de diacre, et elle va prêcher dans un couvent de clarisses. Antoine Froment, Marie Dentière et ses trois filles s'installent ensuite à Massongy (HauteSavoie); ils tiennent un pensionnat où des jeunes filles sont logées et instruites. On retrouve la réformatrice à Genève en 1546. Dans une lettre à Guillaume Farel, Jean Calvin raconte une dispute qu'ils ont eue. Profitant du fait que les pasteurs portent les mêmes longues robes que les scribes du Nouveau Testament, Marie Dentière leur applique les reproches que Jésus leur adressait. Calvin ne comprend pas ou ne veut pas comprendre. Quant à Farel, il l'avait déjà jugée «orgueilleuse vindicative, mauvaise conseillère de son époux».

Marie Dentière aura publié trois livres. En 1536, La Guerre et Deslivrance de la ville de Genesve. En 1539, l'Épître très utile, faite et composée par une femme chrestienne de Tornay, envoyée à la Royne de Navarre, sœur du Roy de France, contre les Turcz, les Juifs, Infidèles, Faulx chrestiens, anabaptistes et Lutheriens; elle y recense les femmes de la Bible et fait malicieusement observer qu' aucune femme n'a jamais trahi Jésus ; c'en était certainement 
trop pour l'Église réformée de Genève qui met cet ouvrage sous séquestre. En 1561, elle édite un sermon de Calvin sur les habits des femmes, auquel elle ajoute une préface de sa main et une traduction personnelle d'une œuvre en latin de saint Cyprien.

Il faudra attendre le 3 novembre 2002 pour que Genève et le protestantisme reconnaissent ce qu'ils lui doivent. Grâce à la ténacité de la pasteure Isabelle Graesslé, première femme à occuper le poste de modératrice de la Compagnie des pasteur.e.s et des diacres de Genève, le nom de «Marie Dentière» est alors gravé sur une stèle du Monument international de la Réformation. Un peu en marge, il est vrai.

Source principale : GRAESSLÉ I., « Vie et légendes de Marie Dentière », Bulletin du Centre protestant d'études, 55 (1), 2003, 3-24.

\section{I.4 Pendant Ce temps-Là, dans la République DE GENÈVE...}

À Genève, la Réforme commence timidement par un chassé-croisé: en 1532, Guillaume Farel, Antoine Saunier et peut-être Robert Olivétan y passent brièvement; le $1^{\text {er }}$ janvier 1533, Antoine Froment prêche sur la place du Molard; quand il doit quitter la ville, c'est Pierre Viret qui lui succède, avant qu'Antoine Froment ne revienne et ne le remplace. Un acte politique leur vient en aide: le 22 août 1533, l'évêque de Genève est contraint de quitter la ville; les protestant·e.s vont profiter de la situation. Et quand, en 1534, Fribourg demande à Genève d'expulser les prédicants et que Berne s'y oppose, Genève choisit son camp: les prédicants peuvent rester.

Le 5 août 1534, Guillaume Farel prêche à la cathédrale SaintPierre et les images y sont détruites - la séquence rappelle les événements à Neuchâtel, quatre ans plus tôt. En 1535, Farel 
obtient le droit d'organiser une dispute théologique dans le couvent de Rives; elle tourne à l'avantage de la Réforme; en mars, Marie Dentière vient rejoindre son second mari, Antoine Froment, diacre à Genève ; en novembre, la messe est provisoirement interdite. Et le 21 mai 1536, le Conseil général vote à l'unanimité le passage à la Réforme. Alors que la Genève catholique comptait plus de trois cents prêtres, huit ou neuf pasteurs suffisent à la Genève réformée.

En 1536, Guillaume Farel retient Jean Calvin (1509-1564), un juriste, natif de Noyon en Picardie, qui vient de se faire connaître à la Dispute de Lausanne et qui passe, un peu par hasard, par Genève. D'abord simple lecteur de l'évangile, il participe, en novembre 1536, au premier colloque des pasteurs de Genève. L'année suivante, Calvin est nommé officiellement prédicateur. Mais il faut encore débattre. En 1537, le Conseil organise deux disputes entre des anabaptistes flamands dont on ne connaît pas les noms; sans surprise, Guillaume Farel, qui mène la première dispute, et Jean Calvin, qui mène la seconde, sont déclarés vainqueurs. À Genève, les anabaptistes sont à peine tolérés, s'ils se montrent discrets ; deux Liégeois, Jean Bomeromenus et Jean Tordeur, le premier mari de la future femme de Calvin, Idelette de Bure (1505-1549), sont expulsés; Jean Jopin de Cologny est condamné à un an de prison; Jacques Merauld reconnaît être anabaptiste quand il est soumis à la torture; il est confié à la famille d'Antoine Froment pour qu'elle lui enseigne la «vraie foi».

Les conflits d'autorité sont latents. Ils éclatent au grand jour en 1538, quand Guillaume Farel et Jean Calvin convoquent la population genevoise à Saint-Pierre pour lui faire adopter la confession de foi qu'ils ont rédigée, et menacent d'excommunication ceux qui refuseraient de l'approuver. Le Conseil de la ville les somme de respecter les principes bernois qui réservent au seul magistrat civil le pouvoir d'excommunier, mais Farel et Calvin refusent d'obéir; le dimanche de Pâques, ils prêchent alors qu'ils sont sous le coup d'une interdiction, mais refusent de célébrer la cène; le 23 avril, ils sont bannis de la ville. 
En 1541, Genève rappelle Jean Calvin qui s'est installé à Strasbourg. Cette fois, c'est pour durer; il peut construire l'Église qu'il désire. Il rédige des Ordonnances ecclésiastiques dans lesquelles il formule le principe d'une autorité ecclésiale, distincte et autonome de l'autorité civile et souveraine en matière religieuse; il met en place quatre ministères: le pasteur à qui sont confiés la prédication, les sacrements et le catéchisme; le docteur qui se charge de l'enseignement; l'ancien qui supervise la communauté; et le diacre qui gère l'aumône faite aux pauvres, un ministère que des femmes peuvent occuper, mais dont elles ne se contentent pas, comme en témoignent les prédicatrices Marie Dentière et Claudine Levet. Le diacre fixe aussi le rythme des activités dominicales pour des dimanches entièrement consacrés à Dieu; dans les trois paroisses de la ville - Saint-Pierre, La Madeleine et Saint-Gervais -, les fidèles assistent au premier sermon, à six heures en été et sept heures en hiver, au second sermon à neuf heures et au catéchisme à midi; en semaine, il n'y a qu'un seul sermon quotidien, délivré tôt le matin, celui du mercredi paraissant particulièrement important. Le diacre précise également la fréquence de la cène qui est célébrée quatre fois par an: les dimanches de Pâques et de Pentecôte, le premier dimanche de septembre et le dimanche le plus proche de Noël. Il organise aussi la discipline en créant un consistoire formé des pasteurs et d'anciens, membres de l'un ou l'autre des deux Conseils de la ville; il est chargé de surveiller et, le cas échéant, de juger et de punir la rectitude des pratiques religieuses et la qualité des mœurs. Faute d'avoir pu imposer l'interdiction des tavernes, le consistoire contraindra par exemple les taverniers à posséder une Bible, pour l'édification de leurs clients.

Si l'Église surveille la vie publique, le pouvoir politique surveille la vie ecclésiastique. Les Ordonnances ecclésiastiques, promulguées par «nous Syndic, Petit et Grand Conseil » en 1541 tente de les prévenir en dressant la liste des «crimes» et des «vices» des pasteurs; elles distinguent entre les «vices 
qui sont intolérables 》- l'hérésie, la «rébellion contre l'ordre ecclésiastique», mais aussi l'usure et les «danses et telles dissolutions» - et les «vices que l'on peut supporter pourvu qu'on les avertisse», ainsi la «façon étrange de traiter l'écriture» ou la «négligence à faire toutes choses requises à l'office».

En 1542, Jean Calvin rédige deux textes théologiques importants: un Catéchisme de Genève, fait en manière de dialogue et une liturgie, La forme des prières et chants ecclésiastiques où il conçoit un culte fait d'une confession des péchés, d'une prédication à partir d'un texte biblique, du chant des psaumes et d'une prière.

La forte personnalité de Calvin n'empêche pas les oppositions. En 1543, des anabaptistes interviennent au cours d'un baptême pour contester l'onction des nourrissons. En 1553, Michel Servet (1511-1553), un médecin catalan persécuté pour ses positions antitrinitaires, se réfugie à Genève ; reconnu, il est arrêté. Dès le 15 août, il est jugé, dans un procès civil mais voulu par Jean Calvin auquel le réformateur assiste personnellement. Consultées par les partisans de la tolérance, toutes les Églises réformées de Suisse se prononcent en faveur d'une condamnation de Servet; celui-ci est effectivement condamné à mort et brûlé à Champel le 27 octobre, alors que Calvin aurait souhaité une mort plus douce. Autre critique dix ans plus tard, quand le pasteur français Jean Morély, propose, dans un ouvrage intitulé Traité de la discipline et de la police chrétiennes, que l'élection des pasteurs et l'administration de la discipline soient confiées à une assemblée des fidèles. En 1563, les pasteurs genevois font brûler le livre, mais se contentent d'excommunier l'auteur.

La contestation vient aussi de l'intérieur; elle vient du premier syndic Ami Perrin (vers 1500-1561), chef du parti des Libertins, qui s'oppose à Jean Calvin et à la théocratie qu'il l'accuse de mettre en place; battu aux élections de 1555, Ami Perrin doit s'exiler. Même les pasteurs ne sont pas à l'abri des sanctions; dix-huit d'entre eux sont cités en consistoire 
pour des accusations de rébellion, d'abandon de poste ou de fornication; ils sont tous privés de cène et quatorze sont contraints à l'exil.

En 1559, l'année où Jean Calvin obtient la bourgeoisie et la citoyenneté de Genève, la ville accueille les pasteurs, les professeurs que Berne a bannis hors du Pays de Vaud et les paroissien.ne-s qui les ont suivis; ils et elles viennent rejoindre Théodore de Bèze (15191605), un natif de Vézelay en Bourgogne, installé à Genève depuis une année et recteur de l'Académie de Genève qu'il a fondée, une institution destinée à former les pasteurs. La réputation de l'Académie déborde rapidement les frontières genevoises; entre 1555 et 1562, elle fournit quatre-vingt-huit pasteurs aux Églises de France, une bonne manière de créer des liens, mais aussi de diffuser la théologie calviniste. La parution de deux ouvrages largement utilisés dans les Églises réformées francophones - le premier en 1562, le Psautier de Genève, comprend les psaumes de la Bible juive, traduits par Clément Marot et Théodore de Bèze et mis en musique par plusieurs musiciens dont Loys Bourgeois (entre 1510 et 1515-après 1561), mais aussi le Notre Père, le décalogue ou le Symbole des apôtres, ce qui en fait un recueil de piété personnelle et de célébration familiale; le second en 1588, la Bible de Genève, traduction en français, œuvre collective des pasteurs et professeurs de Genève, sous la direction de Théodore de Bèze - inscrit cette théologie au cœur du culte et de la piété. Cette solidarité conduit aussi l'Église de Genève et les Églises réformées de la Principauté épiscopale de Bâle à célébrer un jour de jeûne en 1567 par solidarité avec les protestant.e.s de Lyon, un autre le mercredi 3 septembre 1572 pour marquer la Saint-Barthélemy et le massacre des protestant.e.s en France.

Calvin meurt en 1564; il est enterré au cimetière de Plainpalais, sans que rien n'indique sa sépulture. C'est Théodore de Bèze - celui que Calvin lui-même avait choisi - qui lui succède. Face à un théologien qui ne bénéficie pas de la même aura que son prédécesseur - ou se révèle moins autoritaire, comme en témoigne le fait qu'il demande que le mandat de modérateur de la Compagnie des pasteurs soit limité à une année -, le Conseil de la ville impose des mesures qui 
touchent directement et très concrètement à la vie ecclésiale : le 6 mars 1572, la durée des sermons est fixée à une heure et le 25 juillet 1580, elle est ramenée à trois quarts d'heure; en 1581 , la prière du mercredi - jour de marché - est déplacée au jeudi et limitée à une demi-heure. Théodore de Bèze et la Compagnie des pasteurs n'ont d'autre choix que de l'accepter. En 1576, les Ordonnances révisées précisent le serment que doivent prêter les nouveaux pasteurs : être fidèle non plus à la doctrine approuvée par l'Église mais à la doctrine «comme elle est comprise ès livres du Vieil et Nouveau Testament».

\section{i.5 Pendant ce temps-là, dans le Pays de Vaud...}

En 1536, les Bernois envahissent le Pays de Vaud, possession du duc de Savoie; le $1^{\text {er }}$ avril, ils occupent Lausanne et s'approprient les droits temporels de son évêque. La même année, ils réussissent à imposer une Réforme, que Pierre Viret avait déjà commencé à prêcher - sans grand succès - dans les rues et dans les cabarets. Du $1^{\text {er }}$ au 8 octobre, Berne organise une dispute publique qui se tient en français à la cathédrale de Lausanne. Tous les prêtres et tous les religieux sont tenus d'y assister, mais aucun ne le fait. Dix thèses sont proposées, chacune faisant l'objet d'une présentation et d'un débat; sitôt la discussion achevée, la thèse est adoptée.

La Réforme est acceptée, mais il faut encore la réaliser; ce qui ne va pas toujours de soi. Ainsi en novembre, le bailli bernois de Lausanne prétend «nettoyer» l'église de SaintSaphorin des images qu'elle abrite; les habitants se défendent les armes à la main, et le bailli doit concéder le maintien d'un vitrail qui a tout pour déplaire aux défenseurs de la Réforme, tant par son motif - il figure une Vierge à l'enfant - que par son origine - il a été offert six ans plus tôt seulement par l'évêque Simon de Monfalcon.

La mise en œuvre de la Réforme requiert aussi des pasteurs pour la prêcher. Or, ceux-ci font défaut; on ne trouve alors que quatorze prédicants pour tout le Pays de Vaud. Pour en 
former, Pierre Viret contribue à fonder, en 1537, l'Académie de Lausanne. Le respect de la discipline représente une autre préoccupation; comme à Genève, comme à Neuchâtel, on crée des consistoires (des tribunaux formés de magistrats et de pasteurs) qui ont pour tâche de réprimer les infractions. En 1538, le consistoire de Lausanne sanctionne les contacts avec l'Église catholique, l'immoralité, la pratique du jeu ou le port de vêtements jugés indécents.

Mais Pierre Viret aimerait appliquer les principes de Jean Calvin; il voudrait que les pasteurs deviennent les seuls responsables de la discipline. Le 2 avril 1542, les autorités civiles semblent accéder à ses souhaits : elles édictent des règles pour renforcer la fréquentation du culte et du catéchisme. Mais le 15 août, Berne réaffirme son pouvoir en interdisant toute innovation qu'elle soit théologique ou liturgique. Les pasteurs ne sont pas unanimes: André Zébédée, pasteur de Nyon, et Jean Lange, pasteur du village voisin de Bursins, accusent Pierre Viret d'être un hérétique et un luthérien; en 1555, les mêmes s'attaquent à Jean Calvin lui-même qu'ils n'hésitent pas à qualifier d'hérétique.

La contestation ne faiblit pas. En 1558, la Classe de Lausanne demande la réunion d'un synode qui donnerait aux pasteurs des pouvoirs plus étendus, en particulier celui d'interdire aux fidèles de participer à la cène, en sanction de leur mauvaise conduite. Mais Berne estime qu'il s'agit là d'un pouvoir qui revient à l'autorité civile; son Sénat refuse d'entrer en matière; Théodore de Bèze demande alors à être démis de ses fonctions et part pour Genève. Les pasteurs lausannois tentent un coup de force: ils reportent au $1^{\text {er }}$ janvier 1559 la cène prévue pour le jour de Noël. C'en est trop. Après deux mois de réflexion, Berne décide de bannir Pierre Viret ainsi que quelques dizaines de pasteurs et de professeurs de l'Académie de Lausanne; ceux-ci se réfugient à Genève en compagnie d'un millier de protestant·e·s vaudois·es. Un synode, tenu à Morges en mars 1559, élit de nouveaux pasteurs pour les remplacer; la prééminence des autorités civiles en matière ecclésiastique est entérinée. 
Quoi qu'il en soit, l'Église continue sa vie, marquée par exemple par la parution en 1565 du Psautier de Lausanne, une variante de celui de Genève, un projet porté par Guillaume Franc (vers 1505-1571), chantre de l'Église de Lausanne et par la construction de nouvelles églises, les premières proprement réformées : à Mex, près de Lausanne, en 1582, et à L'Étivaz, dans le Pays d'Enhaut, en 1590.

\section{i.6 Pendant Ce temps-là, dans le Valais assujetti...}

Le Bas-Valais, sujet francophone d'un Haut-Valais germanophone, va bénéficier de la forte présence protestante dans ce Haut-Valais - à Ernen, Brig, Visp, Leuk et Sion. Une présence réformée plus forte en influence qu'en nombre, puisque le Valais reste catholique, une présence que l'on qualifie parfois de «nicodémite»- c'est-à-dire de discrète, voire de secrète, à l'instar de Nicodème, un personnage biblique qui ne se risque à rencontrer Jésus que de nuit - mais une présence réelle: dans le Chablais, vers 1536, on condamne des personnes qui ont mangé de la viande pendant le carême; à Saint-Maurice vivent de nombreuses familles protestantes et des Bibles circulent, au point qu'en 1555, l'abbé du lieu décide de brûler un lot qu'il a saisi et qu'en 1559, il écrit un rapport, adressé à Fribourg, pour dénoncer l'iconoclasme et le refus de respecter le jeûne.

En 1577, des gestes iconoclastes sont commis à Sion. Le 10 juin 1585, cinquante et un chefs de famille de cette même ville, dont certains originaires du Valais assujetti, signent un texte en français, intitulé Institution et establissement de l'exercice chrestien, par lequel ils dénoncent les défauts de l'Église catholique et affirment leur volonté de lire la Bible ensemble; c'est le premier indice d'une communauté réorganisée, protestante et francophone en Valais. Mais le Valais ne fait que tolérer les protestant.e.s; pour assister au culte, il leur faut se rendre en territoire bernois, à Aigle notamment; ils le font quand ils le peuvent, car de tels déplacements leur sont régulièrement interdits. Ils se retrouvent alors dans des maisons privées pour prier et chanter des psaumes dans leur langue maternelle, ce 
qui a le don d'agacer les autorités catholiques. Il faut s'adapter, trouver des solutions. En 1591, Pierre (ou Peter) Ambühl (1527-1596), connu comme l'un des chefs des protestant·e·s valaisan·ne·s, se rend à Genève pour demander à la Compagnie des pasteurs comment célébrer des baptêmes quand il n'y a pas de paroisse locale et qu'il est interdit de se rendre dans une église à l'extérieur. Sa demande reste sans réponse.

\section{I.7 Pendant Ce temps-Là, dans le Canton de Fribourg...}

Le protestantisme n'a jamais la possibilité de s'installer à Fribourg, en dehors de Morat, bailliage commun à Fribourg et à Berne, non pas faute d'intérêt, mais parce qu'il y est réprimé.

Dès 1521, le Conseil menace de bannissement quiconque ne ferait même que prononcer le nom du réformateur Martin Luther; il contraint les cabaretiers à dénoncer les contrevenants; en 1524, il met en garde les prédicateurs des ordres des Cordeliers et des Augustins contre toute tentation de prêcher la nouvelle doctrine; le 25 février 1527, il offre à la population du canton le choix entre confesser la foi catholique ou s'exiler; il fait brûler les écrits luthériens et menace d'amende celles et ceux qui en détiendraient. En 1542, dans la collégiale de Saint-Nicolas, chaque dépositaire d'une autorité publique doit, à l'appel de son nom, jurer de suivre «la vraie foi chrétienne».

Celles et ceux qui optent pour la Réforme - il y en a: Ypocras qui imprime et vend des écrits luthériens, Barthélemy Schmid, maître d'école à Guin, qui affirme publiquement qu'il ne faut adorer ni la Vierge ni les saints, le chanoine Leu, Thomas Filistorf qui estime inutile la confession - prennent la fuite ou sont arrêtés. De tous les convertis, Jean Hollard (1491-1569) a peut-être le parcours le plus étonnant. Né à Orbe, il devient, dès 1524, chanoine puis doyen de la collégiale Saint-Nicolas; acquis à la Réforme, il tient une correspondance secrète avec des ami-e.s protestant·e.s; en 1530, il est démis de ses fonctions à Fribourg ; 
il devient prédicateur à La Neuveville, à Neuchâtel et à Orbe, puis, en 1533, il est nommé pasteur à Bex; devenu veuf pour la deuxième fois, il démissionne de son poste en 1558, arguant de son âge.

\section{ORIENTATION BIBLIOGRAPHIQUE}

Crousaz K. \& Solfaroli Camillocci D., Pierre Viret et la diffusion de la réforme: pensée, action, contextes religieux, Lausanne: Éd. Antipodes, 2014.

GROSSE C., Les rituels de la cène: le culte eucharistique réformé à Genève (XVI'-XVII siècles), Genève: Droz, 2008.

Heyer H., L'Église de Genève: Esquisse historique de son organisation suivie de ses diverses constitutions de la liste de ses pasteurs et professeurs et d'une table biographique, 1555-1909, Genève: A. Jullien, 1909.

LÉCHOT P.-O., Une histoire de la Réforme protestante en Suisse (15201565), Neuchâtel: Éditions Alphil - Presses universitaires suisses, 2017.

ROBERT M., Histoire de la Réforme dans le Pays de Neuchâtel/Michèle Robert, Neuchâtel: Éditions Alphil - Presses universitaires suisses, 2017.

Simon C.-A., Le Jura protestant de la Réforme à nos jours, Genève: Éditions jurassiennes de la «Vie protestante», 1951.

Vuilleumier H., Histoire de l'Église réformée du Pays de Vaud sous le régime bernois, Lausanne: La Concorde, 1927. 
Quelques «plus» en Suisse romande et leurs résultats

\begin{tabular}{|c|c|c|}
\hline Lieu & Date & Résultat \\
\hline Saint-Imier & Juillet 1529 & Maintien de la messe \\
\hline Morat & $\begin{array}{l}7 \text { janvier } 1530 \\
\text { (refus le } 20 \text { août 1529) }\end{array}$ & Passage à la Réforme \\
\hline Diesse & $\begin{array}{l}\text { Mars } 1530 \\
\text { (refus le } 6 \text { août 1529) }\end{array}$ & Passage à la Réforme \\
\hline Perles & Novembre 1529 & Passage à la Réforme \\
\hline Môtier-Vully & 20 février 1530 & Passage à la Réforme \\
\hline Chiêtres & 10 avril 1530 & Passage à la Réforme \\
\hline Neuchâtel & 4 novembre 1530 & Réforme 170 Messe 152 \\
\hline La Neuveville & $\begin{array}{l}\text { Décembre } 1530 \\
\text { (refus au printemps) }\end{array}$ & Réforme: +24 voix \\
\hline Moutier & 12 mars 1531 (refus le 22 janvier) & Réforme à l'unanimité \\
\hline $\begin{array}{l}\text { Court, Malleray, } \\
\text { Sornetan }\end{array}$ & 22 et 23 janvier 1531 & Passage à la Réforme \\
\hline Grandson & 26 octobre 1531 & Réforme 54 Messe 44 \\
\hline Yvonand & Août 1532 (refus en janvier) & Passage à la Réforme \\
\hline Concise & 1537 (refus en $1532: 26$ contre 60 ) & Passage à la Réforme \\
\hline $\begin{array}{l}\text { Cressier, } \\
\text { Le Landeron }\end{array}$ & 1542 & Maintien de la messe \\
\hline Provence & 1552 & Réforme 44 Messe 27 \\
\hline Oulens & 1553 (refus en 1552) & Réforme 24 Messe 15 \\
\hline Orbe & 1554 & Passage à la Réforme \\
\hline Goumoëns-la-Ville & 1575 (refus en 1567 et 1570 ) & Passage à la Réforme \\
\hline $\begin{array}{l}\text { Assens } \\
\text { (vote indicatif) }\end{array}$ & $1602\left(2^{\mathrm{e}}\right.$ refus en 1678$)$ & Messe 95 Réforme 81 \\
\hline Penthéréaz & 1619 & Réforme 22 Messe 12 \\
\hline Poliez-le-Grand & 1619 & Passage à la Réforme \\
\hline
\end{tabular}




\section{2}

XVII ${ }^{\mathrm{e}}$ SIÈCLE: UNE ORTHODOXIE PROTESTANTE

Dès 1610, Berne spécifie comment son Académie doit former les pasteurs: elle doit leur enseigner la «vraie foi chrétienne», l'hébreu, le grec et le latin, ainsi qu'une culture générale et de bonnes manières; elle doit aussi leur inculquer une «vraie crainte de Dieu», en leur faisant fréquenter le culte, lire la Bible et pratiquer le chant. Ces expressions - «vraie foi chrétienne», «vraie crainte de Dieu» - laissent imaginer qu'il y aurait aussi des fois chrétiennes et des craintes de Dieu que Berne jugerait fausses.

$\mathrm{Au} \mathrm{XVII}^{\mathrm{e}}$ siècle, le protestantisme suisse romand vit une période de confessionnalisation, c'est-à-dire de renforcement de son identité confessionnelle réformée. Nous avons choisi d'aborder ce siècle de manière thématique plutôt que chronologique, notamment parce que les questions traversent les Églises réformées de Suisse romande. Soulignons toutefois en introduction deux faits régionaux importants. En 1610, les accords de Baden rétablissent les droits du prince-évêque de Bâle sur ses possessions méridionales; l'Église de l'Erguël échappe alors à la tutelle de Bienne pour dépendre directement du prince-évêque. Dans le Pays de Vaud, la double tutelle de Berne et de Fribourg permet de stabiliser la situation dans le bailliage d'Orbe-Échallens. Les derniers «plus» se tiennent en 1619 à Penthéréaz et à Poliez-le-Grand avec comme résultat que ces deux villages passent à la Réforme; à Assens en 1675, où l'on décide de maintenir la messe; Échallens refuse de choisir, même si certain.e.s de ses habitant.e.s protestant·e.s y ont 
abattu les croix en 1619 déjà ; protestant.e.s et catholiques vont pouvoir continuer à y cohabiter en partageant parfois la même église.

\section{I ORThOdoXie ThÉOlOGiQUe}

Le $\mathrm{XVII}^{\mathrm{e}}$ siècle est marqué par le durcissement d'une théologie «calviniste», fixée de manière emblématique lors d'un synode hollandais tenu à Dordrecht du 13 novembre 1618 au 9 mai 1619; on y entérine notamment la «double prédestination», cette doctrine qui postule que Dieu a destiné chaque être humain, avant même sa naissance, soit à la perdition, soit au salut. Mais ce siècle connaît aussi le développement d'une théologie plus ouverte; élaborée à l'Académie de Saumur (France), lieu réputé de formation théologique, elle remet en cause la double prédestination et enseigne que les voyelles de la Bible hébraïque - qui ne figurent pas dans les manuscrits les plus anciens - ne sont pas inspirées par Dieu; il s'agit de la première contestation de l'infaillibilité ou de l'inerrance de la Bible. Quoi qu'il en soit, les Églises réformées de Suisse romande vont préférer la théologie de Dordrecht à celle de Saumur et l'imposer à leurs pasteurs et à leurs fidèles parfois de manière sévère et tatillonne.

La Compagnie des pasteurs de Genève participe aux débats théologiques européens; en 1619, elle envoie deux délégués à Dordrecht (Pays-Bas) - Giovanni Diodati (1576-1649) et Théodore Tronchin (1582-1657); en 1620, elle délègue Bénédict Turrettini (1588-1631) - docteur en théologie, pasteur, professeur et recteur de l'Académie de Genève - au synode d'Alès, en France, pour qu'il y soutienne les décisions de Dordrecht; de manière générale, les Églises romandes tentent de se protéger de l'influence de la théologie plus libérale, en interdisant à leur futur pasteur de fréquenter l'Académie de Saumur, une interdiction qui ne sera pas toujours respectée; avec l'approbation de la Vénérable Classe de Neuchâtel, JeanFrédéric Ostervald (1663-1747) y étudie et y obtient le grade de maître ès art - il est vrai qu'il vient à la fin du siècle. 
Sous l'impulsion des théologiens plus orthodoxes, conduits par François Turrettini (1623-1687) - le fils de Bénédict - qui a lui-même étudié à Genève et à l'étranger, qui a été pasteur de l'Église italienne de Genève et qui sera, lui aussi, professeur à l'Académie, le Conseil des Deux-cents - l'autorité civile - impose, en 1669, aux pasteurs de signer une confession de foi d'inspiration strictement calviniste; ils doivent jurer par écrit et en latin: «Ainsi nous croyons»; quant aux étudiants en théologie, l'exigence est plus stricte; ils doivent jurer - toujours par écrit et toujours en latin: «Ainsi je crois, ainsi je professe, ainsi j'enseignerai et n'enseignerai rien de contraire. » Mais il en faut plus.

\section{LES TURRETTINI, GRAND-PÈRE, PÈRE, FILS ET PETIT-FILS}

On remarque avec intérêt que des immigrés italiens peuvent devenir des notables de Genève et qu'ils peuvent créer une dynastie de théologiens qui, en trois générations, va façonner le protestantisme de la République de Genève.

Signalons d'emblée que ces hommes ne sont pas nés par génération spontanée; ils ont des mères, qui ont sans aucun doute joué un grand rôle dans la réussite de leurs maris et de leurs fils: Camilla Burlamacchi, épouse de Francesco et mère de Bénédict; Louise Micheli, épouse de Bénédict et mère de François; Isabelle de Masse, épouse de François et mère de Jean-Alphonse; Julie du Pan, épouse de Jean-Alphonse.

Francesco Turrettini (1547-1628) fait le commerce de la soie dans la ville-État de Lucques en Lombardie; adepte de la Réforme, il doit quitter sa ville en 1575; après une quinzaine d'années d'errance en Europe, il se fixe à Genève en 1592, où il fait fortune dans la manufacture, dans le commerce de la soie et dans la banque; en 1628, l'année de sa mort, il devient membre du Conseil des Deux-cents de la ville de Genève. 
Bénédict Turrettini (1588-1631) hérite donc d'une belle situation; après des études à Genève, Heidelberg, Leyde, Bénédict obtient en 1606 - il a 18 ans - son doctorat en théologie; en 1611, il est consacré au ministère pastoral; en 1612, il est nommé en même temps pasteur à Genève et professeur de théologie à l'Académie (il en sera même recteur pendant cinq ans); il est pasteur à Nîmes pendant deux ans (1620-1621) et, à ce titre, il participe au synode d'Alès où il défend une théologie strictement calviniste; il obtient qu'elle soit imposée de manière stricte aux pasteurs français qui doivent manifester par leur signature leur adhésion aux décisions du synode de Dordrecht; de retour à Genève, il imposera la même rigidité dogmatique aux pasteurs genevois.

François (1623-1687) est le premier à naître à Genève. Comme son père, il étudie la théologie, il accomplit une partie de ses études à l'étranger (Leyde, Utrecht, Paris, Saumur, Montauban et Nîmes), il reçoit la consécration pastorale - mais il est un temps pasteur de l'Église italienne de Genève -, il devient professeur de théologie à l'Académie, il est nommé recteur; il défend une orthodoxie théologique strictement calviniste, il cherche à imposer une unique confession de foi aux pasteurs genevois mais, à la différence de son père, il s'agit d'une confession de foi, la Formula Consensus Helvetica, dont il est l'un des coauteurs.

Jean-Alphonse (1671-1737) fait preuve de plus d'ouverture; outre la théologie, il étudie les belles-lettres et la philosophie; il rencontre des savants comme les philosophes Pierre Bayle et Nicolas Malebranche ou le physicien Isaac Newton; il promeut une théologie moins dogmatique, plus raisonnable, une «orthodoxie raisonnée». Formant avec le Neuchâtelois Jean-Frédéric Ostervald et le Bâlois Samuel Werenfels le «Triumvirat helvétique», il connaît une large renommée au-delà de Genève et de la théologie, dont témoignent les cinq mille lettres qu'il a écrites.

Source principale: Notices «Turrettini», in Dictionnaire historique de la Suisse, consultées dès le $1^{\text {er }}$ janvier 2018, http://www.hls-dhs-dss.ch/f/home. 
Les quatre cantons «évangéliques » (Bâle, Berne, Schaffhouse et Zurich) s'accordent en 1675 sur un texte commun, la Formula Consensus Helvetica, rédigé par le théologien zurichois Johann Heinrich Heidegger (1633-1698). Y adhérer devient une condition sine qua non à l'exercice d'un ministère pastoral, et même les pasteurs qui, fuyant la France, se réfugient en Suisse doivent la signer. Les cantons évangéliques, Berne en particulier, attendent de leurs alliés qu'ils fassent leur cette confession de foi et qu'ils l'imposent à leurs propres pasteurs et à leurs étudiants en théologie. Berne envoie donc le texte à Neuchâtel; la Vénérable Classe tergiverse; elle ne veut pas imposer une confession de foi aux pasteurs qui ne partagent pas cette théologie, mais elle ne veut pas non plus se fâcher avec ses puissants alliés protestants ; en 1676, elle trouve la solution idéale: la Formula Consensus est approuvée par le doyen et par le secrétaire de la Classe, au nom de tout le corps pastoral.

Ailleurs aussi, la Formula Consensus fait débat. Les pasteurs de Lausanne rechignent à la signer; à Genève, la théologie de Saumur fait des adeptes, à l'exemple de Louis Tronchin (16291705) - le fils de Théodore - qui s'affirme comme le chef de file des pasteurs plus libéraux; il a passé quelques mois à l'Académie de Saumur; il a été pasteur de Lyon pendant sept ans ; l'Académie de Genève en fait, en 1661, son professeur de théologie, un poste qu'il occupe jusqu'à sa mort. Après de longues discussions et au terme de douze rencontres, la Compagnie des pasteurs de Genève finit par adopter la Formula Consensus le 15 février 1678; mais il faut encore dix mois pour qu'elle la ratifie; et, comme à Neuchâtel, le modérateur et son secrétaire sont les seuls à la signer, au nom des pasteurs - ou à leur place - qui n'ont donc pas à s'engager personnellement. Pour autant, certains pasteurs trouvent le climat théologique encore trop contraignant et préfèrent quitter la République de Genève, à l'instar de Jean le Clerc (1657-1736), théologien, historien, hébraïsant et philosophe, qui s'exile aux Pays-Bas en 1683.

En 1699, Berne renforce son contrôle en imposant aux pasteurs vaudois de prêter un Serment d'association contre 


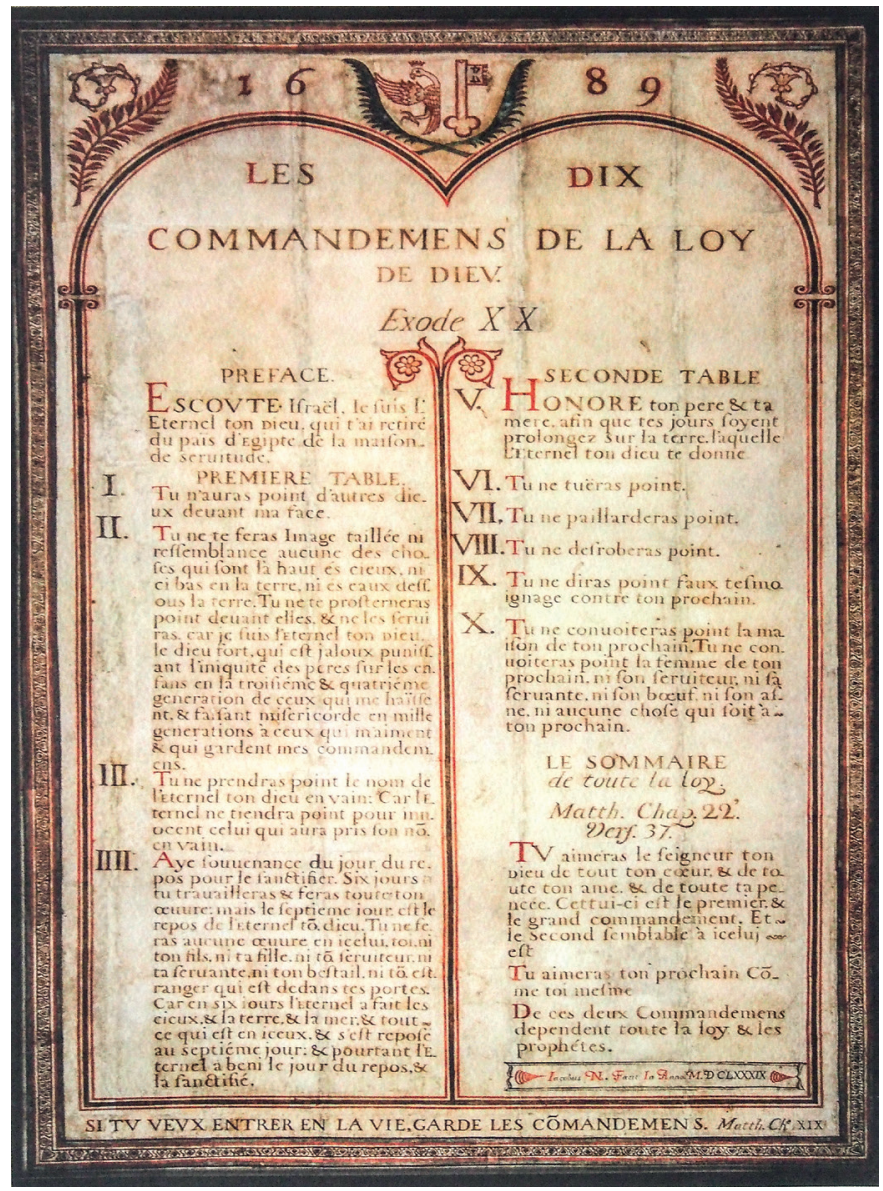

\section{Jacobus N., Les dix commandements}

Fac-similé, Satigny, 1689 / $\mathrm{XxI}^{\mathrm{e}}$ siècle

(C) Musée international de la Réforme, Genève

Les Églises réformées se sont longtemps montrées méfiantes à l'égard des images. Mais celles qui représentaient des textes trouvaient grâce. Dans le temple de Satigny (Genève) figuraient les Tables de la loi avec leur relecture chrétienne. 
le piétisme, le socinianisme et l'arminianisme. Mais il s'agit là des dernières velléités d'un autoritarisme théologique qui apparaît déjà dépassé à la fin du XVII ${ }^{\mathrm{e}}$ siècle et qui va disparaître au XVIII ${ }^{\mathrm{e}}$ siècle.

\subsection{DISCIPLINE ET INDISCIPLINE}

Mis en place dès le $\mathrm{XVI}^{\mathrm{e}}$ siècle, le contrôle des mœurs et de l'orthodoxie théologique occupe une grande place dans la Suisse romande protestante du XVII ${ }^{\mathrm{e}}$ siècle. Il concerne tant les pasteurs que les fidèles.

Commençons par les pasteurs! Ils se contrôlent mutuellement, ou «fraternellement» pour utiliser un euphémisme, tant dans leur conduite que dans leur théologie. Souvent à titre préventif, puisque les réunions hebdomadaires ou mensuelles des Classes donnent l'occasion de s'autosurveiller entre collègues de peur que l'on «s'anonchalise» - on dirait aujourd'hui que l'on «se ramollisse». Mais aussi à titre punitif, quand les pasteurs fautifs sont sanctionnés par leurs collègues. La Classe de Neuchâtel et Valangin suspend ainsi le pasteur Abraham Boyve (1623-1684) de La Chaux-de-Fonds en raison de l'adultère de sa femme, tandis que le pasteur Brandt de La Côte-aux-Fées doit se repentir publiquement d'avoir épousé sa servante alors qu'elle était déjà enceinte.

Mais l'autocontrôle ne semble pas toujours suffisant; les magistrats s'en mêlent parfois; en 1606, le Conseil de Genève suspend de la cène deux pasteurs et menace de les destituer parce qu'ils ont participé à une fête des Rois; au cours du $\mathrm{XVII}^{\mathrm{e}}$ siècle, dix-huit pasteurs sont cités en consistoire pour s'être rebellés, pour avoir abandonné leur poste ou pour «fornication»; quatorze d'entre eux sont suspendus de cène, destitués ou contraints à l'exil. Et dès le début du XVII siècle, Berne crée un poste d'inspecteur pour les Églises jurassiennes; le pasteur qui le détient a pour mission de visiter les paroisses pour surveiller la doctrine et les mœurs de ses confrères et des Anciens, mais aussi de les soutenir lorsque c'est nécessaire; en 1615, c'est le pasteur de Diesse, Jean Fevot (?-1633), qui en 
est chargé ; dans son rapport à Berne, il souligne la nécessité de rétablir le caractère réformé des territoires qu'il a visités.

Poursuivons par les fidèles! Les pasteurs contrôlent leurs paroissien·ne·s en leur rendant des visites régulières; des visites qui, certes, leur permettent de connaître celles et ceux dont ils ont la charge, de maintenir des liens avec les familles et de soutenir les malades mais des visites qui leur permettent aussi de s'assurer, parfois en présence des voisins, des bonnes mœurs et de la justesse de la foi des paroissien.ne-s. La surveillance quotidienne ou la surveillance de proximité est confiée aux Anciens et à ceux que l'on appelle les «garde-vices »; ils doivent signaler tout manquement et dénoncer les coupables soit aux instances ecclésiastiques dans les cas bénins, soit à la justice civile dans les cas plus graves.

Presque dès les premiers temps de la Réforme, les Églises réformées avaient mis en place des consistoires pour juger et sanctionner les coupables; présidés par un pasteur, ces organes fonctionnent sous le contrôle des magistrats qui y délèguent un représentant; ils se réunissent en fonction des besoins, mais souvent avant les dimanches de communion, et jugent diverses infractions à des règles où le religieux et le social se mêlent: le blasphème, le non-respect du repos dominical, l'absence au culte, les insultes prononcées contre des pasteurs, les pratiques catholiques - en 1689, une famille de Gorgier (Neuchâtel) est accusée de traverser le lac pour participer à la messe à Estavayer (Fribourg); faute de preuve, elle est relâchée -, l'ivrognerie, la danse ou les «insolences nocturnes »; à Genève, des ordonnances promulguées en 1642 proscrivent le maquillage, la consommation de confiture, de massepains et de vin doux. Au fil du temps, les consistoires se concentrent avant tout sur la «paillardise», une catégorie qui regroupe plusieurs formes d'inconduites sexuelles, en particulier l'adultère et les relations sexuelles hors mariage. Les sanctions sont parfois pratiques: on interdit aux fiancés et aux veufs ayant eu des relations sexuelles hors mariage de célébrer leur union à l'église; elles cherchent souvent à amener les pécheurs à se repentir avec des 
peines, ou des pénitences, qui incluent admonestation et repentance à genoux - l'agenouillement marquant l'humilité -, avec une subtile gradation: au domicile du pasteur, devant le consistoire, au pied de la chaire durant le culte ou à l'extérieur et en public. En matière religieuse, la suspension de la cène représente la sanction suprême; mais précisément parce qu'elle est suprême, les autorités civiles s'en gardent le monopole.

On s'assure que le pouvoir ecclésiastique est bien établi; les Anciens reçoivent pour mission de quadriller les territoires réformés, mais cela ne suffit pas à maintenir la discipline. Vers 1670, les pasteurs de la Principauté épiscopale de Bâle se plaignent des jeunes «délinquants» qui méprisent les ministres et les consistoires, et qui profanent le dimanche par la débauche et par la danse. Les reproches ne servent à rien: ces jeunes se prétendent soutenus par le bailli catholique de Delémont. Et les Suisses romands semblent se lasser de la Réforme. S'ils vont au culte - ils n'ont pas vraiment le choix -, certains s'y tiennent mal ou y font d'autres choses: à Genève, les jeunes y lisent des livres ou jouent aux cartes ; à Neuchâtel, des hommes y assistent alors qu'ils sont ivres, $\mathrm{y}$ vocifèrent et y vomissent, des jeunes gens se poussent ou dérangent les jeunes filles lorsqu'ils s'avancent pour prendre la cène, un homme décharge des sacs de grain dans le temple, durant le culte; à La Neuveville, des bébés dérangent par leurs hurlements. Autres signes de désintérêt, le catéchisme est moins fréquenté; on peine à recruter des Anciens ; certains mettent en doute la prédestination.

On peut tenter de lutter, comme à Neuchâtel et Valangin, où des ordonnances prises en 1630 renouvellent l'obligation d'assister aux sermons quotidiens, particulièrement aux sermons du dimanche, du mercredi et du samedi et rappellent qu'il convient de «bien» y assister. Mais il faut souvent se résoudre à s'adapter: repousser le culte du matin à sept heures au lieu de six, supprimer les cultes du lundi et du samedi. En 1694, à Genève, on retire aux Anciens le service de la cène à moins qu'ils n'en soient dispensés - question de point de vue. 


\subsection{TOLÉRANCE ET INTOLÉRANCE}

Un premier signe de tolérance religieuse est donné par Genève en 1624; tolérance timide au demeurant, puisqu'elle concerne un pasteur luthérien autorisé à prêcher pour un réfugié allemand dans le cadre familial uniquement; tolérance relative puisque la population genevoise s'indigne quand, cinquante ans plus tard, l'ambassadeur français installe une chapelle catholique à son domicile; mais tolérance réelle quand Genève accueille, en 1659, Jean de Labadie (16101674), un prédicateur piétiste à qui elle demande de s'installer comme pasteur et à qui elle confère la bourgeoisie; intolérance enfin envers celles et ceux que l'on appelle les petits prophètes cévenols, expulsés en 1689. À Neuchâtel, la Classe s'offusque quand Henri II d'Orléans-Longueville, souverain de Neuchâtel et de Valangin, fait célébrer la messe - et fait sonner les cloches - dans la chapelle de son château, lors de sa visite dans ses possessions en 1617. Ailleurs, on trouve la même alternance de tolérance et d'intolérance. En 1655, des pasteurs de l'Erguël, de la Prévôté de Moutier-Grandval, de La Neuveville, de Neuchâtel et de Valangin assistent avec intérêt aux conférences que James Dury donne à Nidau (Berne) et à Erlach (Berne); le pasteur écossais et anglican y plaide pour le rapprochement des différentes confessions protestantes. Mais quand le piétisme commence à apparaître, Berne crée en 1698, une Chambre des religions, destinée à identifier et à punir celles et ceux qui professeraient des croyances jugées dissidentes ou hérétiques. À Saint-Barthélemy (Vaud), les Bernois interdisent en 1675 la célébration des messes catholiques lors des fêtes patronales de saint Sulpice le 19 janvier et de saint Barthélemy le 24 août - au motif qu'elles seraient fêtées avec trop de faste et trop de réjouissances -, mais autorisent trois ans plus tard la célébration de messes plus discrètes - des messes basses - lors des deux mêmes fêtes.

Pourtant, la Suisse romande protestante sait se monter accueillante et même généreuse pour ses coreligionnaires chassés de leurs pays. Dès 1648, on prie dans les paroisses pour les Églises 
vaudoises du Piémont - elles s'appellent «vaudoises» par référence au fondateur du mouvement, Pierre Valdo (1140-1217). On jeûne par solidarité avec elles; on leur attribue le produit de collectes, et certains vont jusqu'à combattre au côté des Vaudois du Piémont, au cours de la «Glorieuse rentrée», qui commence en 1689 par la traversée du lac Léman depuis Prangins (Vaud).

Les huguenots français vont constituer l'écrasante majorité des réfugiés religieux. Fuyant les persécutions, ils arrivent en Suisse romande dès 1660, mais c'est la révocation de l'Édit de Nantes en 1685 qui provoque un exode parmi eux. Beaucoup se réfugient à Genève, qui en accueille certains et qui en renvoie d'autres «en Suisse»; certains ne font que passer sur la route de l'Allemagne; d'autres s'installent aussi bien dans les territoires romands qu'alémaniques. On évoque cent cinquante mille réfugiés pour une Suisse d'un million d'habitants; en six ans, Neuchâtel accueille dix-huit mille réfugiés pour une population de trois mille trois cents habitants; ils sont onze ou douze mille à passer par La Neuveville entre 1671 et 1709 . Pour répondre à leurs besoins, on crée des institutions qui leur sont spécifiques: on célèbre à Bienne un culte en français depuis 1623 et l'on y crée un poste de «pasteur français » en 1662; en 1687, Lausanne crée la Chambre des réfugiés qui doit prendre soin des Français persécutés et réfugiés. On trouve de telles «Bourses françaises» dans d'autres villes et villages du Pays de Vaud: Aigle, Morges, Moudon, Nyon, Payerne, Rolle, Vevey, Yverdon...; en 1689, une «Église française» est fondée à Berne; elle est aussi destinée aux Vaudois séjournant dans la ville. Mais l'accueil a ses limites: seul un pasteur réfugié sur cinq trouve à exercer son ministère, et Genève n'en accueille aucun. La Suisse et la Suisse romande finissent par se lasser des réfugiés; en 1699, la plupart sont repartis ou ont été renvoyés.

La Suisse romande, qu'elle soit protestante ou catholique, se montre beaucoup moins tolérante vis-à-vis de celles et ceux qu'elle qualifie de sorcières et de sorciers. Commencée avant même la Réforme, la répression se poursuit une fois celle-ci faite. La sorcellerie, crime à la fois théologique - on parle de 
lèse-majesté divine - et social est une accusation grave qui vaut à celles et à ceux qui en sont accusés d'être torturés, jugés et souvent exécutés. Les chiffres sont difficiles à établir, mais on estime que 58 sorciers et sorcières ont été exécutés à Genève, juste après la Réforme, entre 1542 et 1546 - Michée Chauderon y est la dernière à être exécutée; elle est pendue en 1652. À Neuchâtel et Valangin, on en dénombre 226 entre 1538 et 1675 ; à la Montagne de Diesse, 66 entre 1611 et 1667 . Le Pays de Vaud se montre le plus sévère avec 3371 exécutions entre 1591 et 1670, soit presque 38 en moyenne annuelle; deux synodes, tenus en 1652 et 1663 , traitent de la sorcellerie, qualifiée d'œuvre du diable; des lettres envoyées aux autorités bernoises leur reprochent leur trop grande clémence.

\subsection{CUltes et hieu de CULTE}

Au moment de la Réforme, les Églises protestantes s'étaient simplement approprié les chapelles, les églises, les collégiales et les cathédrales catholiques. Elles en avaient alors toutefois souvent transformé l'espace intérieur pour qu'il réponde à leurs propres besoins: suppression des chapelles latérales, pour ne garder qu'un seul vaste espace destiné à accueillir celles et ceux qui participaient au culte; abandon des autels et de la célébration de l'eucharistie au profit de la chaire et de la prédication. Mais au fur et à mesure de l'accroissement de la population, il faut en construire de nouvelles; si leur apparence les fait parfois ressembler aux églises catholiques, leur aménagement intérieur est mieux adapté à un culte réformé, plus participatif que la messe et centré sur l'ouie, la lecture de la Bible et la prédication. Elles sont de forme carrée - si elles sont rectangulaires, le rectangle est utilisé dans sa largeur plutôt que dans sa longueur - et les fidèles peuvent s'asseoir sur trois côtés tandis que la chaire est située sur le quatrième. On érige de nombreux temples - c'est souvent le terme que les protestant·e.s utilisent -, par exemple en 1604 à La Brévine (Neuchâtel), en 1609 à Gy (Genève), entre 1662 et 1664 à Chêne-Pâquier (Vaud). Et pour accueillir les réfugiés huguenots, on construit en 1695 le Temple du Bas dans la ville de Neuchâtel. On réorganise aussi l'intérieur des temples et des 


\section{LA CHASSE AUX SORCIÈres}

Bien entendu, la chasse aux sorcières n'est ni une spécialité protestante, ni une exclusivité suisse romande. Mais on constate avec regret qu'elle a aussi eu lieu dans la Suisse romande et dans la Suisse romande protestante.

Peut-être d'ailleurs que les raisons sont plus culturelles que religieuses, car les spécialistes soulignent que les procès pour sorcellerie ont surtout lieu dans le bassin rhénan, dans les régions rurales proches des Alpes et des Pyrénées, le long du Jura et autour du lac Léman. Or, nombre de ces régions forment ce qu'on appelle la Suisse romande. En Suisse même, les spécialistes remarquent que la persécution des sorcières suit une courbe ascendante du nord-est au sud-ouest; c'est précisément au sud-ouest de la Suisse que se situe la Suisse romande; et dans les vastes territoires bernois, c'est le Pays de Vaud qui se montra le plus sévère; le synode traita à deux reprises, en 1652 et 1663, de «l'œuvre du diable» et écrivit au Conseil bernois pour lui reprocher de se montrer trop tolérant.

Combien de sorcières et de sorciers, sachant qu'à Genève, les femmes représentèrent trois quarts des personnes jugées et deux tiers des personnes exécutées, furentelles jugées? Combien furent condamnées? Combien furent torturées ? Combien furent exécutées? Les chiffres varient et sont peu fiables; on évoque 3371 exécutions dans le Pays de Vaud entre 1591 et 1680, soit 37,9 exécutions par an ; 58 à Genève entre 1542 et 1546 , soit 14,5 exécutions par an; 226 à Neuchâtel entre 1538 et 1675 , soit seulement 1,6 exécution par an; enfin, on sait de source sûre - les procès-verbaux sont archivés, numérisés et disponibles en ligne - que 66 procès de sorcières et de sorciers se sont tenus sur la Montagne de Diesse entre 1611 et 1667. 
Comment expliquer la férocité de la chasse aux sorcières? C'est que de nombreux secteurs de la société se sentent menacés par la sorcellerie: la population, qui les accuse de causer du mal aux êtres humains, aux animaux et aux récoltes, juge les sorcières coupables de crime pénal; les autorités civiles, qui les accusent de remettre en cause les hiérarchies sociales, les jugent coupables de crime politique; les Églises enfin, qui les accusent de croire plus au diable qu'à Dieu, les jugent coupables de crime théologique. Le cadre de pensée du $\mathrm{XVI}^{\mathrm{e}}$ siècle, y compris dans la Suisse romande protestante, rend alors plausible la sorcellerie: on croit que des femmes reçoivent du diable le pouvoir de faire du mal ou l'interdiction de faire du bien. Au XVII ${ }^{e}$ siècle, quand on cesse d'y croire, on commence à interpréter ce qui pourrait apparaître comme un cas de sorcellerie au travers d'autres cadres de pensée. Ainsi, en 1757, quand un cas de sorcellerie est évoqué à Évilard (Berne), on envoie une délégation composée notamment d'un pasteur et d'un médecin pour statuer; refusant la qualification de sorcellerie, la commission préfère alors porter un diagnostic médical: le village souffre «d'hystérie collective».

Et quand l'époque moderne cherchera une explication à la chasse aux sorcières, elle l'inscrira elle aussi dans son propre cadre de pensée, proposant tantôt une lecture évolutionniste - la chasse aux sorcières comme signe de l'ignorance d'une époque ou de l'archaïsme de la religion -, tantôt une lecture sociale - la chasse aux sorcières comme condamnation de personnes marginales, étrangères et surtout des femmes émancipées.

Pour découvrir un cas exemplaire: Porret M., L'ombre du Diable: Michée Chauderon, dernière sorcière exécutée à Genève (1652), Chêne-Bourg: Georg, 2009. 


\section{LA CONSTRuCtion du TEMPle de ChÊNE-PÂQuier}

Qu'est-ce qui pousse les Bernois à construire en 1667 un nouveau temple à Chêne-Pâquier (Vaud) ? Ce petit village de la campagne vaudoise - Chêne ne compte alors qu'une dizaine de «feux» soit une cinquantaine de personnes et Pasquier moitié moins - avait-il besoin d'un tel édifice? Et pourquoi détruire l'église paroissiale située tout à côté? Et pourquoi réutiliser ses pierres pour construire le nouveau temple? Probablement pour marquer un territoire, pour construire un temple typiquement protestant et le rendre visible, pour donner un signe manifeste de la Réforme dans une région où les territoires catholiques - parce que fribourgeois - et protestants - parce que bernois - sont étroitement imbriqués.

Car une chose est certaine, le temple de Chêne-Pâquier est typiquement protestant; il est même probablement l'un des temples les plus protestants parmi les temples protestants. C'est à l'architecte biennois Abraham Dünz l'Aîné (16301688 ?) que l'on doit ses plans; c'est probablement aussi à lui que l'on doit le choix d'une forme d'ellipse, une forme qu'il a reproduite pour les temples d'Othmarsingen en Argovie - en 1675 - et d'Oron (Vaud) construit en 1678; il se serait inspiré du Temple de Paradis, un temple construit à Lyon cent ans plus tôt et détruit par un incendie au bout de trois ans; mais il existe une autre version qui circule dans la région, celle d'un plan ellipsoïdal conçu par le maçon - David Potterat - pour mettre à l'épreuve les compétences d'un charpentier dont on ne connaît pas le nom.

Mais peu importe qui en est l'inventeur. Comme le rectangle, l'ellipse - lorsqu'elle est utilisée transversalement, dans le sens de la longueur - convient parfaitement au culte protestant.

Car un plan rectangulaire ou ellipsoïdal crée un espace unique sans distinction hiérarchique, un espace unique avec des bancs disposés en hémicycle sur trois côtés, 
une espace unique avec une chaire qui «ferme»le quatrième côté ; il favorise ainsi la dimension communautaire du culte: chacune et chacun peut voir les visages des autres. Quant au pasteur, il ne fait pas face à la communauté, mais il en est un membre, chargé d'une fonction particulière; une fonction particulière dont témoigne l'emplacement de la chaire en bois. Légèrement surélevée, placée contre le mur au centre d'un long côté, elle représente le point focal ; elle signifie ainsi la primauté de l'annonce de la parole de Dieu, lue dans la Bible et dite dans la prédication; devant elle, une modeste table en pierre - elle aussi en forme d'ellipse - qui sert de guéridon lorsque la cène n'est pas célébrée. Astucieusement, le plan du temple de ChênePâquier renforce la primauté de la chaire en plaçant la porte d'entrée sur l'autre grand côté de l'ellipse; qui ouvre la porte se retrouve donc immédiatement face à cette chaire, et immédiatement proche d'elle puisque seule la largeur d'un petit côté l'en sépare.

Le temple de Chêne-Pâquier offre encore un autre trait caractéristique des temples protestants : sa sobriété; tant à l'extérieur qu'à l'intérieur, les murs sont peints en blanc; les quatre fenêtres sont en verre blanc, rendant le temple très lumineux; à l'intérieur, quatre fines colonnes en bois soutiennent la charpente; quatre petits vitraux représentent les quatre évangélistes - l'omniprésence du chiffre quatre dans un temple qui n'a qu'un mur ne manque pas d'intriguer -; seuls éléments particuliers: à l'extérieur, l'inscription au-dessus de la porte indique que les pierres utilisées pour la construction du temple sont celles de l'ancienne église paroissiale - intéressante volonté de marquer une continuité - et à l'intérieur, la dalle funéraire d'Albert Müller - bailli de Nidau et seigneur du lieu - mort en 1751.

Source principale : Reymond B., Sur le temple elliptique de ChênePâquier 1667-2017, s. 1.: s. n., s. d. 
églises; on y installe des bancs et on veille à ce que les places assises respectent l'ordre social: les Anciens sont assis face à l'assemblée; les magistrats occupent les places les plus proches de la chaire; les hommes et les femmes sont souvent séparés. Des personnalités sont enterrées dans l'église, ce qui aurait paru incongru quelques décennies plus tôt.

Le $\mathrm{XVII}^{\mathrm{e}}$ siècle voit des changements liturgiques: sous la pression des Églises réformées de France, la Compagnie de pasteurs de Genève simplifie ses liturgies, qu'il s'agisse du culte, du baptême, de la cène et du mariage; mais en 1630 , elle introduit dans le culte la lecture des dix commandements ; en 1623, elle abandonne le pain sans levain (les oublies ou oblats) dans la célébration de la cène. En 1638, La Neuveville confie au régent la tâche de lire la Bible avant la prédication et durant la communion. Les changements concernent aussi les jours de fête ; certains sont supprimés, d'autres sont ajoutés : en 1620, le Conseil de La Neuveville supprime la fête de l'Annonciation; en 1694, les pasteurs de Genève acceptent de prêcher le jour de Noël, sans que ce jour devienne pour autant chômé; on y célèbre aussi un culte pour Vendredi saint, l'après-midi à 3 heures; mais le jour n'est pas férié et, dès que le culte est terminé, chacun vaque à ses occupations et les magasins rouvrent. À compter de 1655, la cène est célébrée huit fois par an dans le Pays de Vaud: à Pâques, à Pentecôte, à Noël, lors des trois dimanches qui précèdent ces fêtes, du dernier dimanche d'août et du premier dimanche de septembre.

On décide de réviser le Psautier de Genève déjà vieux de plus d'un siècle; sa langue doit être revue. Conduite par Valentin Conrart, l'entreprise commence en France; après la révocation de l'Édit de Nantes, elle est reprise par des pasteurs français réfugiés à Zurich; en 1688, ils demandent l'aide de l'Église de Genève. En 1690, la nouvelle version, réalisée sous la direction de Bénédict de Pictet, est prête: aux Psaumes, traduits, adaptés ou paraphrasés de l'Ancien Testament, on ajoute douze cantiques pour les fêtes chrétiennes, dont les thématiques sont tirées des évangiles - il 
s'agit de «déjudaïser» les cantiques. D'abord testée dans les écoles, cette version est utilisée dans les cultes dès 1698 . Elle est alors proposée aux autres Églises francophones; beaucoup l'adoptent, mais les Églises wallonnes de Hollande la refusent violemment. C'est aussi au XVII ${ }^{\mathrm{e}}$ siècle qu'apparaissent les musiciens d'église; ils jouent surtout du hautbois ou du basson, mais parfois aussi de la trompette ou du «serpent d'église», un instrument à vent à la forme étrange d'un «s $\gg$.

Les funérailles se modifient; lorsque Théodore de Bèze meurt le 13 octobre 1605, le Conseil de Genève, contre l'avis des pasteurs, décide qu'il sera inhumé dans le cloître de la cathédrale; cette innovation va à l'encontre des principes calvinistes qui imposaient des sépultures anonymes. Quand l'Église d'Erguël édicte, en 1671, quelques indications succinctes sur le ministère pastoral, elle précise que les pasteurs doivent collaborer aux enterrements; ils ne le faisaient donc pas ou pas systématiquement auparavant. Le même règlement autorise les pasteurs, s'ils sont malades, à supprimer le culte - en semaine seulement - et le catéchisme. En 1635, déjà, La Neuveville avait supprimé la prédication du jeudi pour ménager des pasteurs surmenés et menacés dans leur santé; une année plus tôt, Genève avait supprimé les sermons du lundi et du samedi.

Enfin, en 1672, Neuchâtel parachève la visibilité de la Réforme en effaçant toutes les images de sa collégiale, cachant le cénotaphe des comtes de Neuchâtel, martelant jusqu'à la faire disparaître la sculpture d'une Vierge assise sur un trône, au motif que des «papistes » y venaient en pèlerinage pour s'agenouiller en signe d'adoration.

\subsection{Pendant ce temps-Là, dans le Valais ASSUJETTI...}

Concrétisation des progrès de la Réforme à la fin du $\mathrm{XVI}^{\mathrm{e}}$ siècle, le jour de la Pentecôte 1603, la communauté protestante de Sion, forte de ses cent cinquante membres, 
devient une Église quand elle accueille Jean Jaquemot, un pasteur genevois qui célèbre la cène. La réaction catholique ne se fait pas attendre: une Diète convoquée en mars 1604 contraint les protestant.e.s à choisir entre le retour à leur ancienne foi ou l'exil; plusieurs grandes figures protestantes préfèrent se convertir. Mais d'autres résistent encore; une diète tenue en 1626 confirme que le catholicisme est la religion du Valais mais elle en donne une définition minimaliste, attachée au seul comportement public: être catholique, c'est se confesser, communier, assister à la messe et participer aux fêtes; une telle définition permet probablement une certaine liberté quant aux convictions intimes. La diète tenue à Leuk (Valais) l'année suivante le confirme encore une fois: le Valais est catholique! Les protestant·e·s vont finir par se convertir ou s'exiler.

Il semble cependant qu'une exception vienne confirmer cette règle générale: le village de Vouvry, près de l'embouchure du Rhône, conserve une petite population protestante tout au long du XVII ${ }^{\mathrm{e}}$ siècle et au-delà; ce serait un cas unique de présence protestante continue en Valais.

\section{ORIENTATION BIBLIOGRAPHIQUE}

Fatio O., Widmer G. P., Confessions et catéchismes de la foi réformée, Genève: Labor et Fides, 1986.

LÉONARD É.-G., Histoire générale du protestantisme II / L'établissement, vol. 2, Paris: Presses universitaires de France, 1988.

Musée historique de l'Ancien-Évêché (Lausanne), Le refuge huguenot en Suisse = Die Hugenotten in der Schweiz, Lausanne: Musée historique de l'Ancien-Évêché, 1985. 
XVIII ${ }^{\mathrm{e}}$ SIÈCLE: UN PROTESTANTISME D'OUVERTURE

Le 13 juin 1798, Genève devient française, ce qui modifie profondément les rapports entre l'État et l'Église. Les nouvelles autorités interdisent de sonner les cloches et interdisent aux pasteurs de porter leur habit pastoral en public. Elles suggèrent de célébrer un culte le «décadi», jour férié du calendrier révolutionnaire; après discussion, la Compagnie des pasteurs rappelle qu'elle tient à célébrer son culte le dimanche, mais qu'elle est prête à organiser des sermons le décadi, pour peu que ce jour soit chômé.

En Suisse romande protestante, le XVIII ${ }^{\mathrm{e}}$ siècle commence et se conclut par des gestes politiques.

Le premier a une portée locale limitée: en 1707, la lignée des Orléans-Longueville s'étant éteinte, Neuchâtel se choisit un nouveau souverain; parmi dix-sept prétendants, c'est le roi de Prusse qui devient prince de Neuchâtel.

Le second a des conséquences plus larges et plus profondes. En 1798, les armées de la République française envahissent la Suisse. Genève et la Principauté épiscopale de Bâle sont annexés à la France. Neuchâtel reste une principauté, mais on lui donne comme prince Louis-Alexandre Berthier, un maréchal de Napoléon. Le Pays de Vaud prend son indépendance et, pour moins de trois mois, devient la République lémanique. Enfin, le 12 avril 1798, la République helvétique est proclamée. L'article 6 de la nouvelle Constitution reconnaît la liberté de conscience, tout en la subordonnant «aux sentiments de la 
concorde et de la paix», et autorise tous les cultes sous réserve qu'ils «ne troublent point l'ordre public et n'affectent aucune domination ou prééminence». C'est une première dans l'histoire suisse.

Pour présenter le XVIII ${ }^{\mathrm{e}}$ siècle de la Suisse romande protestante, nous retiendrons un découpage en trois régions: la Principauté de Neuchâtel et de Valangin, les territoires sous la domination ou l'influence bernoise (le Pays de Vaud et le sud de la Principauté épiscopale de Bâle) et la République de Genève. Cette division territoriale recouvre des divisions théologiques: «Berne» est plus «conservatrice», «Genève» est plus «libérale», et «Neuchâtel» se situe entre les deux. Nous commencerons par la vie protestante à Neuchâtel, parce que les changements y opérés vont avoir un impact sur les deux autres régions.

\section{I Dans la Principauté de Neuchâtel ET DE VALANGin}

Dans la Principauté de Neuchâtel et de Valangin, le XVIII $^{\mathrm{e}}$ siècle commence avec un peu d'avance, quand JeanFrédéric Ostervald (1663-1747) devient diacre de la ville de Neuchâtel, en 1686. Avec le Genevois Jean Alphonse Turrettini (1671-1737) et le Bâlois Samuel Werenfels (1657-1740), tous trois formant le «Triumvirat helvétique», il va promouvoir une orthodoxie théologique qualifiée de «raisonnée» et imaginer une pratique qui lui corresponde.

S'inspirant de l'Église d'Angleterre, Jean-Frédéric Ostervald est l'auteur de plusieurs innovations: la création d'une cérémonie de Ratification - «l' ancêtre » de la Confirmation - pour les adolescent.e.s; la réintroduction des fêtes liturgiques de Noël, de Pâques, de l'Ascension et de la Pentecôte; et la transformation du culte. Les réformateurs avaient conçu ce dernier comme un enseignement centré sur un sermon; JeanFrédéric Ostervald le transforme en un service divin dont l'objet est de louer Dieu. 


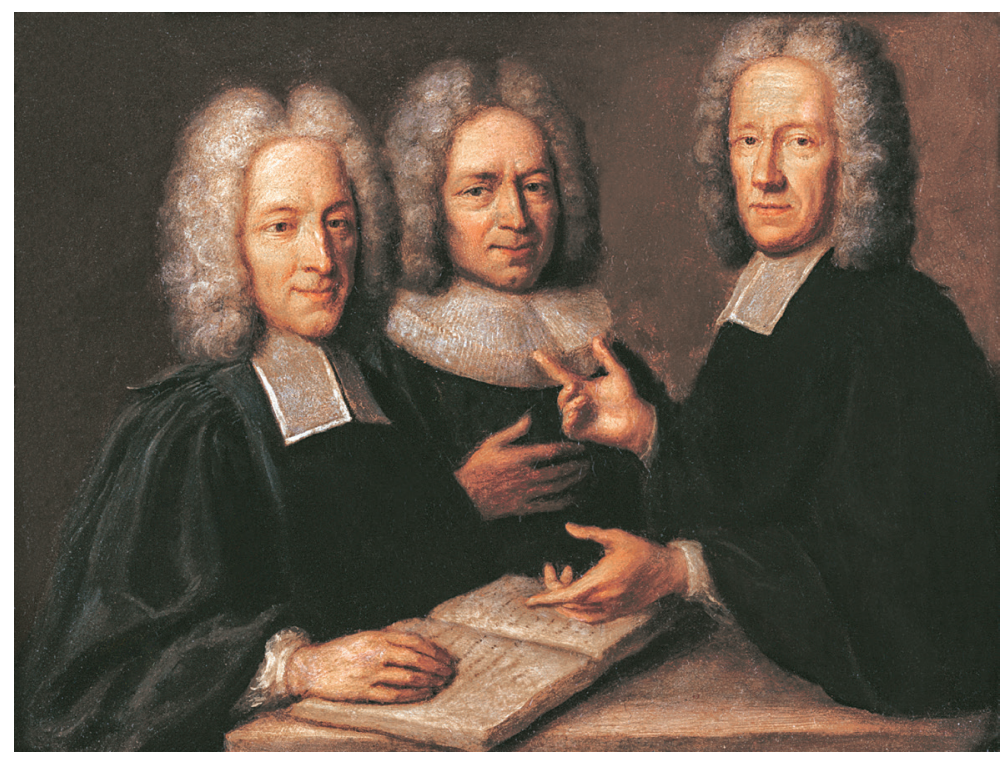

Robert Gardelle, Le triumvirat suisse

Huile sur cuivre, $\mathrm{XVIII}^{\mathrm{e}}$ siècle

(C) Bibliothèque de Genève

Cestroiséminents théologiens-Jean-Alphonse Turrettini(Genève), SamuelWerenfels (Bâle) et Jean-Frédéric Ostervald (Neuchâtel) - forment le «Triumvirat helvétique». Les portraits montrent des différences quant à la robe pastorale: à Neuchâtel et à Genève, elle est agrémentée d'un double rabat; à Bâle, on porte la fraise.

En 1701, sous son impulsion, on repense la formation des pasteurs: la Classe se charge d'examiner les candidats, âgés de 15 à 17 ans, sur leurs connaissances dans les humanités et dans la philosophie; elle vérifie aussi leurs mœurs et leur piété. Elle envoie les candidats qu'elle retient dans une académie, souvent celle de Genève, pour étudier pendant quatre ans les langues anciennes, la philosophie, l'histoire (sacrée et profane) et la théologie; enfin, elle surveille leur moralité, leur interdisant de «fréquenter les dames». 
En 1707, le roi de Prusse, dans les Articles généraux, confirme les prérogatives de la Vénérable Classe des pasteurs - «que ladite compagnie jouisse librement de tous ses droits»- notamment quant aux «choses qui concernent le saint ministère » - il faut comprendre l'élection, la suspension ou le déplacement d'un pasteur.

En 1712, la Classe charge Jean-Frédéric Ostervald de rénover la Discipline des «Églises de la Souveraineté de Neuchâtel et Valangin». Centrée sur le pasteur, celle-ci rappelle comment on le devient, comment on reçoit et exerce un ministère paroissial ; elle fixe le droit pénal ecclésiastique que le pasteur a pour tâche de faire respecter; elle définit les tâches administratives du pasteur, ce qui englobe la célébration des mariages, la direction des écoles ou l'assistance aux pauvres. Probablement parce qu'elle pressent des réactions négatives, la Vénérable Classe choisit de garder cette Discipline secrète, de ne la partager qu'avec les seuls pasteurs membres de la Classe.

Mais quand Jean-Frédéric Ostervald meurt en 1747, la Vénérable Classe opère un repli théologique. Comptant une quarantaine de pasteurs, elle se réunit désormais à huis clos le premier mercredi du mois; les séances sont présidées par un doyen et débutent par un sermon; chaque membre doit promettre de garder secret «ce qui doit être gardé secret». Elle mène le combat contre l'abolition de la pénitence publique au temple, combat inutile puisque celle-ci finit par être supprimée par le Conseil d'État en 1755.

Ce qui n'empêche pas des signes d'ouverture comme en témoignent les baptêmes de la fille adoptive de George Keith (1693-1778) dit Milord Maréchal et gouverneur de la Principauté de Neuchâtel, et de son valet de chambre, tous les deux

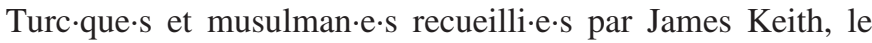
frère de George, à la bataille d'Otchakiv (Turquie) en 1737. 


\section{JEAN-Frédéric OSTERVALD}

Jean-Frédéric Ostervald (1663-1747) est un enfant précoce : à 13 ans, il apprend l'allemand à Zurich; entre 15 et 17 ans, il étudie la philosophie et la théologie à l'Académie de Saumur (France); à 19 ans, il termine ses études à l'Académie de Genève; à 20 ans, il rentre à Neuchâtel, passe ses examens pour être consacré pasteur. En 1684, il épouse Salomé Chambrier, représentante d'une grande famille neuchâteloise. Il est aussi un théologien brillant: en 1686, il devient diacre de la ville de Neuchâtel - à ce titre, il est responsable du catéchisme - et premier pasteur de la ville en 1689; en 1700, il est choisi comme doyen de la Vénérable Classe, un poste qu'il occupe à treize reprises. S'inspirant de l'Église anglicane, Jean-Frédéric Ostervald va profondément réformer et rénover l'Église réformée dans la Principauté de Neuchâtel; à un point tel qu'il est parfois qualifié de «second réformateur de Neuchâtel» - après Guillaume Farel, s'entend.

Il réforme à la fois l'éducation, en créant en 1701 une «école de charité » qui offre un enseignement gratuit aux enfants pauvres, et l'éducation religieuse. D'abord en instaurant en 1700 une cérémonie de Ratification des vœux de baptême qui impose aux catéchumènes la promesse de renoncer «au Diable et à ses ouvres, au monde et à ses pompes, à la chair et à ses désirs ». Puis en publiant en 1702, un Catéchisme composé en trois parties : ce qu'il faut croire pour être sauvé, ce qu'il faut faire pour être sauvé, comment s'exercer à la piété. Enfin, en transformant la pratique du catéchisme qu'il déplace du dimanche au samedi matin, qu'il rend plus scolaire et qu'il interdit aux adultes.

Il réforme la vie sociale et religieuse en réintroduisant dans le calendrier des fêtes que la Réforme avait fait disparaître. En 1703, le Conseil de la ville de Neuchâtel approuve sa proposition de célébrer Noël et l'Ascension : Noël devient 
un jour chômé où sont prononcés deux sermons, où la cène est célébrée et qui se termine par une prière du soir; l'Ascension, comme Vendredi saint, devient un jour à moitié chômé sans que le nombre de célébrations en soit réduit pour autant.

Ostervald réforme le culte en publiant, en 1713, une nouvelle liturgie inspirée par l'Église anglicane. Il remplace le culte traditionnel, composé presque exclusivement d'un sermon, par un service divin, qui permet de rendre grâce à Dieu plutôt que d'instruire les fidèles. Il simplifie la langue, place la lecture de la Bible au cours du culte et non plus avant qu'il commence.

Il rénove la lecture de la Bible en révisant la Bible de Genève; la «Bible Ostervald», parue en 1744, devient une Bible de référence; elle connaîtra quarante-neuf rééditions en cent cinquante ans. Elle est précieusement et pieusement transmise de génération en génération dans les familles neuchâteloises; il faudra attendre le début du $\mathrm{Xx}^{\mathrm{e}}$ siècle pour qu'elle soit vraiment remplacée. Aujourd'hui encore, on en trouve des versions en libre accès sur Internet.

Jean-Frédéric Ostervald meurt en 1747. Il est enterré au Temple du Bas.

Membre correspondant de la très britannique Society for Promoting Christian Knowledge, il a fait connaître Neuchâtel dans toute l'Europe, à Londres, Amsterdam ou Berlin; certaines de ses œuvres ont été traduites en anglais et en allemand, mais aussi en néerlandais, en danois, en hongrois et même en arabe.

Source principale: Barthel P., Jean-Frédéric Ostervald l'Européen: 1663-1747; novateur neuchâtelois, Genève: Slatkine, 2001. 
Sa fille, Emetulla (1730-1820), est baptisée du prénom «chrétien» de Marie Émeté le 24 janvier 1763 par le pasteur Henri David Petitpierre; son valet de chambre, Ibrahim, est quant à lui, instruit, baptisé et admis à la cène à Colombier par le pasteur du lieu, le «doyen Chambrier». Ce sont peut-être les deux premiers musulman·e.s et les deux premiers «non-blanc·he·s» à être baptisé·e·s dans une Église réformée de Suisse romande.

Mais la Vénérable Classe supporte avec difficulté le débat d'idées; par l'intermédiaire du pasteur Frédéric Guillaume Montmollin et du consistoire de Môtiers, elle juge et condamne Jean-Jacques Rousseau, pour ses Lettres de la Montagne, un ouvrage qu'elle juge pernicieux; le 9 septembre 1765, après que sa maison a été caillassée, Rousseau préfère quitter Môtiers et la Principauté de Neuchâtel.

Sur le plan religieux, la Principauté de Neuchâtel et Valangin se signale par une tolérance - sans doute relative, mais une tolérance quand même - pour d'autres formes de protestantisme. Elle le doit sans doute à son souverain, Frédéric II, le «despote éclairé », plus tolérant que la loi, car celle-ci interdit toujours que s'établissent des Églises non réformées dans la Principauté, sauf à Cressier et au Landeron. En 1702, Neuchâtel accueille Béat Louis de Muralt (16651749), ancien capitaine des Gardes suisses à Versailles et auteur de plusieurs essais philosophiques et théologiques. Parce qu'il est piétiste et qu'il reproche aux Églises réformées leur autoritarisme politique, il a été banni de Berne et expulsé de Genève ; il s'installe à Colombier dans la propriété de sa femme, Margarete von Wattenwyl. En 1741, Neuchâtel accueille temporairement le comte de Zinzendorf, qui retourne en Allemagne après avoir visité Genève, Yverdon et Neuchâtel; il séjourne à Montmirail où, malgré les réticences et les résistances des autorités tant politiques que religieuses de Neuchâtel - selon lesquelles la région est déjà trop peuplée -, il peut créer, en 1746, un lieu de retraite pour les Frères moraves, déjà présents à Peseux, au Val-de-Travers, au Locle et à La Chaux-de-Fonds. 


\section{JEAN-JACQues RouSSEAu CAILlassé À Môtiers}

Jean-Jacques Rousseau passe trois années dans la Principauté de Neuchâtel, une région qu'il connaît bien car il y a séjourné à l'hiver 1730-1731, alors âgé de 18 ans, et dont il apprécie les habitants: il fait des Montagnons un modèle à suivre. Mais c'est un peu par hasard qu'il s'y installe; il le doit à Julie-Anne-Marie Boy de la Tour qui, lorsqu'il est chassé de Genève en 1762 à la suite de la parution et de la condamnation de l'Émile, lui propose d'habiter dans sa maison de Môtiers dans le Val-de-Travers.

Quand il arrive à Môtiers, Jean-Jacques Rousseau a déjà connu une vie spirituelle un peu compliquée. Né protestant, il s'est converti au catholicisme en 1538, sans doute par conviction, mais aussi par amour pour Madame de Warens. Cependant, il est «rentré dans l'Église de ses pères» en 1754, une conversion plus politique que religieuse, tout en professant une foi très personnelle. Mais, désireux de s'intégrer dans la communauté qui l'accueille, pensant aussi que son exemple sera édifiant, Jean-Jacques Rousseau écrit le 24 août 1762 à «son» pasteur, Frédéric Guillaume Montmollin, le pasteur de Môtiers, pour lui demander la permission de communier; la réponse est sans doute positive, puisqu'il participe à la cène le dimanche 29 août.

Même si l'attitude de Rousseau détonne dans un village comme Môtiers, où il vit maritalement avec Thérèse Levasseur, sa gouvernante et se promène vêtu «en Arménien», il entretient pendant trois ans de bonnes relations avec le pasteur. Les deux hommes discutent souvent et longuement; Rousseau se rend au culte presque chaque dimanche; il communie avec «humilité et dévotion». Frédéric Guillaume Montmollin prête même sa voiture pour que Thérèse puisse se rendre à la messe dans un village catholique. Rousseau déclare alors à son éditeur qu'il est «naturalisé de la Principauté de Neuchâtel» et «communier de Couvet», le village voisin de Môtiers. 
Mais la situation se détériore brusquement lorsqu'en février 1765, Rousseau publie ses Lettres de la Montagne et que la Classe décide de se pencher sur cet «ouvrage très dangereux». Celle-ci demande au gouvernement de prendre des sanctions contre un ouvrage «aussi pernicieux»- mais peut-on brûler un livre qui contient d'abondantes citations bibliques? - et, manquant peutêtre de courage, confie au consistoire de Môtiers, Travers et Boveresse la charge d'instruire l'affaire. Le dimanche 24 mars, le consistoire se réunit: Rousseau est cité à comparaître cinq jours plus tard. Mais le philosophe est malade et ne s'y présente pas. Peu importe, le consistoire a lieu, présidé par le pasteur Montmollin; il est procédé à un vote, mais la situation est si confuse qu'on ne connaît ni l'objet du vote ni son résultat.

L'été passe, sans que la situation s'apaise. Mais au début du mois de septembre, les événements se précipitentet en une semaine, tout bascule. Dans la nuit du dimanche $1^{\text {er }}$ septembre, après un sermon virulent $\mathrm{du}$ pasteur Montmollin, on jette des cailloux sur la maison de Rousseau. Cette même nuit, on renverse l'un de ses bancset la nuit suivante, on tente de forcer sa porte. Le mardi, Rousseau entend un coup de fusil et ce cri: «Faux Prophète!»; le vendredi, un caillou casse l'une de ses fenêtres.

Le dimanche 8 septembre, Rousseau préfère quitter Môtiers et la Principauté de Neuchâtel. Le 9 septembre, il s'isole sur l'Île-Saint-Pierre, au milieu du lac de Bienne.

Source principale: EIgELdinger F., "Des pierres dans mon jardin»: les années neuchâteloises de J. J. Rousseau et la crise de 1765, Paris \& Genève: Champion \& Slatkine, 1992. 


\subsection{Pendant Ce TeMPS-LÀ, dANS LeS TERritoires SOUS INFLUENCE BERNOISE}

De manière générale, Berne va s'opposer fermement à l'orthodoxie raisonnée, prônée par Jean-Frédéric Ostervald, et à son Catéchisme. En 1701, Berne en confisque un premier brouillon et en 1702, une semaine après sa parution, publie la Censura Bernensis qui le condamne doublement: sur le fond - il ne s'inscrit pas dans la théologie des Églises helvétiques, celle de la Formula Consensus - et sur la forme - les Églises réformées ne peuvent accepter un Catéchisme personnel, œuvre d'un seul individu. Parce que Berne estime qu'il risque de corrompre les Églises et de mettre en danger la foi, elle tente d'en interdire la diffusion en «Suisse romande» et la vente à Neuchâtel. Officiellement, la Principauté respecte cette interdiction, mais officieusement, elle en continue la distribution. Dans les territoires qu'elle administre ou qu'elle influence, Berne impose l'utilisation du catéchisme luthérien d'Heidelberg.

\section{Dans la Principauté épiscopale de Bâle, puis dans le département du Mont-Terrible}

Le Traité d'Aarberg, signé en 1711 entre Berne et le prince-évêque Jean-Conrad de Reinach, reconnaît le droit à l'existence de «réformés jurassiens », à condition que les populations soient confessionnellement homogènes. Dans la Prévôté de Moutier-Grandval, les catholiques résidant sur les Roches doivent déménager sous les Roches et les protestant.e.s faire le chemin inverse. Les piétistes ont plus de chance; pour un temps, ils peuvent s'installer à Bévilard, dans la Prévôté de Moutier-Grandval; d'autres, chassés du Pays d'Enhaut (dans le Pays de Vaud) trouvent dans le Haut-Erguël un refuge temporaire qu'ils finissent par quitter pour la Principauté de Neuchâtel. Après 1750, on trouve à la Chaux d'Abel (Jura) l'une des trois communautés amish de Suisse, une autre demeurant dans le Val-de-Ruz (Neuchâtel). 
La partie protestante de la Principauté épiscopale semble divisée en deux: d'un côté, la Prévôté de Moutier-Grandval très inféodée à Berne, de l'autre, La Neuveville et l'Erguël qui bénéficient de plus d'indépendance.

Les Classes de La Neuveville et d'Erguël adoptent en 1726 la liturgie d'Ostervald, mais cela ne vaut que pour le culte ordinaire. Pour la célébration de la cène, elles conservent celle de Calvin. En 1742, elles laissent aux pasteurs la liberté de choisir la liturgie qui leur convient, mais dans un même mouvement, elles adoptent rapidement le Catéchisme d'Ostervald.

Dans le même temps, Berne veille à maintenir la bonne doctrine dans la Prévôté de Moutier-Grandval; ainsi, lors des visites d'Église, elle distribue des exemplaires du Catéchisme d'Heidelberg. La ville tient aussi à rappeler à la Prévôté ce qu'elle lui doit: le 7 janvier 1578, on commémore le bicentenaire de la Réforme bernoise, en célébrant deux cultes, une cène et en frappant des médailles commémoratives.

Tout au long du XVIII ${ }^{\mathrm{e}}$ siècle, la vie ecclésiale continue: les mariages sont célébrés publiquement, généralement pendant les cultes de semaine; les enfants sont baptisés au début du culte dominical. Les services funèbres incombent encore aux régents (les maîtres d'école), mais les pasteurs commencent à s'y impliquer. Ainsi, le pasteur de Renan (Berne) demande à la Classe de l'Erguël comment enterrer une personne qui a été excommuniée. Avant les enterrements, les familles et les amis des défunts prennent l'habitude de se rassembler au domicile des défunts pour lire la Bible. Le catéchisme, qui réunit enfants et adultes, a lieu le dimanche après-midi ; en semaine, le pasteur instruit les jeunes gens qui se préparent à participer à la cène.

Les Classes s'occupent toujours de la discipline et règlent les affaires de mœurs. En 1730, la Classe d'Erguël interdit au pasteur d'Orvin, François-Louis Faigaux (1706-1752), de se marier avec sa cousine germaine Isabelle Cornélie d'Aubigné. Il s'ensuit un bras de fer avec le prince-évêque qui lui avait accordé une dispense. Intransigeante, la Classe d'Erguël obtient 
gain de cause: en 1732, le pasteur Faigaux doit quitter Orvin; il s'installe aux Pays-Bas puis en Allemagne. Mais les Classes s'occupent aussi de théologie; au milieu du XVIII ${ }^{\mathrm{e}}$ siècle, la Classe d'Erguël blâme et bannit le pasteur FerdinandOlivier Petitpierre parce qu'il ne croit pas que Dieu condamne les pécheurs à des peines éternelles. Les autorités politiques exercent elles aussi leur pouvoir: arrivé le 9 septembre 1765 de Môtiers à l'Île de Saint-Pierre, située au milieu du lac de Bienne, en face de La Neuveville, Jean-Jacques Rousseau en est expulsé le 16 octobre de la même année. Il pense alors pouvoir se réfugier à Bienne, mais il en est aussi chassé.

Berne, enfin, ne se montre pas plus tolérante envers les juifs et les juives. En 1787, les autorités bernoises rappellent qu'il est interdit à ces dernier-ère-s de s'établir sur l'ensemble de leur territoire, y compris francophones.

En 1792, quand les armées de la République française envahissent le nord de la Principauté épiscopale, les pasteurs David-Henri-Fidèle Cunier (1753-1811) à Courtelary, BenoîtAimé Himley (1743-1829) à Saint-Imier et Georges-Auguste Liomin (1769-1819) à Péry participent à l'Assemblée nationale d'Erguël qui se tient dans le temple de Courtelary. Cette réunion a pour objet la fondation d'une république indépendante. Berne met deux ans à réagir, mais en 1794, elle déclare un jour de jeûne dans la prévôté de Moutier-Grandval - un jeûne suivi par toute la population, catholiques et anabaptistes compris - et appelle les fidèles à se méfier des «funestes principes d'irréligion et d'impiété».

Le XVIII ${ }^{\mathrm{e}}$ siècle connaît encore un dernier épisode politique quand, en 1797, la République française annexe la partie sud de la Principauté épiscopale de Bâle. Elle impose alors aux Églises réformées un statut et une organisation française, c'est-à-dire une organisation centrale qui les rattache à l'Église réformée française. Elle crée quatre Églises consistoriales: Bévilard (Bévilard, Court-Grandval, Moutier, Sornetan et TavannesChaindon), Corgémont (Corgémont-Sombeval, Courtelary, Péry et Tramelan), Saint-Imier (Renan et Saint-Imier) et 
Bienne (Bienne, Diesse, La Neuveville, Nods, Orvin, Perles, Vauffelin). Elle les oblige à se montrer discrètes, en interdisant par exemple la sonnerie des cloches, et les contraint à vendre leurs biens, tout en acceptant les ventes fictives, c'est-à-dire la vente à des paroissien.ne-s qui les mettent à disposition des Églises. Enfin, elle les organise en consistoire local et en grand consistoire régional, dont elle confie l'administration aux pasteurs auxquels elle adjoint six à douze anciens.

\section{Dans le Pays de Vaud...}

Le $\mathrm{XVIII}^{\mathrm{e}}$ siècle voit les premières manifestations de dissidence religieuse.

En 1701, la Classe de Lausanne se plaint à Berne de la présence de cercles piétistes à Vevey. Une semaine après avoir reçu la lettre, Berne demande aux pasteurs veveysans de s'informer et de transmettre leurs informations à la Chambre des religions.

La même année, à Yverdon, un jeune diacre piétiste David Faigaux (1675-1746), père de François-Louis et originaire de Sorvillier (Berne), fait preuve d'esprit d'initiative: il se propose pour assurer l'instruction religieuse de la jeunesse. On lui confie les enfants des écoles primaires et du collège, qu'il catéchise le vendredi matin, et il compose un abrégé du Catéchisme d'Heidelberg - La Religion Chrétienne Dans Sa Source Et Dans Toutes Ses Parties - qui ne reçoit l'approbation ni de la Classe d'Yverdon ni de la Ville de Berne; ce qui ne l'empêche pas de devenir par la suite pasteur à Bévilard et à Nods.

En 1706, de jeunes pasteurs vaudois, mécontents de l'orthodoxie rigoureuse imposée par Berne, cherchent à obtenir des modifications de la Formula Consensus. Non seulement ils n'obtiennent pas satisfaction, mais Berne renforce encore sa tutelle. Le $1^{\text {er }}$ juillet 1722, Berne compose les cinq Classes du Pays de Vaud - Lausanne-Vevey, Morges, Orbe, PayerneMoudon et Yverdon-Romainmôtier -, pour contraindre tous les pasteurs à signer cette même Formula Consensus et à prêter le Serment d'association. 
C'est dans ce contexte qu'en 1723, Jean Daniel Abraham Davel (1670-1723), major des milices vaudoises, conduit une révolte contre Berne. Si ses motifs sont avant tout nationalistes, ils sont aussi théologiques et ecclésiaux. Connu pour sa piété, Davel reproche aux Bernois la manière dont ils gèrent l'Église réformée dans le Pays de Vaud. Dans un élan presque mystique - il avait 18 ans quand une «Belle Inconnue» lui aurait prédit un grand destin - il se sent investi d'une mission divine, celle de libérer le Pays de Vaud. Le 31 mars, Davel entre dans Lausanne à la tête d'une troupe non armée; le $1^{\text {er }}$ avril, il est arrêté. Emprisonné au château de Chillon, torturé, il répète que sa mission lui a été inspirée par Dieu. Le 17 avril, le tribunal des bourgeois de Lausanne le condamne à mort et le 24 avril, il est décapité à Vidy, près de Lausanne.

Il faut attendre 1758 pour que Berne renonce à exiger des pasteurs vaudois qu'ils adhèrent par leur signature à la Formula Consensus, ce qui n'empêche pas, pendant ce temps, le protestantisme dans le Pays de Vaud de changer. En 1725, une nouvelle liturgie paraît. On célèbre des cultes de confirmation, dès 1728 pour les enfants des écoles de charité, en 1745 pour les jeunes garçons et pour les jeunes filles qui terminent leur période d'instruction religieuse; dès 1756, cette cérémonie est fixée au jeudi avant Pâques. En 1732, on précise que les mariages doivent être célébrés au temple, «en pleine assemblée de l'Église », avant ou après le sermon. En 1733, on installe un orgue dans la cathédrale de Lausanne; l'innovation plaît: on retrouve un orgue à Yverdon en 1767, à Saint-François à Lausanne en 1777, à Morges en 1778, à Sainte-Claire à Vevey en 1779, à Saint-Laurent à Lausanne en 1790.

En 1730, le pasteur français Antoine Court (1696-1760), réfugié à Lausanne, y organise un Séminaire français destiné à former les «pasteurs du Désert»; ces pasteurs qui officient clandestinement en France à la fin de la guerre des Camisards n'ont ni les moyens - ils ne possèdent pas tous une Bible - ni les prérequis - ils ne connaissent pas les langues bibliques - ni 
le temps de suivre les cours de l'Académie. Au Séminaire, installé dans le quartier de la Cité, dans une maison privée à côté de la cathédrale, ils reçoivent une formation courte, un an d'abord, deux ans par la suite, qui va à l'essentiel. Quant aux pasteurs vaudois, ils se forment à l'Académie qui comprend, selon les époques, six ou sept chaires: théologie pratique, théologie dogmatique, morale, philosophie, langues savantes, histoire et droit.

\section{LA CRÉATION DU SÉMINAIRE FRANÇAIS de LAUSANNE}

Lausanne a hébergé entre 1723 et 1812, le «Séminaire français », c'est-à-dire l'institution qui va fournir aux Églises françaises du «Désert» - c'est ainsi que l'on nomme, par analogie à l'Exode, le temps d'un protestantisme clandestin - les guides spirituels dont elles ont besoin.

Le Séminaire français doit presque tout à un Français, Antoine Court (1695-1760). Bien qu'il ait lui-même étudié la théologie à l'Académie de Genève pendant un an et demi entre 1721 et 1722 (ou peut-être parce qu'il a étudié la théologie à l'Académie de Genève), il crée à Lausanne - Genève paraissant trop près d'une France trop menaçante - un lieu de formation théologique répondant aux besoins des futurs pasteurs français.

C'est que le rôle du pasteur n'est pas le même en France qu'en Suisse romande: des étudiants formés dans les académies ne pourraient pas remplir les tâches qui leur sont confiées, et il n'est pas certain que les étudiants français pourraient suivre tous les cours d'une académie. C'est qu'il convient de former le plus grand nombre de pasteurs dans le plus court laps de temps.

Car les Églises du Désert ont besoin de missionnaires, de «pasteurs de choc» et veulent les préparer à ce qui les attend. Après avoir pris un nom d'emprunt pour protéger sa famille, le candidat-pasteur fait l'expérience 
d'un ministère pastoral itinérant; si sa vocation résiste à la difficile épreuve du terrain, il est alors envoyé au Séminaire de Lausanne. Il y suit un programme de formation qui peut durer un ou deux ans, qui varie selon les périodes, mais qui inclut des cours de théologie, chrétienne et naturelle, de morale, de latin et si possible de grec, de controverse - il convient de savoir se défendre, aussi sur le plan intellectuel - et de «devoir des ministres»: homilétique et catéchèse. Tous ces cours sont assurés par des professeurs, au nombre de quatre à sept, qui donnent aussi des collegia privata, c'est-à-dire des leçons privées et payantes.

Le nombre des étudiants s'accroît régulièrement, et les pasteurs formés au Séminaire français représentent la très grande majorité des pasteurs en activité dans les Églises réformées de France. En 1744, on compte 25 étudiants qui représentent $76 \%$ des pasteurs français; en 1759, ils sont 50 , soit $83 \%$ des pasteurs français; en 1763,54 , soit $87 \%$ des pasteurs français; et en 1789,160 , soit $91 \%$ des pasteurs français.

Durant toute son existence, le séminaire est installé sur la colline de la cité, en plein centre de Lausanne, juste à côté de la cathédrale et de l'académie; il ne dispose pas de locaux propres, et les cours se donnent successivement chez les professeurs, puis dans une chambre, dans une serre, puis dans un appartement «chauffable» de la maison de David Levade, l'un des enseignants.

Que les futurs pasteurs vivent seuls à Lausanne suscite des inquiétudes quant à leur moralité; on déplore souvent que les pasteurs reviennent en France avec des «goûts mondains» et des «habitudes déréglées» qui prêtent le flanc à la critique catholique.

Source principale: LASSERRE C., Le séminaire de Lausanne, 1726-1812: instrument de la restauration du protestantisme français: étude historique fondée principalement sur les documents inédits, Lausanne: Bibliothèque historique vaudoise, 1997. 
Le XVIII ${ }^{\mathrm{e}}$ siècle est une période favorable aux bâtisseurs. À lui seul, l'architecte Guillaume Delagrange construit cinq temples: à Lausanne (Saint-Laurent) en 1716-1717; à Bercher en 1724, où il réutilise au maximum des parties de l'église existante; à Chexbres en 1726-1727; à Échandens en 1729; et à Dommartin en 1732-1734. Il dessine encore, en 1730, le plan de l'église de Saint-Saphorin-sur-Morges. Mais tous les projets n'aboutissent pas. En 1710, à Échallens, la partie protestante veut disposer de son propre temple et souhaite, en outre, que la partie catholique contribue à son financement. Mais les catholiques refusent, et le projet capote. En 1766, Berne envisage de faire démolir la cathédrale de Lausanne pour bâtir une église baroque; mais le manque d'argent empêche la réalisation du projet.

Le paysage religieux vaudois continue à se diversifier. En 1526, la baronne veveysane Françoise-Louise de Warens (1699-1762) se convertit au catholicisme. C'est chez elle, le dimanche des Rameaux 1738, que Jean-Jacques Rousseau fait de même. En 1774, le pasteur Jean-Philippe Dutoit-Membrini (1721-1793) crée à Lausanne le « cercle mystique de Lausanne » ou «maisonnée des âmes intérieures», un mouvement quiétiste - il prône la passivité pour laisser Dieu agir - qui rassemble les «fidèles de la doctrine de l'intérieur». Le premier pasteur de Lausanne, Jean-Antoine-Noé Pollier de Botttens (17131783 ) rédige plusieurs articles pour l'Encyclopédie de Diderot et d'Alembert, sans toutefois les signer.

\subsection{Pendant ce temps-là, dans la République DE GENÈVE...}

Au XVIII ${ }^{\mathrm{e}}$ siècle, l'Église de Genève est la première Église suisse romande à abandonner officiellement la stricte théologie calviniste. Elle le fait officiellement en 1725, quand elle renonce à contraindre les pasteurs à signer la Formula Consensus ou toute autre confession de foi.

Mais elle a commencé à faire preuve de tolérance et d'ouverture dès 1709, quand elle a décidé de laisser aux écoles la liberté de choisir leur Catéchisme; beaucoup préfèrent alors 
celui d'Ostervald à celui de Calvin. On voit naître des initiatives individuelles. En 1736, le pasteur Jacob Vernet (1698-1789) crée une «Société pour l'instruction religieuse de la jeunesse » ou «Société des catéchumènes». Il y organise une formation chrétienne avec un enseignement élémentaire pour les enfants, suivie de cours de religion pour préparer les plus âgés à participer à la cène. Il y ajoute des cours de «chant sacré ». La Société s'occupe aussi de l'instruction générale: elle fonde quatre écoles, deux de chaque côté du Rhône, deux pour les filles et deux pour les garçons; les enfants y sont admis dès l'âge de 6 ans. Elle ouvre ensuite des écoles pour les enfants de 12 à 15 ans : le soir et en hiver pour les garçons, le matin et en été pour les filles. Les idées évoluent, et la théologie suit ces évolutions. En 1774, le pasteur Jacob Vernes (1728-1791), issu du refuge huguenot, ami de Rousseau et de Voltaire, rédige son propre Catéchisme à destination des jeunes gens: il est de tendance «rationaliste». Mais en 1788, la Compagnie des pasteurs publie un nouveau Catéchisme «officiel».

L'évolution touche aussi la liturgie. En 1705, la révision du Psautier est achevée. La Commission que préside Bénédict Pictet y ajoute cinquante-quatre cantiques sacrés, dont douze pour les fêtes. En 1724, une commission composée de pasteurs et de laïcs est chargée de réviser la liturgie du culte, des sacrements, cène et baptême, et du mariage afin de les adapter à l'époque. Elle revoit les horaires, elle révise la forme: adaptation linguistique et raccourcissement des prières, ce qui ne pose pas de problème. Mais jusqu'où faut-il aller? Que signifie concrètement abandonner «les expressions un peu dures»? Faut-il supprimer les mentions de la corruption foncière de la nature humaine ou suffit-il d'adoucir les termes utilisés? La politique s'en mêle, et le Conseil reproche à la Compagnie d'avoir retranché des points essentiels de la doctrine calviniste. On finit par se mettre d'accord sur un texte de compromis, mais qui intègre les idées nouvelles. En 1737, on introduit, à l'instar des Églises de Neuchâtel et Valangin, une «Réception des catéchumènes»; en 1743 apparaît une nouvelle liturgie, celle d'un jour de jeûne, fixé au premier jeudi du mois de septembre. 
Les changements portent aussi sur la discipline. Ceux que l'on qualifie de «révoltés», qui ont transgressé de quelques manières les Ordonnances, doivent encore manifester publiquement leur repentance devant le consistoire pour pouvoir de nouveau participer à la cène, mais on les autorise à le faire, en privé, au domicile des pasteurs.

Le mouvement concerne également le ministère pastoral. Les pasteurs se plaignent de leur charge de travail. Jacob Vernes se fait leur porte-parole en déclarant qu'un tel rythme n'est plus nécessaire au XVIII ${ }^{\mathrm{e}}$ siècle. Entre 1770 et 1775 , on manque de pasteurs et la Compagnie voit dans la pénurie la conséquence de la surcharge de travail. On allège alors quelque peu le programme des cultes. Dans les cinq temples de la ville de Genève (Saint-Pierre, Saint-Gervais, Saint-Germain, La Madeleine, et La Fusterie ou Temple Neuf, construit en 1715), on en célèbre seulement deux par dimanche, un le matin et un l'après-midi, plus un troisième tôt le matin les jours de cène. Le catéchisme a lieu le dimanche à midi à Saint-Gervais et à La Madeleine, le lundi à neuf heures à La Fusterie. Dans ce même temple, tous les lundis, mardis et vendredis à quatorze heures, a lieu une prière suivie de la lecture des œuvres d'Ostervald.

Les relations avec les autres Églises se transforment aussi. Depuis novembre 1769, la messe est célébrée à Genève, dans la chapelle du résident de France.

Mais la tolérance a des limites : en juin 1762, sur un rapport du procureur général, Genève saisit les premiers exemplaires de deux livres de Jean-Jacques Rousseau, le Contrat social et l'Émile, et les fait brûler. Le philosophe avait pourtant fait son retour au protestantisme en 1754 - «faisant réparation » devant le consistoire, il avait annulé sa conversion au catholicisme -, condition nécessaire pour revenir dans sa Genève natale et en redevenir un citoyen. Et lorsque Genève révise sa constitution en 1796, elle précise que «tout acte public d'une religion différente de la religion protestante ou réformée n'est pas permis dans la République». 


\section{ORIENTATION BIBLIOGRAPHIQUE}

Hammann G., «Du début du XVII ${ }^{\mathrm{e}}$ siècle à 1814: un régime ecclésiastique qui se maintient et s'effrite», in Hammann G., Robert M. (éd.), De Guillaume Farel à nos jours: Églises et communautés religieuses dans le pays de Neuchâtel, Neuchâtel: Éditions G. Attinger, 1993, p. 309-315. Jelmini J.-P., «Les pieux dimanches de Jaques Sandoz. Prédication et catéchisme dans une paroisse des Montagnes neuchâteloises au tournant des XVII ${ }^{\mathrm{e}}$ et XVIII ${ }^{\mathrm{e}}$ siècles », in Henry P., Tribolet M. de (éd.), In dubiis libertas: Mélanges d'Histoire offerts au Professeur Rémy Scheurer, Hauterive: Éditions G. Attinger, 1999, p. 297-311.

Pitassi M. C., De l'orthodoxie aux Lumières: Genève 1670-1737, Genève: Labor et Fides, 1992. 


\section{4 \\ XIX ${ }^{\mathrm{e}}$ SIÈCLE: DIVERSIFICATION \\ DES ÉGLISES PROTESTANTES}

Le $1^{\text {er }}$ mars 1848 , des révolutionnaires venus des Montagnes neuchâteloises (du Locle, de La Chaux-de-Fonds, mais aussi de Saint-Imier) conquièrent le château de Neuchâtel sans tirer un coup de feu et imposent la République à la Principauté de Neuchâtel et de Valangin. La Vénérable Classe se range résolument du côté des monarchistes. Fidèles au serment qu'ils ont prêté au roi de Prusse, les pasteurs jurent «solennellement et devant Dieu» de persévérer «dans les sentiments d'amour, de respect, de reconnaissance, d'attache inviolable» à «Sa Majesté». Ils refusent de désigner un aumônier pour les soldats, de célébrer un culte de reconnaissance pour la victoire: la République réquisitionne alors un pasteur, et c'est Ferdinand-Henri Gagnebin (1816-1890) qui est désigné. Les pasteurs refusent encore de célébrer un culte pour inaugurer les travaux de la Constituante: la République fait venir Auguste Krieg (1828-1863), le pasteur de La Neuveville. Ils refusent même d'utiliser les formulaires à l'en-tête de la «République et canton de Neuchâtel» et demandent à être déchargés des tâches d'état civil: une des conséquences pratiques de ce refus sera l'instauration d'un mariage civil.

Ce sont encore des événements politiques qui marquent le début du XIX ${ }^{\mathrm{e}}$ siècle en Suisse romande. 1798 avait vu la naissance de la République helvétique, calquée sur la République française; 1802 voit Napoléon imposer à la «Suisse» un Acte de Médiation, qui confirme notamment la neutralité religieuse 
de l'État et qui reconnaît la liberté de conscience. Au moins de droit, sinon de fait. La Principauté épiscopale de Bâle, Genève et le Valais connaissent une situation particulière, puisque ces territoires sont intégrés à l'empire napoléonien. Dès la fin de 1813 , commence un long processus qui va permettre à la Suisse de retrouver son indépendance, mais sous une forme totalement nouvelle. En 1815, le Congrès de Vienne redessine les frontières de la Suisse et des cantons suisses.

Un autre événement politique à la croisée du religieux et du politique va marquer le milieu du $\mathrm{XIX}^{\mathrm{e}}$ siècle. Se sentant menacés, les cantons catholiques (Fribourg, Lucerne, Schwyz, Unterwald, Uri, le Valais et Zoug) concluent secrètement en décembre 1845 une alliance de secours mutuel - elle reçoit en allemand le nom de «Sonderbund», qui signifie «alliance particulière». En 1847, les cantons protestants déclarent la guerre aux cantons catholiques et les troupes fédérales les forcent à capituler. Conséquence directe de ce conflit, on inscrit dans la nouvelle Constitution fédérale, en 1848, la possibilité pour tous les chrétien.ne·s, quelle que soit leur confession mais eux et elles seulement, de s'installer dans tous les cantons - les juifs et les juives devant attendre 1874 .

Quant aux relations entre Église et État, deux tendances traversent la Suisse romande protestante. En même temps que les cantons fixent des lois ecclésiastiques qui définissent les structures et le fonctionnement des Églises nationalisées, d'autres formes de protestantisme émergent dans des Églises «dissidentes », libres ou indépendantes, dont la caractéristique commune est d'être séparées de l'État.

\section{I NATIONALISATION DES ÉGLISES RÉFORMÉES}

\section{Dans le département du Haut-Rhin, puis dans le canton de Berne}

Le $\mathrm{XIX}^{\mathrm{e}}$ siècle commence alors que la Principauté épiscopale de Bâle est encore partie intégrante de la République française. Les conséquences sont tout d'abord pratiques. 
Le principe de liberté des cultes donne une existence légale au protestantisme dans le Nord et au catholicisme dans le Sud; l'état civil est confié aux maires; la nomination des pasteurs est soumise au ministre des Cultes qui, en contrepartie, offre des bourses pour des études dans les facultés de théologie françaises: Montauban, Strasbourg et Genève; on prie pour les autorités françaises. Mais elles sont aussi symboliques: avec d'autres collègues, CharlesFerdinand Morel (1772-1848), pasteur à Corgémont, est invité au couronnement de l'empereur Napoléon le 16 décembre 1804.

En 1816, la Principauté épiscopale de Bâle est attribuée au canton de Berne. Les conséquences de ce changement politique ne se font pas attendre. Le $1^{\text {er }}$ janvier 1816, l'État rend aux pasteurs la charge de l'état civil. Le 28 mai 1817, les quatre Classes d'Erguël, de Nidau, de La Neuveville et de Bienne sont fusionnées en une seule Classe, la Classe du Jura. Berne exerce son pouvoir jusque dans les détails: elle autorise, par exemple, la paroisse de Nods à célébrer un culte le samedi et le pasteur de Renan à baptiser en semaine les enfants en danger de mort. Mais les pasteurs ont aussi des idées et savent les imposer. Au début du XIX ${ }^{\mathrm{e}}$ siècle, le pasteur Georges A.R. Moschard (1745-1806) concrétise son intérêt pour la santé en introduisant à Bévilard, la vaccination contre la variole. Charles-Ferdinand Morel, pasteur à Corgémont, s'intéresse à l'agronomie - il améliore les races de mouton et promeut la culture des pommes de terre dans l'assolement triennal - et témoigne de la dimension sociale de l'Église. Inspiré par la Caisse des pauvres des communautés anabaptistes, il crée deux institutions publiques d'entraide: en 1816, la Caisse centrale des pauvres et, en 1829, la Caisse d'épargne de Courtelary. Il négocie aussi avec les maires l'installation dans les temples de «troncs », ces tirelires destinées à récolter l'aumône des paroissien·ne·s.

Berne valorise sa mémoire protestante avec l'introduction d'un «Dimanche de la Réformation ». Destiné à commémorer 
l'affichage par Martin Luther de 95 thèses, il est fixé au premier dimanche de novembre.

Berne promulgue une nouvelle loi ecclésiastique en 1852. $\mathrm{Si}$ elle rend par exemple l'école indépendante de l'Église réformée, elle modifie en profondeur la structure de cette Église. Elle confie la gestion des paroisses à un conseil de paroisse dont elle fixe la composition - le pasteur et quatre à treize anciens - et la fréquence des réunions - une fois par mois, le dimanche après le culte. Elle instaure aussi des synodes d'arrondissement - le Jura en est un - composés de tous les pasteurs, diacres et suffragants ainsi que d'un délégué laïque par tranche de deux mille protestant·e·s, ainsi qu'un synode cantonal. En 1854, c'est le Grand Conseil qui décrète que le Vendredi saint est dorénavant «une grande fête chrétienne » et un jour férié.

Dès 1865, Albert Bitzius (1835-1882), pasteur de la paroisse germanophone de Courtelary - le fils d'un autre Albert Bitzius, lui aussi pasteur mais plus et mieux connu comme écrivain sous son pseudonyme de Jérémias Gotthelf - prône la création d'une Église libérale, sans dogme. Le synode de l'Église réformée bernoise s'organise alors en «fractions théologiques », comme les parlements accueillent des partis politiques. Deux fractions additionnent leurs spécificités et s'affrontent parfois : une fraction dite libérale et une fraction dite évangélique. Le synode jurassien, en bloc, choisit de rejoindre la seconde.

Berne adopte, en 1874, une nouvelle loi ecclésiastique qui vise à limiter l'influence de l'Église. Elle le fait en desserrant les liens qui la lient à l'État: elle laisse aux paroisses le soin de choisir leur pasteur, en accord avec leurs options théologiques. Elle diminue le rôle des synodes régionaux, en les privant de tout statut officiel, mais elle les autorise à titre officieux.

Le pouvoir bernois favorise le développement du protestantisme dans le nord du Jura. En 1868, la paroisse 


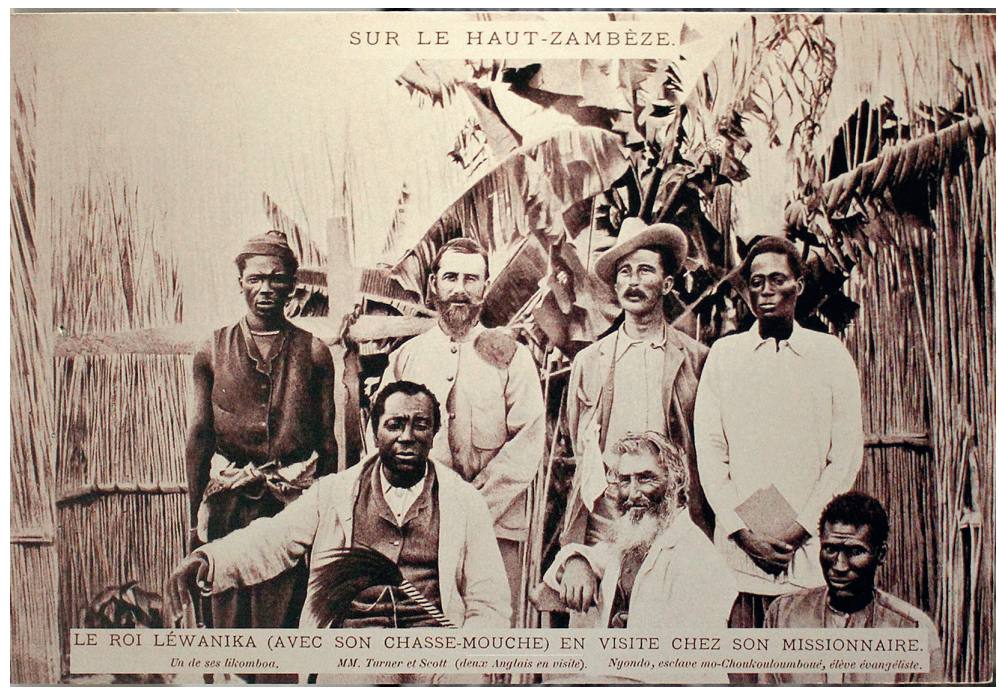

Anonyme, Sur le Haut Zambèze

Fac-similé, XIX ${ }^{\mathrm{e}}$ siècle

(C) Musée international de la Réforme, Genève

La légende de cette photographie est aussi instructive que la photographie elle-même. On y lit que le roi a son propre missionnaire, que l'esclavage existe encore et que l'on peut être esclave et évangéliste tout à la fois.

réformée de Delémont inaugure son temple, sans clocher ni cloche - ils seront ajoutés soixante et un ans plus tard. Le $1^{\text {er }}$ janvier 1877 , on célèbre un premier culte protestant à Porrentruy; il se tient dans l'église catholique Saint-Pierre; pendant quatorze ans, il sert de lieu de culte à la communauté protestante jusqu'à l'inauguration du temple en 1891 ; l'Église protestante réformée de Porrentruy compte jusqu'à cinq cents paroissien.ne·s presque exclusivement germanophones. 


\section{Pendant ce temps-là, dans le canton de Genève...}

En 1802, l'Église réformée de Genève installe une commission chargée de trouver des moyens de «relever la piété». Son fonctionnement est original: elle réunit des pères de famille et des chefs d'atelier issus des différents quartiers de la ville pour comprendre les problèmes et leur trouver des remèdes.

Dès 1814, quand Genève se rapproche de la Suisse - elle devient officiellement canton suisse en 1815 -, l'État reprend le contrôle de l'Église réformée. Il réclame d'approuver tous les changements, qu'ils soient superficiels ou fondamentaux, qu'ils touchent le culte, la discipline ou le catéchisme.

Mais c'est un État profondément transformé, y compris sur le plan religieux, puisque vingt-deux communes limitrophes sont rattachées au canton de Genève. Autrefois partie intégrante du Royaume de Sardaigne ou du Royaume de France, elles sont restées fidèles au catholicisme. Pour la première fois depuis la Réforme, Genève compte des catholiques parmi sa population et, comme corollaire, des catholiques dans son gouvernement.

Genève reste cependant attachée à certaines de ses traditions. En 1832, quand la Diète fédérale choisit le troisième dimanche de septembre pour célébrer un jour de jeûne commun aux cantons catholiques et protestants, Genève l'adopte, mais en 1837, sous la pression de la population, elle revient à l'ancien Jeûne genevois, fixé au premier jeudi de septembre.

Dès 1842, la révolution radicale menée par James Fazy entraîne la nationalisation progressive de celle que la nouvelle Constitution nomme "Église protestante nationale». La Constitution de 1847 en définit l'organisation: c'est un consistoire composé de vingt-cinq membres laïques et de six ecclésiastiques - ils sont élus par les protestants du canton jouissant de leurs droits politiques - qui 
la gouverne. L'Église protestante n'est plus dirigée par la Compagnie des pasteurs, mais par une autorité représentative de la population masculine protestante, élue selon les principes démocratiques de l'époque. L'Église protestante nationale est organisée en deux «bancs », le «banc de la Ville» et le «banc de la Campagne». Chaque «banc» compte, outre les pasteurs et les professeurs, une cinquantaine d'Anciens, des «chefs de famille» qui assistent les pasteurs dans leurs tâches.

Le don par l'État de terrains pour construire l'église catholique Notre-Dame à Cornavin, achevée en 1857, puis une synagogue pour la communauté juive, achevée en 1859 , un temple maçonnique à Plainpalais, achevé en 1859 et qui devient en 1873 l'église catholique du Sacré-Cœur, ainsi qu'une église orthodoxe russe dans le quartier des Tranchées, achevée en 1866, marque la fin de la Genève exclusivement protestante.

La Compagnie des pasteurs poursuit son œuvre de traduction biblique, confiant cette tâche à Jacques-Jean-Louis Segond (1810-1885), pasteur, professeur et hébraïsant. Sa traduction de l'Ancien Testament paraît en 1874 et celle du Nouveau Testament en 1880. Jugée d'abord «libérale», la «Bible Segond» deviendra rapidement la Bible de référence de tous les courants protestants, appréciation unanime qui en fera un grand succès de librairie.

En 1874, l'État achève son contrôle de l'Église nationale, lorsqu'il supprime la consécration des pasteurs pour la remplacer par un serment au Conseil d'État et qu'il décrète la liberté totale de prédication, chaque pasteur prêchant sous sa propre responsabilité. Mais les temps changent vite: en 1880, le Grand Conseil propose la suppression du budget des cultes, ce qui entraînerait la séparation des Églises et de l'État, une mesure refusée dans un vote populaire par 9000 «non» contre 4000 «oui ». 


\section{Pendant ce temps-là, dans le canton de Vaud...}

Dans ce qui devient, en 1815, le canton de Vaud, l'Église réformée reste ce qu'elle était durant la période bernoise: une Église d'État. Mais au XIX ${ }^{\mathrm{e}}$ siècle, elle cesse d'être - et sera de moins en moins - la seule Église.

En 1802, le gouvernement helvétique se réfugie à Lausanne. Or, il compte parmi ses membres des catholiques, dont le Fribourgeois Joseph d'Église, qui obtient que l'on célèbre la messe dans le chœur de la cathédrale de Lausanne, inutilisé par les protestant·e.s. En 1810, la loi autorise «l'exercice de l'une des deux Religions dans une commune où cette Religion n'est pas actuellement établie», en clair, une pratique catholique dans un territoire essentiellement, très majoritairement et très officiellement protestant. Dès 1812, la communauté catholique peut disposer de l'église Saint-Étienne à Lausanne mais elle doit la partager avec la communauté protestante germanophone et, plus tard, avec les anglicans. Il faut attendre 1830 pour que soient créées des paroisses catholiques: une première vague, de dix ans, à Aigle, Morges, Nyon, Vevey et Yverdon; puis une seule à Rolle jusqu'en 1870. C'est pendant cette même période que disparaît le simultaneum (le partage des églises entre catholiques et protestant.e.s) dans les trois paroisses du district d'Échallens où il avait cours: à Assens en 1846, à Bottens en 1847 et à Échallens en 1865. Chaque confession possède désormais sa propre église.

L'État va aussi s'immiscer dans le débat religieux intraprotestant et exercer son pouvoir en matière de théologie. Le 15 janvier 1824, le gouvernement interdit «les assemblées de la secte des mômiers », un terme qui désigne les chrétien·ne·s revivalistes. Il proscrit les réunions religieuses qui se tiendraient hors des cultes ou hors des temples, sous peine d'amende ou même de bannissement, une loi abrogée dix ans plus tard.

Conduit par Henri Druey, l'État exerce aussi son pouvoir sur l'Église réformée du canton de Vaud: en 1832, il cherche 
à diminuer l'autorité des pasteurs, en associant des laïcs à son gouvernement; en 1834, un député la définit comme une Église de multitude; en 1835, on instaure le mariage civil et dès 1836 , il n'est plus nécessaire d'obtenir une autorisation pour conclure un mariage mixte entre catholiques et protestant.e.s. En 1839, le Grand Conseil décide de faire de la Bible la seule règle de foi de l'Église réformée. En 1863, il impose à celle-ci un système représentatif calqué sur le système politique. Les paroisses sont gouvernées par un conseil de paroisse composé de laïcs élus et du pasteur, membre d'office. Chaque paroisse élit des conseillers d'arrondissement; les Conseils d'arrondissement élisent des députés au synode, à raison de deux laïcs pour un pasteur, et le synode, qui détient le pouvoir législatif de l'Église nationale, élit une Commission synodale qui en est l'exécutif. En 1845, l'obligation faite aux pasteurs de lire en chaire le message du gouvernement en faveur de la nouvelle Constitution provoque la démission de quarante pasteurs et entraîne, en 1847, la création de l'Église évangélique libre du canton de Vaud. Les motifs de la séparation étant plus ecclésiologiques - elle porte sur le rapport à l'État - que théologiques, la Société vaudoise de théologie, fondée en 1873, rassemble les pasteurs des deux Églises.

Si l'État finance «son» Église nationale, il en règle aussi les structures et le fonctionnement institutionnel. Les pasteurs sont des fonctionnaires, assermentés par le préfet lors de leur consécration; ils sont des agents de l'État à qui incombent la surveillance des écoles et, jusqu'en 1874, la tenue des registres d'état civil.

\section{Pendant ce temps-là, dans le canton de Neuchâtel...}

Devenu canton suisse, encore principauté du roi de Prusse, Neuchâtel doit s'occuper de la place du catholicisme et ce d'autant plus qu'il compte depuis 1814, une troisième commune catholique, celle du Cerneux-Pequignot qui lui a été attribuée. En 1819, le gouvernement neuchâtelois refuse aux catholiques le droit de construire une église dans la ville de Neuchâtel, tout 
en leur confirmant l'usage de la chapelle de l'hôpital. En 1822, le curé de Neuchâtel, Joseph Aebischer, se rend à Berlin pour demander au roi de Prusse l'autorisation d'ériger un bâtiment. Le roi accorde sa permission, le comte de Pourtalès offre un terrain adjacent à l'hôpital et, en 1832, la chapelle - il est interdit de la nommer «église»- est consacrée.

Dès 1830, la Classe élargit l'enseignement théologique et assoit la formation théologique de ses pasteurs. Lorsqu'en 1841, l'Académie est fondée, la Classe refuse d'y transférer sa faculté de théologie. En fait de théologie, l'Académie n'abritera qu'une chaire de «littérature sacrée », dont le titulaire sera le pasteur Abram-François Pétavel (1791-1870) qui avait fondé, en 1824, la Société des amis d'Israël, une œuvre pionnière pour les relations entre judaïsme et christianisme.

Selon les termes de la loi ecclésiastique de 1849, la République et canton de Neuchâtel fixe l'organisation et le fonctionnement de l'Église. Elle retire à la Vénérable Classe l'exclusivité de son pouvoir et la confie à un synode composé de dix-neuf laïcs et de treize «ecclésiastiques». Elle supprime les consistoires admonitifs, nationalise les biens ecclésiastiques et prend en charge les salaires des pasteurs dont elle fixe le nombre et dont elle organise l'élection.

En 1868, le penseur français Fernand Buisson (1841-1932), réfugié à Neuchâtel, donne des conférences sur la réforme de l'enseignement primaire. Il y dénonce un enseignement basé sur l'Ancien Testament qu'il juge immoral et propre à favoriser la superstition. Entre décembre 1869 et février 1870, Félix Pécaut (1828-1898), un pasteur français, anime des assemblées «libérales» à La Chaux-de-Fonds, au Locle, au Val-de-Ruz, à Neuchâtel - on lui concède le Temple du Bas - et même à Saint-Imier. En 1872, le Grand Conseil impose à l'Église nationale de faire une place au christianisme libéral.

En 1873, une nouvelle loi ecclésiastique, plus radicale encore, supprime toute confession de foi dans l'Église nationale, décrète une liberté totale d'enseignement et ôte au synode 
toute compétence en matière de doctrine. Soumise au peuple, cette loi est adoptée de justesse, et non sans contestation. Elle entraîne la création d'une Église évangélique neuchâteloise indépendante de l'État. Par-delà la séparation et malgré les profondes différences théologiques, la Société des pasteurs et ministres neuchâtelois rassemble les pasteurs des deux Églises. En 1874, le gouvernement neuchâtelois crée une faculté de théologie qu'il intègre à l'Académie, la plaçant ainsi sous son contrôle.

Soucieux de la mémoire protestante, désireux de marquer un territoire, on érige en 1876, une statue de Guillaume Farel sur l'esplanade de la collégiale à Neuchâtel. Il y est représenté brandissant une Bible et écrasant Pierre, celui que l'Église catholique a sanctifié et qu'elle considère comme le premier pape.

\subsection{NAISSANCE DES ÉgLiSES LibReS OU INDÉPENDANTES}

\section{Dans le canton de Genève...}

Genève va connaître trois temps de Réveil, marqués par des différences théologiques avec l'Église «officielle» puis nationale, mais aussi entre les différentes Églises libres.

En 1810, le premier Réveil est piétiste. Des étudiants de l'Académie, dont Ami Bost (1790-1874), HenriLouis Empeytaz (1790-1853) et Louis Gaussen (1790-1873), fondent une «Société des amis» qui favorise l'édification personnelle, la communion et qui promeut une morale puritaine. Ils créent une école du dimanche pour former les enfants et organisent une œuvre de secours pour «les pauvres et les affligés », avant d'ouvrir une Église dans le quartier du Bourgdu-Four, en contrebas de la cathédrale.

Le deuxième Réveil, néocalviniste, débute en 1817 quand César Henri Abraham Malan (1787-1864), pasteur et professeur de latin, prêche au temple de La Madeleine à Genève. 
Contestant que les vertus morales permettent d'obtenir le salut, il appelle à la conversion. Mais tous les Genevois n'aiment pas être qualifiés de pécheurs: César Malan est suspendu par le Conseil d'État. Il se met alors à prêcher à Ferney, en France voisine, et, en 1824, il crée sa propre Église, l'Église du Témoignage pour laquelle il fait construire une chapelle dans sa propriété de Pré-L'Évêque. Mais son Église périclite, et la plupart de ses membres rejoignent l'Église de Bourg-du-Four. César Malan se consacre alors à des tournées de conférences et des campagnes d'évangélisation jusqu'en Angleterre et aux Pays-Bas, ainsi qu'à des publications.

Le troisième Réveil est évangélique. En 1831, les pasteurs Louis Gaussen et Jean-Henri Merle d'Aubigné (1794-1872) fondent avec d'autres notables genevois une Société évangélique. Révoqués de l'Église nationale, les deux pasteurs constituent en 1832 une École de théologie et, en 1834, une Église indépendante, dénommée Église évangélique libre de Genève, qui porteront toutes les deux le surnom de «L'Oratoire», du nom du lieu où se déroulent les cours et les cultes.

Le protestantisme revivaliste se montre inventif dans son ecclésiologie. Il crée de nombreuses Sociétés visant divers objectifs, par exemple l'évangélisation avec la Société biblique, fondée en 1814, la mission, avec la Société des missions évangéliques fondée en 1817 ou la lutte contre l'alcoolisme avec la Société suisse de tempérance, fondée en 1877 par le pasteur Louis-Lucien Rochat (1849-1917). Ce «revivalisme» se montre fidèle à la tradition protestante, en faisant construire pour le troisième centenaire de la mort de Calvin, une «Salle de la Réformation» ou «Calvinium », inaugurée en 1867. Un revivaliste genevois devient mondialement célèbre: Henri Dunant (1828-1910), membre de la «Réunion du Jeudi», un cercle de Réveil, très actif dans la création de l'Union chrétienne de jeunes gens de Genève en 1853, co-organisateur de la Conférence mondiale des Unions chrétiennes à Paris en 1885, et qui, entre-temps, a fondé, en 1863, le Comité international de secours aux militaires blessés avec quatre autres genevois, Louis Appia (1818-1898), 
Guillaume-Henri Dufour (1787-1875), Théodore Maunoir (1806-1869) et Gustave Moynier (1826-1906), un comité bientôt connu par son emblème, une Croix-Rouge. Pour elle, Henri Dunant reçoit en 1901 le premier prix Nobel de la paix. Dunant finit sa vie dans le canton d'Appenzell, loin de toute Église, s'autodéfinissant simplement comme «jeune disciple du Christ comme au premier siècle» et demandant à être «enterré comme un chien», sans aucune cérémonie.

\section{LES GUVRES DES ÉGLISES PROTESTANTES}

Le $\mathrm{XIX}^{\mathrm{e}}$ siècle protestant en Suisse romande connaît une exceptionnelle floraison d'«œuvres» protestantes. Inspirées de ce qui se fait en Angleterre, ces œuvres correspondent à une nouvelle manière de concevoir et de réaliser la mission de l'Église. Elles sont très étroitement liées aux Églises libres ou indépendantes. Tandis que les Églises nationales privilégient un découpage territorial, car la paroisse, à la mission généraliste, en est l'unité de base, d'autres courants du protestantisme travaillent selon un découpage par activité. Ils créent des «Sociétés» qui se consacrent à des activités spécifiques. À elles de les penser, de les organiser, de les gérer et de récolter les fonds qui permettent leur réalisation.

Certaines Sociétés ont pour objet l'évangélisation ou la formation théologique. La première Société biblique est créée à Genève en 1814, avec pour but d'encourager et de faciliter la lecture de la Bible. En 1826 naît la Société des missions évangéliques de Lausanne pour proclamer l'évangile dans les régions où personne ne l'a encore jamais annoncé. En 1884, les Églises réformées de Suisse romande - libristes, indépendantes ou nationales - unissent leurs forces et fondent une Mission romande. En 1830, à Genève encore, se crée une Société des écoles du dimanche, dont le but est de proposer un programme spécifique de formation chrétienne aux enfants: l'«école du dimanche» 
doit leur apporter en matière de foi, ce que l'école leur apporte en matière d'instruction les jours de semaine. Vers le milieu du $\mathrm{XIX}^{\mathrm{e}}$ siècle, les cantons romands fondent des Sociétés pour les protestants disséminés. Celles-ci se répartissent les territoires catholiques et fournissent aux protestant.e.s les ressources humaines et financières leur permettant de vivre leur foi. D'autres Sociétés veillent à ce que l'évangile transmis soit le bon: ainsi, en 1841, un groupe de laïcs créent la Société laïque pour le maintien de la saine doctrine dans l'Église évangélique réformée du canton de Vaud.

Le protestantisme suisse romand est aussi très actif et très créatif dans le domaine social. Dans le Jura bernois, le pasteur Charles-Ferdinand Morel fonde deux banques, à dix ans d'intervalle: la Caisse centrale des pauvres en 1816 et la Caisse d'épargne de Courtelary en 1826. En 1842, l'Église libre du canton de Vaud crée la maison des diaconesses d'Échallens qui déménage ensuite à Saint-Loup (Vaud). En 1877, le pasteur genevois Louis-Lucien Rochat, originaire de la Vallée de Joux, crée la Société suisse de tempérance, qui devient mondialement célèbre quand elle prend, en 1883, à la fois comme nom et comme symbole, la «Croix-Bleue». En 1837, les milieux libristes inaugurent un Institut d'enseignement pour filles à Lausanneet en 1873, l'Église indépendante ouvre une école normale évangélique à Peseux (Neuchâtel).

À la croisée des domaines sociaux et religieux, on trouve les Sociétés pour la sanctification du dimanche. La première est fondée à Vevey en 1834, et la plus célèbre est peut-être la Fédération internationale pour l'observation du dimanche, fondée à Genève en 1861 par le banquier Alexandre Lombard (1810-1887). Le respect du dimanche a des visées sociales - généraliser le principe d'un jour hebdomadaire de repos - mais aussi, évidemment, des motivations religieuses: il faut permettre aux gens de participer au culte. Ainsi, en 1887, la Société des pasteurs du Jura bernois se plaint que les chemins de fer offrent des tarifs réduits le dimanche, contribuant ainsi à ce que les foules désertent les temples. 
Enfin, c'est l'Église évangélique libre de Genève qui est la première Église protestante de Suisse romande à accorder le droit de vote aux femmes, en 1891.

\section{Pendant ce temps-là, dans le canton de Vaud...}

Dans le canton de Vaud, on peut faire remonter l'idée d'une Église libre au 3 mars 1822, quand le pasteur suffragant David-Alexandre Chavannes (1794-1855) organise des réunions dans sa cure à Aubonne. Des villageois en colère injurient les participants, les menacent, les frappent à coups de bâton et leur lancent des pierres. Les mêmes événements se reproduisent à Orbe, à La Sarraz, à Saint-Loup, à L'Isle, à Mont-la-Villeet le gouvernement prend des sanctions. Seulement, ce ne sont pas les émeutiers mais les pasteurs qui sont punis. En septembre 1824 à Vevey, dix-sept personnes se réunissent autour du pasteur Charles Rochat (1792-1838) dans ce que l'on prend l'habitude d'appeler un «conventicule». En vertu de la loi adoptée cinq mois plus tôt, le pasteur Rochat est aussitôt banni pour un an et il se réfugie en France. Mais le mouvement est amorcé et d'autres Églises évangéliques naissent à Lausanne, à Yverdon, sur les bords du lac Léman et dans le Chablais. Pour justifier théologiquement leur indépendance, elles peuvent compter sur Alexandre Vinet (1797-1847): en 1826, ce théologien vaudois publie un Mémoire en faveur de la liberté des cultes où il qualifie d'adultères les liens entre l'État et «la religion». Il sera entendu presque vingt ans plus tard.

Le dimanche 3 août 1845, environ quarante pasteurs de l'Église évangélique réformée refusent de lire en chaire un message du gouvernement en faveur de la nouvelle Constitution. En novembre, cent quarantecinq pasteurs - d'autres sources évoquent un nombre de cent quarante-neuf ou même cent quatre-vingts - démissionnent, pour protester contre «l'asservissement de l'Église nationale à l'État radical». L'année suivante, le synode constituant d'une nouvelle Église commence 


\section{Henriette Feller-Odin}

Henriette Odin (1800-1868) naît à Montagny dans le canton de Vaud, où son père est secrétaire municipal et régent de l'école. À 22 ans, elle épouse Louis Feller, directeur de la police municipale de Lausanne, qui meurt quatre ans plus tard. Elle élève les enfants de son mari et, en 1835, lorsqu'ils sont tous mariés, part pour le Québec. Selon la tradition, elle serait «l'une des trois femmes seules qui ont osé traverser l'Atlantique». "Seule» signifie ici «sans mari», car elle est accompagnée par Louis Roussy (1812-1880), un jeune diplômé en théologie. Tous les deux sont envoyés par la Société des missions de Lausanne. Si elle a choisi le Québec, c'est qu'elle a une amie à Montréal, Jenny Olivier, revivaliste comme elle, qui lui a décrit l'immensité de la tâche d'évangélisation à accomplir dans le Bas-Canada. Elle pourra vérifier l'exactitude de cette description.

Henriette Feller-Odin s'installe à Montréal, où elle inaugure un ministère d'instruction et d'évangélisation. Elle ouvre une «classe de sept enfants» et fait du colportage de maison en maison pour diffuser la Bible. Mais devant l'hostilité de l'Église catholique, Henriette Feller-Odin et Louis Roussy quittent Montréal pour Saint-Jean-sur-Richelieu, cinquante kilomètres plus au sud. Leur présence n'y est pas mieux acceptée et ils s'éloignent encore plus au sud, plus loin des villes - dans une région dont le seigneur est anglais - et s'installent dans une «terre de colonisation». En 1836, ils y fondent la Mission de Grande-Ligne. Henriette Feller-Odin y ouvre la première école et développe un véritable service social, donnant des conseils de santé et aidant les gens à rédiger leur correspondance. Rapidement, ce sont quarante enfants qui suivent l'école et soixante personnes qui participent aux cultes. En 1840, on inaugure une chapelle et une école résidentielle, c'està-dire un internat. Grande-Ligne représente la première communauté protestante francophone au Canada. 
Mais les Églises anglicanes, presbytériennes et méthodistes décident de prendre à leur compte la mission au Canada. Si ces Églises protestantes ont certainement de bonnes intentions, la mission représente aussi un bon moyen de provoquer l'enthousiasme de leurs membres, de susciter des vocations et de récolter de l'argent. En 1839, elles créent la French Canadian Missionary Society dont l'intitulé en anglais dit bien l'origine. Henriette FellerOdin n'adhère pas à cette nouvelle société, préférant conserver son indépendance et défendre sa propre vision de la mission. La Mission de Grande-Ligne, plutôt baptiste à l'origine - Henriette Feller-Odin est opposée au baptême des enfants -, s'ouvre aux autres dénominations protestantes et elle parvient à développer son œuvre en recrutant des pasteurs locaux, deux fois plus que sa rivale au Canada.

Mais les institutions ecclésiales sont puissantes. Forte de ses réseaux, la French Canadian Missionary Society réussit à obtenir le soutien des principales Sociétés de mission en Europe: la London Missionary Society, la Société écossaise pour la propagation de l'évangile, les sociétés bibliques de Londres, de France et de Montréal, et même les Sociétés missionnaires de Lausanne et de Genève. Henriette Feller-Odin se sent trahie. Mais elle poursuivra sa tâche en ouvrant en 1855 l'Institut Feller qu'elle dirigera jusqu'à sa mort et qui formera la plupart des pasteurs francophones du Canada et des États-Unis.

Source principale: LALONDE J.-L., Des loups dans la bergerie. Les protestants de langue française au Québec 1534-2000, SaintLaurent: Fides, 2002. 
ses travaux. Le 12 mars 1847, la Constitution de l'Église évangélique libre du canton de Vaud est adoptée et l'Église crée, en novembre, la Faculté de théologie libre pour former ses pasteurs. Encore interdite par les lois de 1847 et 1849, l'Église évangélique libre obtient un statut légal dans la Constitution de 1861 qui reconnaît la liberté de culte. L'Église indépendante va faire preuve de dynamisme en créant des œuvres pour répondre à différents besoins : dès 1850, des écoles confessionnelles dans le Pays d'Enhaut et à Lausanne; en 1852, la Société des Écoles du dimanche; en 1862, une Société pour la sanctification du dimanche; en 1875, deux pasteurs, Ernest Creux (1845-1929) et Paul Berthoud (1847-1930), fondent la première station missionnaire suisse romande au Transvaal, une station qu'ils nomment «Valdezia»; jusqu'alors, les missionnaires suisses romands travaillaient pour et avec la Société des missions évangéliques de Paris.

En 1898, l'Église libre est la première Église vaudoise, et seulement la seconde en Suisse romande, à donner aux femmes le droit de vote paroissial pour élire les pasteurs et les Anciens. C'est d'ailleurs une femme qui pourrait incarner l'Église libre au XIX ${ }^{\mathrm{e}}$ siècle, Valérie de Gasparin (1813-1894). Riche et instruite, mariée au comte Agénor de Gasparin, Valérie n'apprécie guère la Maison des diaconesses d'Échallens, un hôpital fondé en 1842 par le pasteur de l'Église libre d'Échallens, Louis Germond (1796-1868), et par sa femme, Louise Wist (1799-1875). Elle reproche à la Maison d'imposer aux infirmières un modèle monastique, puisqu'elles sont diaconesses et qu'elles doivent faire vœu d'obéissance, de célibat et de pauvreté. En 1855, Valérie de Gasparin critique ce modèle d'abord par la pensée, dans un ouvrage intitulé Des corporations monastiques au sein $d u$ protestantisme, puis par le geste quand elle crée à Lausanne en 1859 la première école laïque d'infirmière: l'École normale des garde-malades indépendantes, qui devient par la suite «La Source». 


\section{Pendant ce temps-là, dans le canton de Neuchâtel...}

Dans le canton de Neuchâtel, des protestant.e-s revivalistes se réunissent à Coffrane en 1824 dans la grange de l'instituteur, Jean-François Magnin. En 1825, deux pasteurs, l'un vaudois, Henri Juvet, et l'autre genevois, Henri-Louis Empeytaz, viennent y célébrer le culte et surtout la cène. L'idée que ce sacrement puisse être administré hors du temple fait scandale. Les fidèles sont qualifiés de sectaires et on leur interdit de célébrer les sacrements. Jean-François Magnin est emprisonné dans le château de Valangin, puis condamné à dix ans d'exil - il en purgera cinq.

Mais d'autres assemblées se créent, par exemple à La Côteaux-Fées. Dès 1838, des habitants des Ponts-de-Martel, inspirés par la foi d'une jeune fille estimant que Dieu l'a sauvée d'une tempête de neige, se retrouvent le dimanche soir pour prier, lire la Bible et chanter des cantiques. En 1840, le roi de Prusse autorise la communauté revivaliste de la ville de Neuchâtel à construire un oratoire à la Place-d'Armes, tout en posant deux conditions : qu'il n'occupe pas le rez-de-chaussée du bâtiment et que son architecture ne puisse laisser deviner qu'il s'agit d'un lieu de culte. Dès 1851, c'est à La Chaux-de-Fonds que se réunissent des chrétien·ne·s touchéee-s par le Réveil, d'abord dans trois appartements puis dans une ancienne buanderie transformée en lieu de culte.

En 1873, le gouvernement neuchâtelois va bouleverser le paysage religieux. En mai, il promulgue une loi nationalisant les Églises réformées et catholiques. Refusant cette nationalisation, vingt-deux pasteurs et les trois professeurs de théologie démissionnent de leur poste. On dépose une initiative qui aboutit et, en septembre, le peuple neuchâtelois refuse de rétablir la séparation de l'Église de l'État. En novembre, un synode constituant d'une nouvelle Église - il émane de dix-neuf Églises locales - se réunit à la Collégiale et, en janvier 1874, adopte une Constitution ecclésiastique qui donne naissance à l'Église évangélique neuchâteloise indépendante de l'État. Un synode la dirige, qui est composé 
de tous les pasteurs, professeurs et ministres ainsi que de trois fois plus de laïcs. En 1894, l'Église indépendante compte vingt-trois Églises, dont l'une hors du canton de Neuchâtel, celle de Môtier, au Vully (Fribourg).

\section{Pendant ce temps-là, dans le canton de Berne...}

Berne n'échappe pas à la tendance générale de création des Églises libres en Suisse romande. Il faut dire qu'Ami Bost, l'un des initiateurs de l'Église libre du Bourg-du-Four à Genève, est pasteur suffragant à Moutier de 1816 à 1818 . Durant les années 1820, Félix Neff (1797-1829) organise des réunions de Réveil dans la Prévôté de Moutier. Dès 1850, l'Église libre du canton de Vaud envoie des missionnaires dans le Jura qui suscitent une première assemblée revivaliste, la «réunion de Belfond», du nom de l'endroit où elle se réunit, un lieu situé près de Tavannes. La «rencontre de Gléresse » a lieu dans l'église du même village ; à Courtelary, le pasteur Jean-François-Louis Paulet invite des personnes extérieures à son culte de famille. Enfin, la première Église libre est fondée à Cormoret en 1880, elle dépend de l'Église libre vaudoise.

\subsection{Pendant Ce temps-Là, dans le Canton de Fribourg...}

La loi ecclésiale du 21 février 1854 accorde à l'Église réformée, une Église bilingue dont le siège est à Morat, un statut public dans l'ensemble du canton de Fribourg. Mais l'histoire protestante de Fribourg a recommencé, après les quelques décennies du XVI ${ }^{\mathrm{e}}$ siècle, vingt ans auparavant. Et paradoxalement, elle a recommencé grâce au catholicisme.

Depuis la République helvétique, l'ancien bailliage de Morat appartient au canton de Fribourg. Or, ce canton est et reste catholique, ce que confirme la Constitution fribourgeoise de 1803 qui fait de «la religion catholique, apostolique et romaine» la «religion publique» du canton de Fribourg, mais de «la religion réformée» la «seule 
religion publique » du district de Morat. Ce qui n'empêche pas qu'à Morat, les catholiques puissent pratiquer leur « religion», mais en privé.

Ce qui n'empêche pas non plus qu'à Fribourg, les protestant.e.s puissent pratiquer leur «religion», mais en privé également. Ce qui, enfin, n'empêche pas non plus que la Commission des protestants habitant la ville de Fribourg obtienne l'autorisation de célébrer un culte, mais un culte discret qui ne soit pas annoncé par des cloches. C'est ainsi que le 22 mai 1836, le dimanche de la Pentecôte, Christophe Möhrlen, un pasteur de la Société évangélique de Berne, célèbre à Fribourg non pas un mais deux cultes, un en allemand le matin et un autre en français l'après-midi. Les choses évoluent rapidement: en automne, la communauté nomme son pasteur, le Bâlois Guillaume LeGrand après qu'il a prononcé deux sermons probatoires, l'un en français et l'autre en allemand.

En 1851, la loi sur l'exercice des cultes permet la création d'une Église réformée de droit public - elle est donc subventionnée par l'État - sur l'ensemble du territoire fribourgeois, ce qui déplaît même à l'intérieur de l'Église réformée. Ainsi, le pasteur de Fribourg, Adolphe Dubuis (1818-1871) refuse le statut d'Église cantonale. Démis de ses fonctions par le Conseil d'État en 1854, il refuse de quitter son poste. Il est alors expulsé de force et renvoyé dans le canton de Berne sous escorte policière.

Le 27 décembre 1857, l’Église évangélique réformée du canton de Fribourg inaugure sa chapelle en ville de Fribourg. L'édifice a été financé grâce aux dons des protestant·e·s des cantons de Bâle, de Genève, de Neuchâtel et de Vaud. En 1858, l'Église crée deux écoles, la première pour les enfants germanophones, la seconde pour les enfants francophones. Le pasteur prêche chaque dimanche matin, soit en allemand - une partie des paroissien.ne.s sont des paysan'ne.s ou des artisan.e.s bernois.e.s -, soit en français - une autre partie vient des cantons de Neuchâtel et de Vaud. Le 
dimanche après-midi, il donne un catéchisme dans l'autre langue; le jeudi, il assure un catéchisme pour les enfants francophones et, en hiver, un autre catéchisme pour les enfants germanophones. Enfin, il prépare les jeunes gens et les jeunes filles à la cène: pour les germanophones, cette préparation a lieu entre Nouvel An et Pâques, et pour les francophones, de l'automne jusqu'à Noël. Le pasteur est enfin chargé de tenir un registre des naissances, des mariages et des décès; chaque mois, il doit transmettre ces informations à la police. Enfin, l'Église réformée de Fribourg dispose d'un cimetière installé sur un terrain offert par la municipalité, ce qui n'est pas indifférent quand les défunt·e.s protestant·e·s ne sont pas admis dans les cimetières catholiques.

Souvent, le protestantisme s'installe dans le canton de Fribourg par l'intermédiaire d'écoles protestantes, créées par crainte que l'enseignement, très catholique, ne catholicise les enfants protestants. L'école protestante et la maison de l'instituteur ou de l'institutrice deviendront vite des lieux de formation, de célébration et de rencontre pour les protestant·e.s des villages où elles sont établies et pour les alentours.

Dans la Broye, en 1853, la Société neuchâteloise de secours pour les protestants disséminés loue puis achète l'ancienne chapelle jésuite d'Estavayer que le gouvernement fribourgeois a accordée aux cent quarante protestant.e.s staviacois.es. En 1857, on y ouvre une école protestante, pour laquelle on construit un bâtiment en 1860 .

En Gruyère, des cultes sont célébrés à Bulle depuis le 21 janvier 1839 et en 1840, la communauté compte déjà soixante membres. Dans un premier temps, ce sont des pasteurs vaudois qui la servent, mais en 1884, le Comité vaudois d'entraide aux protestants disséminés finance un poste de pasteur. En 1893, la communauté protestante pose la première du temple qu'elle inaugure une année plus tard.

Dans la Glâne, la Communauté protestante de Romont, soutenue par la Société évangélique de Lausanne, ouvre une école 
vers 1850 . En 1879, elle compte cent septante protestant.e.s francophones, et quelques Alémaniques auxquels le pasteur de Payerne vient rendre visite, à pied, dix fois par an.

Dans le district du Lac, la paroisse de Gurmels est reconnue par l'État en 1874. Elle bâtit son temple grâce à un don de la baronne parisienne Laure de Chatoney qui aime séjourner dans sa «campagne» de Meyriez, au bord du lac de Morat. En 1890, la région s'industrialisant et accueillant de nombreux francophones, on ouvre une école protestante à Courtepin. Enfin, la paroisse de Môtier, au nord du lac de Morat, vit un schisme en 1887. N'acceptant pas l'élection d'un pasteur de tendance libérale, une partie de la communauté réformée crée une Église libre qu'ils affilient à l'Église évangélique indépendante du canton de Neuchâtel.

\subsection{Pendant Ce temps-là, dans le canton du Valais...}

Quand le Valais devient canton suisse en 1815, il spécifie dans sa Constitution que la religion catholique est la seule religion d'État, ce qui ne reste pas seulement une déclaration d'intention, comme en témoigne le cas de cet habitant du Dizain d'Hérens, condamné à vingt coups de verges et au bannissement perpétuel parce qu'il est protestant.

Il faut attendre la seconde moitié du XIX ${ }^{\mathrm{e}}$ siècle pour que le protestantisme s'enracine en Valais. Juridiquement, c'est la loi de 1852 qui accorde au pasteur ou à l'instituteur de l'école protestante le droit de tenir un registre d'état civil. Il faut attendre la guerre du Sonderbund et l'occupation du Valais par des troupes genevoises, donc au moins en partie protestantes, pour que des cultes y soient célébrés, notamment par le pasteur Jacques-Jean-Louis Segond, aumônier militaire. Il faut surtout que le Valais accepte, en 1875, d'appliquer le principe de liberté de croyance et de conscience énoncé dans la Constitution fédérale. Pratiquement, il faut que le Valais se modernise et qu'il ait besoin d'expertise extérieure, y compris celle qu'apportent des protestant·e.s. 
Mais dès les années 1830 , des protestant·e·s, dont la sœur d'Alexandre Vinet, se rendent en Valais pour distribuer des brochures et des Bibles: aux soldats, dans les trains, dans les stations touristiques et même dans le parloir du monastère cistercien de Collombey. Dès 1838, un pasteur de Vevey vient célébrer des cultes à Sion, à l'Hôtel du Lion d'Or. Il y existe une communauté protestante, avec une école protestante, depuis 1843. Un pasteur bilingue, appenzellois ou saintgallois, Emmanuel Schiess s'y installe en 1858. Un temple, financé par la commune de Sion et des dons privés, parmi lesquels 793,15 francs donnés par l'empereur Guillaume ${ }^{\mathrm{er}}$, est inauguré le 3 octobre 1876 par une entrée en cortège, Bible en tête. À Martigny, des cultes sont célébrés dès 1840 , comme en témoigne la plainte formulée par l'évêque de Sion qui dénonce au Conseil d'État les «mômiers» et leur «fanatique prosélytisme». Si les cultes ont longtemps lieu dans des hôtels tenus par des protestant·e.s, en 1881, ils sont célébrés dans une salle de l'Hôtel de Ville mise à disposition par les autorités communales. À Saint-Maurice, les protestant.e.s arrivent avec la construction du chemin de fer en 1859. À Monthey, des cultes sont célébrés dès 1870 , d'abord au stand de tir, puis dans un hôtel, enfin à l'arsenal. En 1882, le Comité vaudois de secours aux protestants disséminés y crée un poste pastoral, desservi par les pasteurs de Bex ou d'Aigle. À Saxon, où des protestant.e.s contribuent à développer la culture de l'asperge, de la pêche, de la fraise et de l'abricot, le premier culte est célébré en 1872, par le pasteur de Sion, Alfred Lasserre. La communauté protestante est fondée le 2 novembre 1891, et l'école protestante ouvre trois jours plus tard. Dès 1897, l'école dispose de son propre bâtiment qui abrite une salle de classe, où l'on célèbre aussi le culte dominical, et un appartement pour l'instituteur. Enfin, dès 1870, les Églises bernoises, genevoises et vaudoises célèbrent des cultes dans des stations pour les touristes suisses: en plein air à Randa, dans des hôtels aux Marécottes, à Saint-Luc, à Zinal, dans des chalets à La Fouly et à Morgins. Peut-être plus surprenant, l'Église 
anglicane fait de même pour les touristes anglais et construit ses propres chapelles, notamment à Arolla, à Finhaut, à Saas-Fee et à Zermatt.

À la fin du $\mathrm{XIX}^{\mathrm{e}}$ siècle, la Paroisse évangélique du Valais compte trois communautés - Sion, Brigue et Saxon - et le protestantisme valaisan représente environ $1,5 \%$ de la population.

\subsection{Pendant Ce temps-LÀ, D’autres formes \\ DE PROTESTANTISME S'INSTALLENT \\ EN SUISSE ROMANDE...}

Profitant d'une certaine tolérance, puis d'une véritable liberté de culte, d'autres Églises ou communautés protestantes vont s'installer en Suisse romande.

Les anabaptistes vont obtenir un droit d'existence officiel, sanctionné dans le canton de Neuchâtel dès 1819 par la possibilité pour eux d'être exemptés de service militaire, exactement comme le sont les boiteux, les sourds, ceux qui ont une hernie ou des doigts manquants.

En 1837, le pasteur anglais John Nelson Darby (1800-1882) prononce des conférences à Genève où il prêche un christianisme radical sans aucun ministère institué. Ses idées séduisent, en particulier dans les cantons de Vaud et de Neuchâtel. En 1839, il séjourne à Lausanne et, dès 1840, des assemblées darbystes s'implantent en Suisse romande, dont une dizaine dans les montagnes du canton de Vaud, c'est-à-dire le Jura et le Pays d'Enhaut. En 1842, le mouvement se scinde en deux groupes: les «frères étroits », restés fidèles à un strict darbysme, et les «frères larges » qui sont à l'origine des Églises évangéliques.

On trouve en Suisse romande protestante des Églises méthodistes dès 1839 - la première est construite à Lausanne en 1867, la même année où un pasteur méthodiste s'installe à Genève - et des Églises baptistes dès 1849 . L'Église adventiste du Septième Jour est présente dès 1874 
et construit une chapelle à Tramelan, considéré comme le «berceau de la réforme adventiste en Europe», en 1886. C'est Ellen White (1827-1915), la fondatrice de l'Église, qui prêche ce jour-là; dès 1893, elle organise des formations bibliques à Peseux (Neuchâtel). L'Église anglicane, pour sa part, construit des chapelles à Genève en 1853 et à Lausanne, en 1877.

À la fin du $\mathrm{XIX}^{\mathrm{e}}$ siècle, l'Armée du salut est particulièrement mal accueillie en Suisse romande. Ses uniformes, son organisation militaire, ses appels trop directs à la conversion dérangent. En 1882, Catherine Booth (1829-1890), la propre fille de William Booth, le fondateur de l'Armée du salut, y prononce des conférences qui déchaînent les passions: des élans de ferveur populaire comme de violentes oppositions. Conséquence immédiate en 1883, les gouvernements genevois et neuchâtelois interdisent les réunions salutistes. À Neuchâtel, la loi limitant l'interdiction aux réunions «en soirée », les salutistes s'autorisent à se réunir en journée, dans des maisons ou des appartements privés, comme à Grandchamp, dans la propriété du pasteur Félix Bovet. Le gouvernement neuchâtelois interdit alors «toute réunion quelconque et en quelque lieu que ce soit», une interdiction qui vaut à Catherine Booth d'être arrêtée, incarcérée dans la prison de Neuchâtel, puis jugée au tribunal de Boudry. Elle est acquittée, mais doit quitter le canton. Le canton de Vaud est tout aussi récalcitrant à la présence des salutistes. En 1888, Charlotte Stirling, capitaine écossaise de l'Armée du salut - une femme pouvait donc détenir du pouvoir dans une Église, et c'est peut-être ce qu'on lui reprochait -, est jugée à Orbe pour avoir rassemblé des enfants et pour avoir rendu visite à une fillette âgée de 12 ans qui était en train de mourir. Elle est condamnée à cent jours de prison au château de Chillon. Il faut attendre 1889 pour que le Tribunal fédéral reconnaisse l'Armée du salut comme une institution religieuse et que les cantons, Vaud le premier, lui accordent le droit d'exister. 


\section{LA SuISSE ROMANDE PROTESTANTE NÉGRIÈre}

On estime que la Suisse a contribué auX XVIII ${ }^{\mathrm{e}}$ et XIX ${ }^{\mathrm{e}}$ siècles à réduire en esclavage de 18000 à 172000 Africain·e·s. Pour se dédouaner de l'accusation d'avoir été un «État négrier», la Suisse a toujours refusé de reconnaître une quelconque responsabilité: ce seraient des Suisses et non pas la Suisse qui auraient participé au système de l'esclavage. À chacun de décider si elle a tort ou raison.

Le protestantisme suisse romand pourrait utiliser le même mode de défense. Pourtant, s'il n'a pas été directement engagé dans le système de l'esclavage, il en a été complice, activement par certains protestants, passivement par un silence largement partagé.

On distingue trois types de participation suisse romande au système esclavagiste: la possession des esclaves, les bénéfices tirés du trafic des esclaves, le financement de la traite négrière. Or, ceux qui y participent sont presque tous issus de familles protestantes. Ils s'inscrivent dans une «internationale huguenote» qui favorise les réseaux protestants et les alliances familiales : on conclut des affaires entre gens «dignes de confiance» et quoi de mieux pour la confiance qu'une foi partagée? Être protestant devient parfois même une condition: en 1748, les autorités bâloises relaient un appel hollandais: les «chefs de famille» de la «Sainte Religion Réformée » peuvent bénéficier d'un voyage payé pour le Surinam; ils recevront «autant de terres qu'ils pourront cultiver» et «dix esclaves par famille» pour les aider à défricher.

Parmi les protestants suisses romands qui utilisent des esclaves, on peut citer le Genevois François Fatio (16221704) qui possède une plantation sucrière au Surinam, le Neuchâtelois Jean Pierre Pury (1675-1736) qui fonde Purysburg aux États-Unis en 1731 ou le Vaudois JeanSamuel Guisan (1740-1801) qui, fort de son expérience 
acquise au Surinam et en Guyane, publie en 1788 un ouvrage où il explique comment bien gérer des esclaves. Plus troublant, des Suisses romands possèdent encore des esclaves au Brésil à la fin du $\mathrm{XIX}^{\mathrm{e}}$ siècle, sans commettre rien d'illégal, puisque l'esclavage n'y sera aboli qu'en 1888. À Leopoldina en 1876, on trouve des planteurs neuchâtelois - Auguste Béguin et Auguste Cousandier - et des Vaudois - L. Bornand, Albert Champion, Félix et Octave Joseph, ainsi que Samuel Tattet.

Parmi les protestants suisses romands qui ont tiré bénéfice de la traite négrière, on peut citer de nombreuses compagnies suisses, souvent installées à Nantes ou à La Rochelle. Leurs noms ne sont pas inconnus dans les cantons de Genève, de Neuchâtel ou de Vaud: Balguerie et Cie, Baux, Favre, Gorgerat frères, Henry et Cie, JeanLouis d'Illens, Montet, Pelloutier, Petitpierre et Cie, David de Pury, Rivier et Cie, Charles Rossel, Simon et Roques, J.-R. Wirz et Cie.

Mais «l'internationale huguenote» va aussi faciliter la diffusion des idées anti-esclavagistes et abolitionnistes, notamment grâce aux mouvements de Réveil. Le pasteur genevois revivaliste Henri Merle d'Aubigné (1794-1872) participe à la création du Comité genevois pour le relèvement des esclaves affranchis. De manière générale, les sociétés abolitionnistes s'implantent surtout dans les cantons protestants. En 1861, on estime que $8 \%$ des familles vaudoises et $10 \%$ des familles neuchâteloises donnent au moins cinq centimes par semaine pour racheter et libérer des esclaves aux États-Unis. En 1876, Héli Chatelain, un missionnaire vaudois, participe à la fondation à New York de la Philafrican Liberator's League.

Source principale: David T., Etemad B., Schaufelbuehl J. M., La Suisse et l'esclavage des Noirs, Lausanne: Éditions Antipodes \& Société d'histoire de la Suisse romande, 2010. 


\section{ORIENTATION BIBLIOGRAPHIQUE}

BASTIAN J.-P., La fracture religieuse vaudoise, 1847-1966: l'Église libre, la «Môme» et le canton de Vaud, Genève: Labor et Fides, 2016.

Delaloye D., La présence des réformés en Valais aux XIX ${ }^{e}$ et XX ${ }^{e}$ siècles: de l'exclusion à l'intégration, Sierre: Éditions Monographic, 2005.

Forclaz B., «La Suisse frontière de catholicité? Contre-réforme et Réforme catholique dans le Corps helvétique», Schweizerische Zeitschrift Für Religions-Und Kulturgeschichte. Revue Suisse d'histoire Religieuse et Culturelle, 106, 2012, p. 567-583.

Perret N.-L., Minorité créative ou partenariat responsable? La reconnaissance par l'État de l'Église évangélique réformée dans le Canton de Fribourg en 1854, Neuchâtel: Éditions Heinstein, 2006.

REYMOND B., La multitude pour horizon: l'Église nationale vaudoise 1789-1966, Le Mont-sur-Lausanne: Éditions Ouverture, 2017.

Scholl S., «Des ancêtres encombrants. Recomposition et mémoire de la Réforme au Xix ${ }^{\mathrm{e}}$ siècle», in ButTicaz S., Grosse C., ARnold M. (éd.), Unité et diversité des Réformes : du XVI siècle à nos jours, Genève: Labor et Fides, 2017, p. 151-171. 


\section{5 \\ $\mathrm{XX}^{\mathrm{e}}$ SIÈCLE: UN PROTESTANTISME RENOUVELÉ}

Quand, à la fin du $\mathrm{Xx}^{\mathrm{e}}$ siècle, les protestant.e.s valaisan-ne-s décident de construire une chapelle aux Mayens de Sion, lieu de résidence estivale des riches Sédunois·es, l'Église catholique interdit aux artisans catholiques de participer à sa construction. Pour contourner l'interdiction, la communauté protestante doit aller chercher le bois de la porte, du plancher, du plafond, de la galerie et des bancs dans le Haut-Valais et le faire scier dans le Chablais. La chapelle, bâtie en pierre dans un style pittoresque, est inaugurée en 1901. Pas rancunière, la communauté protestante met sa chapelle à disposition de l'Église catholique.

On pourrait caractériser le $\mathrm{xx}^{\mathrm{e}}$ siècle protestant en Suisse romande précisément comme un siècle où le protestantisme devient vraiment suisse romand. Ce qui ne signifie pas pour autant qu'il n'y ait plus qu'une seule Église protestante suisse romande. D'abord parce que le fédéralisme suisse impose, au moins sur le plan juridique, que les Églises restent cantonales. Ensuite parce que, même dans un petit territoire comme la Suisse romande, chaque Église réformée garde certaines de ses spécificités. Enfin, parce que le protestantisme suisse romand devient de plus en plus divers et de plus en plus international.

\section{I UN PROTESTANTISME SUISSE ROMAND}

Cinq grandes tendances parcourent le protestantisme suisse romand. Toutes les Églises réformées ne leur accordent pas la même importance, toutes n'avancent pas au même rythme, mais toutes sont concernées. 


\section{Vers des femmes responsables...}

$\mathrm{Au} \mathrm{Xx}^{\mathrm{e}}$ siècle, les Églises réformées de Suisse romande acceptent enfin de partager le pouvoir avec les femmes. En 1908, l'Église nationale du canton de Vaud accorde le droit de vote aux protestantes - il faudra attendre 1959 pour que les Vaudoises obtiennent ce droit sur le plan politique. En 1910, c'est le tour de l'Église protestante de Genève, pour les femmes qui en font la demande et sans qu'elles puissent être élues dans les conseils de paroisse ou au synode jusqu'en 1923; en 1916, celui de l'Église nationale du canton de Neuchâtel et, en 1929, celui de l'Église réformée du canton de Berne, qui ne rendra les femmes éligibles qu'en 1945.

C'est aussi au $\mathrm{Xx}^{\mathrm{e}}$ siècle que les Églises réformées de Suisse romande acceptent que les femmes étudient la théologie, puis qu'elles accèdent au ministère pastoral.

En 1912, les femmes obtiennent le droit d'étudier la théologie à Neuchâtelet, en 1917, la Faculté libre de Lausanne accueille sa première étudiante. La même année, l'Église protestante de Genève crée un certificat d'études bibliques spécialement destiné aux «jeunes filles», et en 1925, elle ouvre un Institut des ministères féminins qui permet aux étudiantes de suivre tous les cours de la Faculté de théologie, à l'exception de ceux portant sur les langues anciennes. En 1926, Nelly Schaller-Houriet obtient une licence de la Faculté libre de Neuchâtel.

En 1928, l'Église protestante de Genève reconnaît le ministère féminin mais limite les femmes au rôle de pasteures auxiliaires; les membres de l'Église acceptent cette innovation à une large majorité. En 1929, Marcelle Bard (1903-1988) est consacrée et en 1930, elle devient aumônière adjointe à l'hôpital, puis pasteure dans la paroisse de la Servette. En 1943, elle est admise comme membre de plein droit de la Compagnie des pasteurs.

La Vaudoise Lydia von Auw (1897-1994) obtient sa licence en théologie en 1924, et elle est admise en 1931 au pastorat par l'Église évangélique libre du canton de Vaud, qui a ouvert le 
ministère pastoral aux femmes une année plus tôt. Lors de la fusion des Églises réformées en 1966, elle est la seule femme à signer le registre des pasteurs de la nouvelle Église évangélique réformée du canton de Vaud.

\section{Lydia von Auw}

Lydia von Auw naît le 6 août 1897 à Morges dans une famille de cinq enfants. Après qu'elle a obtenu un baccalauréat ès lettres à l'École supérieure de jeunes filles à Lausanne, qui nécessite la connaissance du grec et de l'hébreu, elle choisit, à 20 ans, d'étudier la théologie à «la Môme», la Faculté de théologie de l'Église libre du canton de Vaud. En 1924, elle obtient sa licence avec un mémoire consacré à l'histoire du modernisme catholique en Italie. Le choix de ce sujet la conduit à effectuer un premier séjour en Italie, à la Faculté vaudoise protestante de Rome. Après ses études, elle retourne en Italie pour travailler auprès des Unions chrétiennes de jeunes filles à Turin, à Florence et à Rome.

Sa carrière pastorale débute en 1926, quand elle assure six mois d'intérim dans l'Église libre de Rolle (Vaud), puis une année dans celle de Cormoret (Berne). En 1929, elle retourne à Rome où elle mène des recherches pour sa thèse de doctorat dans les archives du Vatican. En 1931, elle revient dans le canton de Vaud et devient pasteure intérimaire à Ollon. En 1932, elle est officiellement admise comme pasteure par la Commission du saint ministère de l'Église libre. Après un nouveau séjour en Italie, elle est successivement pasteure, toujours intérimaire, à Bex puis à Essertines-sur-Yverdon. En 1935, elle obtient son premier poste stable, comme aumônière à l'hôpital de Saint-Loup; cette même année, elle est consacrée comme pasteure et choisit Ollon comme lieu de la cérémonie. 
Parallèlement à son ministère pastoral, Lydia von Auw poursuit ses recherches académiques. En 1936, elle donne un cours sur l'islam à la Faculté de théologie libre et fait des séjours de recherche à Assise, à Florence et à Rome. En juillet 1948, elle obtient son doctorat à la Faculté de théologie de l'Université de Lausanne pour une thèse intitulée Angelo Clareno et les spirituels Italiens, portant sur un moine franciscain du Moyen Âge, persécuté pour sa pauvreté radicale.

Elle va encore occuper deux postes pastoraux: de 1949 à 1960, elle est pasteure dans l'Église de Granges de Sainte-Croix, c'est-à-dire pour les villages de L'Auberson, Sainte-Croix et Baulmes; et le 10 juillet 1960, elle occupe un premier poste comme titulaire, celui de l'Église de Chavannes-le-Chêne, au-dessus d'Yvonnand. Lors de la fusion des Églises libre et nationale en 1966, elle est la seule femme à signer le registre des pasteurs de l'Église évangélique réformée du canton de Vaud.

Lydia von Auw revient à Morges en 1966 pour y passer sa retraite; elle y décède le 14 mai 1994, à 96 ans.

Outre sa mère qui l'a accompagnée dans ses divers postes pastoraux, Lydia von Auw aura eu deux ami-e.s proches: Jeannette Cathélaz, qui fut la femme de chambre de la famille von Auw dès 1919, puis suivit Lydia dans sa retraite à Morges jusqu'à sa mort; et Ernesto Buonaiuti, professeur d'histoire du christianisme à l'Université de Rome, qu'elle rencontre en 1923. Si c'est Buonaiuti qui l'aiguilla vers les lettres manuscrites d'Angelo Clareno, c'est elle qui lui fit découvrir les milieux universitaires lausannois quand, excommunié et chassé d'Italie, il donna des cours à l'Université de Lausanne. Jusqu'à sa mort en 1946, ils échangeront quatre cents lettres.

Source principale: Кову G., Lydia von Auw: pasteure, théologienne, historienne, Yens-sur-Morges \& Divonne-les-Bains: Cabédita, 2005. 
Les paroisses ne sont pas en reste. Ainsi, en 1925, Élisa Serment (1865-1957) est la première femme à être élue au Conseil de l'Église libre de Lausanne; elle est aussi membre de la Commission sociale et députée au Synode de l'Église libre. En Valais, «Mme Gygax de Riddes» - l'histoire n'a pas retenu son prénom - devient présidente du Conseil paroissial de Saxon en 1937.

Dans le canton de Berne, les paroisses de l'Église nationale réformée évangélique décident en 1963 de modifier leur Constitution pour admettre les femmes au ministère pastoral. Pour que la décision ait force de loi, il faut encore que le peuple bernois sanctionne l'inscription de ce principe d'égalité dans la Constitution cantonale, et c'est chose faite en 1965, à une époque où les hommes sont encore les seuls à pouvoir voter.

Dans le canton de Neuchâtel, Lucy Schmidt - on précise «Mademoiselle Schmidt» - qui a suivi des cours de théologie de 1912 à 1916, prêche, une seule fois, à Chézard-Saint-Martin en 1920. En 1962, Antoinette Lozeron, licenciée en théologie, qui occupe déjà en fait sinon en droit un poste pastoral à La Chaux-de-Fonds - elle y est pasteure auxiliaire -, est autorisée à siéger au synode, jusque-là exclusivement masculin. Mais il faut attendre 1971 pour que l'Église réformée évangélique neuchâteloise ouvre officiellement le ministère pastoral aux femmes. En 1973, l'Église évangélique réformée du canton de Vaud fait de même: elle consacre immédiatement quatre femmes, deux pasteures et deux diacres.

La situation évolue. Si, en 1979, les étudiantes constituent par exemple un tiers des effectifs de la Faculté de théologie de l'Université de Genève, en 1999, elles sont plus de la moitié. Mais le changement prend un peu de temps : en 1990 , les pasteures représentent encore seulement environ $15 \%$ du corps pastoral des Églises réformées de Suisse romande. Les femmes, pasteures et laïques, finissent par briser le plafond de verre: en 1980, Nicole Fischer-Duchâble devient présidente de l'Église nationale protestante de Genève; la même année, Hedwig Schneider est élue présidente du 


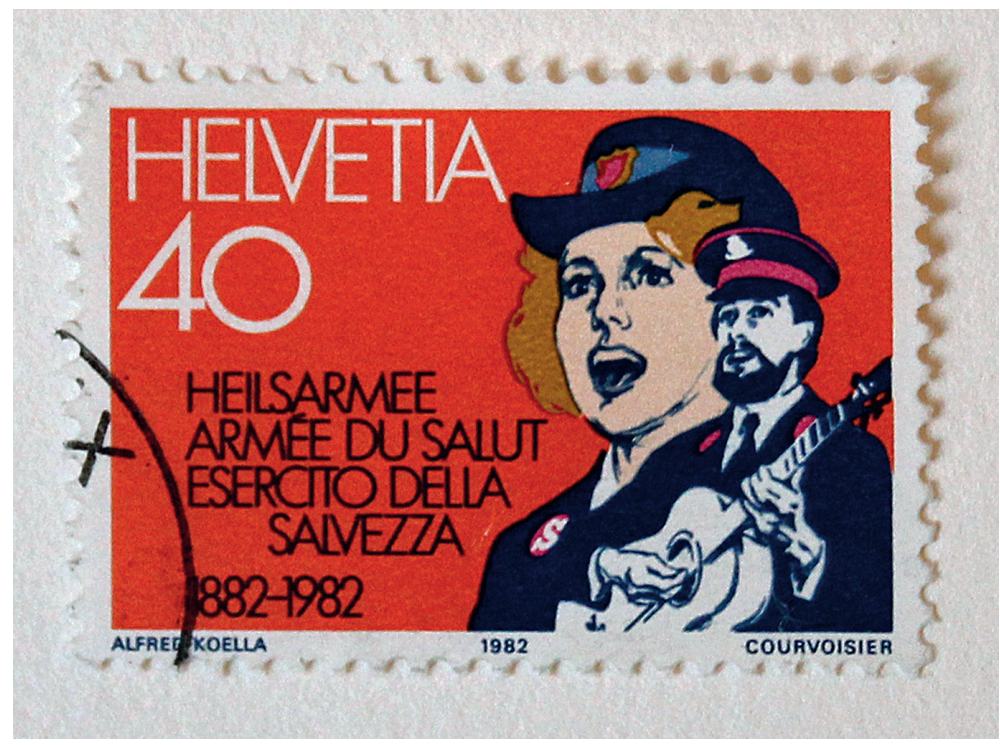

Alfred Koella, Timbre pour le centenaire de l'Armée du Salut Suisse, 1982

(C) Musée international de la Réforme, Genève

Ce timbre-poste paraît comme une reconnaissance tardive de la valeur de l'Armée du salut. La date de 1882 renvoie à la première tournée de conférences de Catherine Booth. Il faudra encore attendre sept ans pour que l'Armée du salut soit légalement tolérée.

Conseil synodal de l'Église évangélique réformée du canton de Fribourg. En 1999, la pasteure Isabelle Ott-Baechler devient présidente du Conseil synodal de l'Église réformée évangélique du canton de Neuchâtel. Dans l'Église évangélique réformée du canton de Vaud, Esther Gaillard devient en 2009, la première femme à présider le Conseil synodal ; en 2014, Sylvie Arnaud en préside le Synode et les femmes forment la majorité du Conseil synodal. 


\section{Vers de nouvelles relations avec l'État...}

En 1907, les Neuchâtelois doivent se prononcer sur une initiative demandant la séparation des Églises et de l'État. Deux tiers des votants refusent l'initiative et maintiennent donc le statu quo. La même année, en scrutin populaire, les Genevois acceptent la suppression du budget des cultes par une majorité constituée avant tout, mais pas uniquement, des catholiques et des socialistes. En 1909, la séparation des Églises et de l'État devient effective. La Faculté de théologie demeure au sein de l'université, mais elle devient une faculté autonome de théologie protestante, gérée par une fondation.

En 1935, le Synode jurassien, qui rassemble les pasteurs francophones du canton de Berne, est officiellement reconnu par le Conseil synodal et par le Grand Conseil du canton de Berne. La loi de 1945 généralise et rend obligatoire l'impôt de paroisse, destiné à financer des activités locales.

En 1941, les instances des deux Églises, nationale et indépendante, du canton de Neuchâtel acceptent le principe d'une fusion et décident que l'Église en résultant sera indépendante de l'État. L'une des deux Églises étant nationale, il faut un vote populaire pour entériner cette décision. Ce vote ne mobilise pas les foules - la participation n'est que de $31,66 \%$-, mais le résultat est clair: 6717 «oui» contre 4828 «non». Le 27 mai 1943, l'Église réformée évangélique neuchâteloise tient son premier synode. Les facultés de théologie fusionnent elles aussi : la nouvelle faculté est intégrée à l'université, tout en restant sous l'autorité de l'Église. En 1959, le synode de l'Église réformée évangélique neuchâteloise demande l'instauration d'un impôt ecclésiastique obligatoire: une écrasante majorité des Neuchâtelois, $79 \%$ de «non», le refuse en 1960.

C'est le 7 décembre 1949 qu'est créée l'Église réformée évangélique du Valais. En 1962, la loi sur l'instruction publique reconnaît l'école protestante et en 1974, le Valais 
révise sa Constitution pour accorder à l'Église réformée un statut de droit public dont bénéficie déjà l’Église catholique romaine.

Vingt-cinq ans après les Églises neuchâteloises, c'est au tour des Églises nationales et libres du canton de Vaud de fusionner. Le 15 mars 1966, elles réunissent dans la salle du Grand Conseil vaudois à Lausanne - le symbole est éloquent - le Synode fondateur de l'Église évangélique réformée du canton de Vaud. Elles adoptent un statut d'Église d'État. Les deux facultés de théologie fusionnent elles aussi, dans le cadre de l'université. Certains membres de l'Église libre refusent d'appartenir à l'Église évangélique réformée, ainsi le pasteur Edmond Isaac (1906-1984) qui préfère rejoindre une Église indépendante de l'État, ou encore la paroisse de l'Église libre vaudoise à Cormoret (Berne) qui survit à la fusion.

Dans le canton de Berne, la «question jurassienne»va diviser l'Église réformée entre loyalistes probernois et autonomistes jurassiens. Le 8 juin 1974, le synode exprime sa volonté de «rester uni au-delà des résultats et conséquences du plébiscite du 23 juin», le «plébiscite» désignant le vote sur la création d'un canton du Jura. En 1979, la naissance de ce nouveau canton oblige à repenser le statut des protestant.e.s de cette région. Solution classique en Suisse, on crée une nouvelle Église cantonale, l’Église évangélique réformée de la République et Canton du Jura. Celle-ci regroupe trois paroisses, une pour chacun des districts de Delémont, des Franches-Montagnes et de Porrentruy. Elle bénéficie d'une contribution ecclésiastique obligatoire et de subventions publiques. Par contrecoup, l'Église réformée dans le canton de Berne doit elle aussi se réorganiser: elle crée une entité intercantonale - l'Union synodale réformée évangélique Berne-Jura - compétente notamment en matière de spiritualité, de doctrine, de formation et de consécration pastorales.

En 1981, la population suisse refuse à une très forte majorité, l'inscription de la séparation des Églises et de l'État dans 
la Constitution fédérale. La question du statut des Églises reste donc du ressort des cantons, qui la règlent de manière différente: dans les cantons de Berne, Fribourg, Jura, Vaud et Valais, des Églises d'État - sous des formes juridiques chaque fois différentes - et à Genève et à Neuchâtel, des Églises indépendantes avec des rapports plus ou moins étroits avec l'État.

\section{Vers un renouveau liturgique...}

Sur le plan liturgique, le $\mathrm{xx}^{\mathrm{e}}$ siècle est marqué par un double mouvement, vers plus de solennité d'abord et plus de familiarité ensuite.

Le désir de solennité est porté par une volonté de redécouvrir et de remettre en usage une liturgie inspirée de l'Église primitive et de la tradition catholique. Dans le canton de Vaud, le pasteur Jules Amiguet (1867-1946) construit le temple de Saint-Jean à Lausanne sur le modèle d'une église paléochrétienne, tandis que son collègue Richard Paquier (1905-1985) crée en 1930 le mouvement Église et Liturgie qui redécouvre la richesse liturgique de l'Église primitive, mais aussi de l'Église anglicane. Il inspire à Grandchamp et à Taizé leur première liturgie, à Crêt-Bérard son «office divin». Jean-Jacques von Allmen (1917-1994), professeur de théologie pratique à la Faculté de théologie de l'Université de Neuchâtel poursuit ce travail en dialogue avec l'Église catholique qui l'invite comme observateur au concile de Vatican II. L'Église réformée neuchâteloise lui doit par exemple l'introduction des couleurs liturgiques dans les églises et sur les étoles des pasteur·e·s. Le désir de solennité culmine sans doute dans les deux gros volumes de Liturgie romande: une Liturgie pour les jours de fête, parue en 1979 et une Liturgie du dimanche pour le temps ordinaire, parue en 1986. Qu'elle soit «romande» est déjà, en soi, un événement dans l'histoire du protestantisme suisse romand. 


\section{LE MONACHISME PROTESTANT}

Hélène Laufer-Gautier est la fille d'un professeur d'Ancien Testament à la Faculté libre de Lausanne, et une ancienne élève de l'École Vinet, membre des Associations chrétiennes d'étudiants. En avril 1914, elle organise à Morges, avec quelques-unes de ses amies, une rencontre pour des femmes protestantes mariées - et socialement privilégiées - des cantons romands, soit Genève, Neuchâtel et Vaud. Toutes signent du nom de leur mari: Mesdames Paul Laufer-Gautier, André Chavannes-Du Pasquier, Henri Reverdin de Beaumont, Paul de Pury-Mestral, etc. La première réunion des «Dames de Morges », un nom qui leur restera même quand elles auront essaimé en Suisse romande, est consacrée à l'éducation. Les participantes y présentent quatre conférences, dont une consacrée à «L'éducation de nous-mêmes par nos enfants» donnée par Geneviève Micheli, et célèbrent elles-mêmes le culte qui termine la rencontre. Dès 1916, les Dames de Morges décident d'ajouter à leur réunion annuelle à Morges des rencontres dans les villes où elles demeurent: Genève, «Haut-Lac», Lausanne, Neuchâtel, plus tard à Bâle, à Berne et à Zurich.

Du 29 septembre au 3 octobre 1931, quelques-unes d'entre elles organisent des «Journées de silence et de recueillement vécues avec le Christ» pour les femmes de 40 à 65 ans à Grandchamp, une propriété située à Areuse (Neuchâtel). Souhaitant une présence plus permanente, Marguerite de Beaumont (1895-1986) s'y installe en 1936, vite rejointe par Marguerite Bossert, puis, en 1940, par Irène Burnat. La Communauté de Grandchamp existe dès 1944, lorsque Geneviève Micheli (1883-1961), veuve et mère de trois enfants, en devient la première «mère». Se consacrant à la réconciliation, la communauté adopte la règle et l'office de Taizé en 1952. Les sœurs qui viennent de divers pays et appartiennent à différentes confessions 
protestantes (réformées, luthériennes, méthodistes) vivent et prient à Areuse, au Sonnenhof (Bâle-Campagne), à Lomme, près de Lille (France) et à Woudsend (Pays-Bas). Elles y accueillent des hôtes pour des retraites spirituelles. Sœur Minke (1929-2013) en sera la «mère» pendant presque trente ans, de 1970 à 1999. En 1980, l’Église réformée évangélique du canton de Neuchâtel reconnaîtra Grandchamp parmi ses «communautés non paroissiales». Entre 1940 et 1942, Roger Schutz (1915-2005) s'installe à Taizé en Bourgogne pour accueillir des réfugiés. Il est à lui seul une figure suisse romande. Il est né à Provence (Neuchâtel) et a étudié la théologie à Strasbourg et à la Faculté libre à Lausanne. En 1942, il doit quitter la France et se réfugie à Genève où il fonde une première communauté. En 1944, alors qu'il a été consacré pasteur à la collégiale de Neuchâtel, il retourne à Taizé avec trois camarades, le Genevois Max Thurian (19211996), le Neuchâtelois Daniel de Montmollin (1921- ) et le Vaudois William-André Berruex (1924-2005). À Pâques 1949, huit frères prononcent les «trois væux perpétuels» de pauvreté, de soumission à l'évangile et de célibat, fondant ainsi une communauté monastique. En 1952, frère Roger en rédige la Règle, et l'église de la Réconciliation est bâtie la même année. En 1972, la communauté accueille un premier frère catholique. En 2005, frère Roger est assassiné par une femme roumaine au cours d'une célébration.

En 1988, la communauté protestante bâloise Don Camillo s'installe à Montmirail dans le canton de Neuchâtel. Elle rénove l'ensemble des bâtiments. Célibataires ou mariée.s, les membres mettent en commun leur argent et vivent au rythme des trois prières communes, le matin, à midi et le soir; ils accueillent des hôtes pour des séjours et des formations; une famille d'agriculteurs exploite la ferme qui se trouve sur le domaine. 
Le désir de familiarité se traduit par la liberté, parfois donnée et parfois prise, avec laquelle les cultes sont célébrés. Plutôt que d'uniformiser son déroulement, chaque paroisse, chaque pasteur.e l'adapte à la sensibilité de la communauté ou aux circonstances. Dans le meilleur des cas, le culte est conçu et célébré par un groupe de paroissien.ne.s. C'est encore une liturgie qui offre le meilleur symbole de cette liberté, celle de la région Centre-Alpes-Rhône de l'Église réformée de France qui publie, en 1974, une liturgie sous forme de classeur. Elle est donc française, mais largement utilisée en Suisse romande. Les textes liturgiques sont présentés sous forme de fiches regroupées par rubrique, et c'est désormais aux célébrant·e·s de construire un culte individualisé en choisissant les fiches qui conviennent à une célébration. En 1991, la commission de liturgie de l'Église évangélique réformée du canton de Vaud décide de «limiter la liberté» et propose son propre classeur de fiches liturgiques intitulé: «Chantez en l'honneur du Seigneur un chant nouveau». Quelques années plus tard, elle modernise le même principe en créant LiturgiCiel, un logiciel, puis un site Internet qui recueille et met à disposition des prières et d'autres textes liturgiques.

La construction de nouveaux bâtiments emprunte souvent à ces deux mouvements. Pour plus de solennité, les Églises adoptent pour le lieu de culte un dispositif inspiré des Églises catholiques, avec la table de communion au centre, flanquée de la chaire d'un côté et des fonts baptismaux de l'autre. Pour plus de familiarité, dès 1960, les Églises réformées privilégient des centres paroissiaux multifonctionnels qui comprennent un lieu de culte, des salles de réunion, une cuisine, des toilettes, etc.

Le $\mathrm{Xx}^{\mathrm{e}}$ siècle marque aussi le retour en grâce des images dans les temples et dans les églises. Aussi surprenant que cela puisse paraître, c'est seulement à cette époque que la croix y fait son apparition. On la date des années 1915-1920 et on la localise à Saint-Jean à Lausanne et dans le temple de Carouge. Mais on y figure aussi des scènes, surtout des scènes bibliques et surtout des actualisations de scènes bibliques, comme si les épisodes racontés par les évangiles se déroulaient dans la Suisse romande contemporaine - sur les vitraux ou sur les murs. 
Parmi les artistes protestants, on trouve deux précurseurs, deux contemporains, le Vaudois Eugène Burnand (1850-1921) et le Neuchâtelois Paul Robert (1850-1923). En 1909, Louis Rivier (1885-1963) réalise des fresques à Mex (Vaud); en 1918, Serge Pahnke illustre l'abside du temple de Plainpalais à Genève et, en 1931, il dessine les vitraux du temple de Jussy (Genève); en 1924-1925, Philippe Robert décore l'église de Chaindon à Reconvilliers (Berne) avec deux fresques et trois vitraux; en 1933, Charles L'Eplattenier (1874-1946) peint deux parois de l'église de Coffrane (Neuchâtel). Mais l'art n'a pas forcément de confession: pas rancunière, l'église SaintFrançois à Lausanne se dote d'un vitrail d'Alexandre Cingria (1879-1945) qui écrivait pourtant en 1917: «L'art religieux ne peut pas renaître tant que le protestantisme existera.»

\section{Vers un rétrécissement des Églises réformées...}

Le $\mathrm{Xx}^{\mathrm{e}}$ siècle connaît une sécularisation couplée à une redistribution des appartenances à l'intérieur même du protestantisme. Conséquence directe de ces deux phénomènes, toutes les Églises réformées de Suisse romande connaissent depuis les années 1960 une nette diminution du nombre de leurs membres - les cantons de Fribourg et du Valais faisant exception -, une chute du nombre des baptêmes, des confirmations et des mariages qu'elles célèbrent, une légère baisse des services funèbres.

Les Églises réformées tentent de réagir à ce contexte en prenant des mesures parfois drastiques de restructuration et de rationalisation. Si elles cherchent parfois à maintenir leur service avec moins de ressources humaines et financières, elles n'ont pas toujours d'autre choix que de diminuer leurs prestations. Là où les Églises réformées dépendent des contributions volontaires des fidèles, comme à Genève et à Neuchâtel, elles essayent aussi de mobiliser et de responsabiliser les protestant·e.s au travers de campagnes d'affichage ou de lettres personnalisées. La situation paraît si difficile que le professeur de théologie pratique de l'Université de Genève, 
Jean-Marc Chappuis (1924-1987), imagine le pire et écrit en 1984 L'Histoire fantastique de William Bolomey dernier pasteur chrétien. Le seul élément rassurant est peut-être que ce dernier pasteur chrétien - pour lui, c'est un homme - sur terre vit en Suisse romande, dans le canton de Vaud...

\subsection{UN PROTESTANTISME INTERCANTONAL}

Le $\mathrm{XX}^{\mathrm{e}}$ siècle voit trois initiatives locales qui ont un impact fort dans les autres cantons romands.

En 1923, le pasteur Raoul Dardel transmet le premier culte radiodiffusé depuis le studio de l'aérodrome de Cointrin. Dès 1924, Radio-Genève et Radio-Lausanne diffusent chaque dimanche un culte protestant. En 1954, le pasteur Robert Stahler propose une émission œcuménique, intitulée C'est demain dimanche, pour la Télévision genevoise qui cherche du contenu. Dès 1955, avec l'abbé Jacques Haas, il crée pour la Télévision suisse romande l'émission Présence qui est d'abord alternativement protestante et catholique, et qui s'ouvre ensuite aux catholiques chrétien·ne·s puis aux juifs et aux juives. En 1964, à l'occasion de l'Exposition nationale à Lausanne, le pasteur Philippe Zeissig et l'abbé Georges Juvet proposent la Minute acuménique à la Radio suisse romande: cette émission quotidienne connaît un immense succès.

En 1920, sur l'impulsion du pasteur Charles Béguin, responsable des Unions chrétiennes de jeunes gens est construit le camp de Vaumarcus, à la frontière des cantons de Neuchâtel et de Vaud. Dès 1948, Albert Girardet, aumônier de jeunesse dans l'Église nationale du canton de Vaud imagine un centre de rencontre. L'Église donne son accord, mais prévient qu'elle refuse de le financer. Situé près de Puidoux, au lieu-dit à Crêt-Bérard, ou «colline du berger », entièrement construit par les jeunes protestant $\cdot e \cdot s$ du canton de Vaud, il est inauguré en 1953. Les deux idées fortes de Crêt-Bérard - construire un centre de rencontre, de formation et de prière, l'implanter dans un endroit retiré pour favoriser 
le partage, la réflexion et la méditation - sont reprises dans les autres cantons suisses romands. Dans le Valais, on démonte le Foyer du soldat de Savatan, on le déplace et on le reconstruit à Sapinhaut en 1956. À Neuchâtel, le Louverain est lui aussi bâti par la jeunesse protestante au-dessus des Geneveys-sur-Coffrane; il est inauguré en 1967. À Genève, dans un endroit moins isolé, c'est le presbytère de Cartigny qui est agrandi pour être transformé en centre de rencontres. Dans le Jura bernois, on bâtit un centre à Sornetan (Berne) en 1971, et dans le canton de Fribourg, le chalet de Charmey est ouvert en 1972.

En 1954, un groupe de personnes faisant partie de l'Église protestante de Genève, dont le pasteur Raynald Martin (1906-1998), crée un Centre social protestant, une association privée à but non lucratif, indépendante de l'Église. Y sont offerts des conseils juridiques, un service de placement et, dès 1956, le Vestiaire social, où l'on distribue gratuitement des vêtements, notamment aux réfugiés hongrois. La première brocante est ouverte en 1953 à Vernier. L'idée est reprise dans le Jura bernois en 1958, à Lausanne en 1961, à Neuchâtel en 1964 où il est un service de l'Église évangélique réformée.

Le $\mathrm{xx}^{\mathrm{e}}$ siècle voit aussi les Églises réformées de Suisse romande reprendre à leur compte certaines des missions assumées jusqu'ici par des «Sociétés » et mettre en commun leurs ressources et leurs missions.

En 1921, les Sociétés cantonales des Écoles du dimanche s'associent dans un Comité romand des Écoles du dimanche. En 1966, les Sociétés sont dissoutes et la tâche de la formation des enfants est confiée directement aux Églises qui créent une Agence romande d'éducation chrétienne. En 1973, on lui ajoute un secteur «adolescence».

En 1963, huit Églises protestantes - nationales ou libres - de Suisse romande, prenant le relais de six sociétés missionnaires, décident d'assumer elles-mêmes «leur fonction apostolique 
dans les pays d'outre-mer». Elles créent pour ce faire un Département missionnaire dont le siège est fixé à Lausanne, pour «participer à l'évangélisation du monde».

Pendant les années 1960, les Départements de l'instruction publique des cantons de Berne, de Fribourg et de Vaud et des Églises catholiques et réformées s'associent pour créer Enbiro - l'acronyme d'Enseignement biblique romand -, une maison d'édition des programmes scolaires d'enseignement culturel du christianisme.

En 1967, les Églises réformées de Suisse romande reconnaissent le statut de diacre et fondent le Département romand des ministères diaconaux. C'est en 1974 que la première volée de diacres commence sa formation.

En 1971, avec des Églises protestantes en France et dans les pays francophones «d'outre-mer» - en Afrique, en Amérique latine, dans le Pacifique et l'océan Indien -, les Églises réformées des sept cantons de Suisse romande participent à la création de la Cevaa, une Communauté évangélique d'action apostolique. Il n'y a plus, dès lors, des «Églises mères » au nord et des «Églises filles» au sud, mais seulement des «Églises sœurs » tout autour du monde.

En 1979, la structure «Terre Nouvelle» permet de coordonner les actions des trois œuvres d'entraide protestantes: le Département missionnaire, l'Entraide protestante et Pain pour le prochain.

Enfin, en 1994, les Églises réformées de Suisse romande, la Conférence des Églises réformées de langue française en Suisse alémanique et l'Église évangélique libre de Genève constituent ensemble la Conférence des Églises protestantes de la Suisse romande. Cherchant à «faire rayonner la foi chrétienne reformée en Suisse francophone», cette structure coordonne le travail des Églises et gère certains ministères cantonaux, notamment dans les médias et dans la formation des pasteur.e.s et des diacres. 


\section{L'assassinat d'Arthur Bloch À Payerne en 1942}

Le 16 avril 1942, Arthur Bloch, un marchand de bétail, se rend de Berne à Payerne pour acheter des bêtes sur le marché. Quelques jeunes hommes l'attirent dans une étable au prétexte de lui vendre une vache. Là, ils l'assassinent, le dépècent et placent son corps démembré dans trois bidons à lait qu'ils vont jeter dans le lac de Neuchâtel. La victime a été choisie parce qu'elle était de confession juive, et Arthur Bloch a été assassiné parce que les jeunes hommes étaient nazis. Les cinq auteurs de l'assassinat sont arrêtés dans les jours qui suivent. Ils sont jugés en février 1943: le tribunal de Payerne condamne Fernand, Fritz et Robert à la réclusion à vie, Georges à vingt ans de réclusion et Max à quinze ans de réclusion. En 1947, Philippe, l'idéologue nazi instigateur de l'assassinat d'Arthur Bloch est condamné à vingt ans de réclusion.

L'assassinat d'Arthur Bloch est sans aucun doute une grande honte. Mais est-il pour autant une grande honte pour le protestantisme suisse romand? On pourrait argumenter qu'il est le fait de cinq individus, qu'il a été commis au nom de l'idéologie nazie et qu'il n'engage pas la responsabilité protestante. Sauf que...

Sauf que l'assassinat d'Arthur Bloch s'est produit dans une ville protestante depuis que Berne a envahi le pays de Vaud en 1536, une ville dont la culture est, à l'époque, encore largement protestante. Selon le recensement de 1941, le district de la Broye, dont Payerne est le cheflieu, compte $83,68 \%$ de protestant.e.s.

Sauf que l'idéologue nazi qui a inspiré l'assassinat d'Arthur Bloch est licencié en théologie de la Faculté de théologie de l'Université de Lausanne, qu'il est un ancien pasteur protestant, certes contraint à démissionner en 1934, mais parce qu'il a divorcé et non en raison de son idéologie nazie! 
Sauf que les quatre jeunes hommes originaires de Payerne - le cinquième vient de Langnau, dans l'Emmental - et coupables de l'assassinat d'Arthur Bloch ont tous été baptisés dans l'Église nationale évangélique réformée du canton de Vaud: Fernand le 24 mai 1908, Robert-Ernest le 31 décembre 1916, Max Jean le 8 septembre 1918 et Georges le 2 septembre 1923. Ils ont également tous été confirmés dans l'Église nationale évangélique réformée du canton de Vaud: Fernand le 13 avril 1924, Robert le 20 mars 1932, Max le 25 mars 1934 et Georges le 2 avril 1939. Enfin, Robert a fait baptiser l'un de ses enfants dans l'Église nationale évangélique réformée du canton le 8 février 1942, soit deux mois avant qu'il ne participe à l'assassinat d'Arthur Bloch.

Sauf qu'à l'époque de l'assassinat d'Arthur Bloch, l'Église nationale évangélique réformée du canton de Vaud s'est montrée au mieux indifférente au sort des juifs et des juives, au pire antisémite. Ainsi n'a-t-elle pris aucune initiative en faveur des juifs et des juives persécuté.e.s, et quand d'autres ont sollicité son appui - par exemple l'Église libre en 1933, la Fédération des Églises protestantes de la Suisse en 1936 -, elle s'est réfugiée dans le silence ou a exprimé son refus. En outre, elle a toujours renoncé à condamner ses pasteurs notoirement antisémites. La responsabilité protestante semble pleinement engagée dans l'assassinat d'Arthur Bloch en 1942.

Pour connaître le déroulement des faits: Pilet J., Le Crime nazi de Payerne: 1942, en Suisse, un Juif tué pour l'exemple, Neuchâtel: Livreo-Alphil, 2017 ( $1^{\text {re }}$ édition: 1977).

\subsection{UN PROTESTANTISME FÉDÉRAL}

Le $\mathrm{Xx}^{\mathrm{e}}$ siècle voit les Églises cantonales mettre leurs forces en commun.

En 1920, à Olten, les Églises protestantes suisses fondent la Fédération des Églises protestantes de la Suisse. Pour la Suisse 
romande, y adhèrent les Églises réformées de Berne, de Fribourg, de Genève, de Neuchâtel (nationale et indépendante), du Valais et de Vaud (nationale et libre). En 1922, l'Église évangélique méthodiste de Suisse et l'Église évangélique libre de Genève la rejoignent. En 1928, cette Fédération se dote d'un Service de presse protestant qui vise à informer les médias de l'actualité protestante et les protestant·e.s, de l'actualité générale.

En 1946, la Fédération crée l'Entraide protestante suisse, plus connue sous son sigle EPER, qui regroupe, centralise et renforce les œuvres de solidarité des Églises. Dès 1967, elle coorganise avec l'Église catholique des campagnes œcuméniques de financement. En 1970, la Fédération des Églises protestantes crée Pain pour le prochain, le partenaire protestant d'Action de Carême, un organisme catholique. Elle conclut aussi des accords avec la Conférence épiscopale. Toutes deux parviennent à une reconnaissance mutuelle du baptême en 1963 et à un accord sur les mariages mixtes en 1967.

La Fédération suisse des femmes protestantes est fondée en 1947. À travers elle, les femmes protestantes s'engagent pour l'œcuménisme - elle travaille avec la Ligue suisse des femmes catholiques -, pour la paix et pour la justice sociale. Elle participe à l'organisation de la Journée mondiale de prière, un mouvement de femmes chrétiennes et laïques, célébrée le premier vendredi du mois de mars.

Durant les années 1960 s'ouvre un débat sur le statut des Églises réformées de Suisse romande. Faut-il poursuivre avec l'option de la Fédération ou le temps est-il venu de créer une seule Église protestante pour l'ensemble du territoire suisse? Se méfiant d'une Église trop centralisée, on préfère garder le modèle de la Fédération, laissant le pouvoir aux Églises cantonales.

En 1971, la Fédération est le partenaire protestant lors de la fondation de la Communauté de travail des Églises chrétiennes en Suisse. À terme, celle-ci facilite la collaboration de douze confessions: Armée du salut, Bund Schweizer 
Baptistengemeinden, Diocèse orthodoxe de Suisse du patriarcat œcuménique de Constantinople, Église anglicane en Suisse, Église catholique chrétienne de Suisse, Église catholique romaine de Suisse, Église évangélique méthodiste en Suisse, Fédération d'Églises évangéliques luthériennes dans la Suisse et la Principauté de Liechtenstein, Fédération des Églises protestantes de Suisse, Représentation de l'Église orthodoxe roumaine de Suisse, Représentation de l'Église orthodoxe serbe en Suisse, Représentation de l'Église syriaque orthodoxe en Suisse.

Côté plus sombre de la Fédération des Églises protestantes, sa difficulté à reconnaître le caractère néfaste de l'apartheid en Afrique du Sud. La forte implication des Églises protestantes blanches dans ce système de ségrégation et le ferme engagement économique de la Suisse dans ce pays ont pour résultat qu'il faut attendre 1982 pour que le Synode des délégués adopte une déclaration affirmant que le soutien à l'apartheid est incompatible avec l'évangile.

De 1981 à 1987 se tient le Synode suisse. Lancé à l'initiative d'un groupe de pasteur·e·s et de laïques, il réunit, comme le Conseil national suisse, deux cents délégué·e·s, dont un tiers est nommé par les Églises protestantes suisses, un tiers par les œuvres d'entraide et un tiers par les initiant·e.s. Il contribue à repenser l'identité protestante sur des thèmes classiques - «renouveau du culte» avec douze thèses sur le sens et la forme du culte réformé, «paroisses vivantes »-, mais aussi sur des questions plus originales - «être chrétien dans un pays riche», «communautés des sexes et des générations ».

\subsection{UN PROTESTANTISME INTERNATIONAL}

Le $\mathrm{Xx}^{\mathrm{e}}$ siècle voit aussi le protestantisme suisse exercer un rayonnement international.

Dans la perspective du quatrième centenaire de la naissance de Calvin en 1909, Genève décide d'ériger un monument destiné à tous ses habitants ainsi qu'aux gens qui la visitent. 
En 1908, un concours est lancé, et c'est le Mur des réformateurs imaginé par les architectes suisses Alphonse Laverrière et Jean Taillens - il est orné en son centre de quatre statues monumentales de ceux que Genève juge être les principaux réformateurs : Guillaume Farel, Jean Calvin, Théodore de Bèze et John Knox - qui remporte le premier prix. Dans un esprit d'œcuménisme intraprotestant, ce monument commémoratif cherche à plaire aussi bien aux libéraux, aux calvinistes orthodoxes qu'aux évangéliques. Dans une perspectiveinternationale, il évoque évidemment la Réforme à Genève, mais aussi, dans des scènes latérales, le protestantisme en Allemagne, personnalisé par la figure de Frédéric-Guillaume de Brandebourg, en Angleterre avec Oliver Cromwell, en Écosse avec John Knox, aux États-Unis avec Roger Wiliams, en France avec l'amiral de Coligny, en Hongrie avec István Bocksay et aux Pays-Bas avec Guillaume $\mathrm{I}^{\mathrm{er}}$ le Taciturne. Certes, le mur reflète la réalité internationale du protestantisme, mais le choix dépend aussi de la volonté d'attirer des donateurs de toutes origines, protestantes et géographiques. La première pierre est posée en 1909, et le monument est inauguré en 1917.

Outre ce travail de mémoire, les Églises protestantes «suisses romandes» ou des Églises ou des membres de ces Églises vont jouer un rôle sur la scène internationale.

Le pasteur lausannois Louis Émery met en œuvre une Conférence des Églises pour la paix, qui aurait dû se tenir en janvier 1914 mais qui est annulée faute d'intérêt.

La Suisse romande accueille deux grandes conférences œcuméniques entre les deux guerres mondiales, qui réunissent des Églises de diverses confessions et de divers pays : en 1920 se tient à Genève la Conférence du christianisme pratique et, en 1927, c'est à Lausanne qu'a lieu la Conférence mondiale Foi et Constitution. Ces deux mouvements œcuméniques fusionnent pour faire naître, en 1946, un Institut œcuménique (un lieu de formation théologique situé à Bossey) et en 1948, le Conseil œcuménique des Églises dont le siège est installé à Genève. La Fédération des Églises protestantes de la Suisse 
fait partie des membres fondateurs de ce Conseil œcuménique, malgré certaines réserves sur le principe d'inscrire une confession de foi - même réduite au plus petit dénominateur commun, «Jésus Christ Dieu et Sauveur» - dans sa Constitution.

Mais le $\mathrm{Xx}^{\mathrm{e}}$ siècle voit également le protestantisme suisse romand se laisser influencer par ce qui vient de l'étranger.

Ainsi, en 1925, de la venue du pasteur sud-africain Calvin Matsivi Mapopé à l'occasion du cinquantième anniversaire de la Mission suisse romande en Afrique du Sud. Celui qui est l'un des trois premiers pasteurs «indigènes » à avoir été formés et reconnus par la Mission romande est probablement l'un des tout premiers pasteurs noirs à intervenir dans des paroisses protestantes en Suisse romande. Il parle dans la salle de la Réformation à Genève, à la cathédrale de Lausanne, au Temple du Bas à Neuchâtel. Il rend aussi visite à des familles et notamment à la famille Schutz, installée à Provence (Neuchâtel) et dont il bénit les enfants, y compris un garçon de dix ans, prénommé Roger, qui fondera la communauté de Taizé quelques décennies plus tard.

L'Assemblée œcuménique de jeunesse européenne se tient à Lausanne en juillet 1960. Elle est marquée par un geste qui, à l'époque, paraît risqué, la célébration d'une intercommunion ou d'une communion ouverte à tous les chrétien·ne·s.

Un Congrès international pour l'évangélisation mondiale se tient durant l'été 1974, encore à Lausanne. Organisé notamment par le célèbre évangéliste étatsunien Billy Graham (19182018), il rassemble pendant dix jours plusieurs milliers de chrétien·ne.s venus du monde entier. Il en résulte la Déclaration de Lausanne et le Lausanne Movement - «Lausanne»étant utilisé ici comme un nom commun -, un mouvement évangélique, actif dans l'évangélisation.

Enfin, en 1975, le pasteur Jean Zida fonde une première Église africaine. Accueillant surtout des Congolais, elle célèbre son culte dans la chapelle des Terreaux à Lausanne, puis dans la chapelle du Coteau à Pully. Vingt et un ans plus 
tard, les Églises africaines sont assez nombreuses pour éprouver le besoin de créer une Conférence des Églises africaines en Suisse.

\subsection{Pendant Ce temps-Là, dans les Églises PROTESTANTES de SUISSE ROMANDE...}

$\mathrm{Au} \mathrm{Xx}^{\mathrm{e}}$ siècle, le protestantisme poursuit sa diversification. Des Églises protestantes évangéliques et pentecôtistes naissent, s'installent, se développent et meurent parfois. En 1925, la Ligue pour la lecture de la Bible, qui en encourage la lecture quotidienne, s'installe à Vennes, au-dessus de Lausanne et y installe son Institut biblique et missionnaire. En 1967, il déménage et s'installe à Saint-Légier, au-dessus de Vevey. Entre 1952 et 1979, la Ligue a pour secrétaire général Maurice Ray (1914-2005), un pasteur très charismatique qui anime Le Courrier du cour sur la Radio suisse romande et tient une chronique hebdomadaire dans la Gazette de Lausanne. En Suisse romande, le pentecôtisme commence par des événements ponctuels : des «Conventions » à La Chaux-de-Fonds, à Caux, au-dessus de Montreux, au Mont-Pèlerin, au-dessus de Vevey, des conférences annuelles, souvent prononcées par des prédicateurs britanniques. Elle se poursuit par l'établissement d'Églises - ainsi des Églises évangéliques de Réveil et des Églises apostoliques dès 1935 à Genève et Lausanne -, puis par le développement de communautés charismatiques indépendantes dès 1970 .

Les régions traditionnellement catholiques deviennent des terres de mission pour les mouvements protestants, qu'ils soient réformés, évangéliques ou pentecôtistes.

Dans le futur canton du Jura, la paroisse réformée des Franches Montagnes inaugure son temple à Saignelégier en 1913 et y installe des cloches en 1927. En 1922, une Assemblée des frères évangéliques s'installe à Vendlincourt et, en 1954, elle construit une chapelle à Miécourt. En 1938, les mennonites commencent la construction d'une chapelle 
à Courgenay; en 1939, l'Église néo-apostolique fonde une communauté à Delémont où elle bâtit une église en 1974; en 1972, l'Assemblée chrétienne s'installe à Delémont; en 1976, la Fraternité chrétienne, une communauté pentecôtiste, s'installe à Porrentruy où elle célèbre son culte dans un ancien cinéma.

Fribourg est l'un des deux cantons romands où le protestantisme se développe. Cette croissance est alimentée tant par des migrations intercantonales que par des conversions. Elle concerne aussi bien l'Église réformée - le Grand Conseil accepte de créer des nouvelles paroisses, à Bulle en 1930 où un premier pasteur entre en fonction en 1949, à Estavayer-leLac en 1941, à Romont et à Châtel-Saint-Denis en 1951 - que les Églises évangéliques et pentecôtistes. L'Église néo-apostolique est présente à Fribourg depuis 1950, et l'Église adventiste du septième jour existe, toujours à Fribourg, depuis 1958, mais aussi à Morat et à Bulle. De nombreuses Églises évangéliques ou pentecôtistes francophones s'ouvrent durant les années 1980: en 1982 l'Église évangélique de Réveil à Fribourg et l'Église évangélique missionnaire d'Estavayerle-Lac, à Bulle en 1984 l'Église évangélique missionnaire et en 1985 l'Église évangélique apostolique. «Pierre Vivante» s'installe en 1991 dans l'ancien Hôtel de la Gare à Siviriez et «Espace rencontre» se développe à Villars-sur-Glâne dès la fin des années 1990.

Dans le Valais, la part de la population protestante augmente rapidement: entre 1900 et 1930, elle fait plus que doubler, passant de $1,5 \%$ à $3,4 \%$. On crée donc de nouvelles paroisses. À Montana, on célèbre des cultes dès 1903, au sanatorium Le Clairmont, dès 1910 dans la chapelle anglicane, dès 1920 dans la chapelle construite en panneaux démontables et, dès 1959 dans le temple. Le premier pasteur résident s'y installe en 1929. À Martigny, on inaugure le temple et l'école en 1932 et en 1939, et l'on crée un poste pastoral pour Martigny et Saxon, dont la chapelle est achevée en 1914. L'Église évangélique du Bouveret-Saint-Gingolph est constituée le 26 octobre 1919, 
et en 1921, elle dispose d'une chapelle. Des chapelles ou des temples sont construits dans les stations touristiques: aux Mayens de Sion en 1900, à Champéry en 1912 - avec ses trois cent vingt places, il est à cette époque le plus grand du Valais -, à Champex en 1935 et à Verbier en 1938.

Quelques événements particulièrement importants marquent la vie des Églises réformées en Suisse romande.

L'Église réformée évangélique du canton de Neuchâtel lance pendant les années 1960 les Chantiers de l'Église, une vaste entreprise de construction de nouveaux bâtiments pour répondre à de nouveaux besoins. Ceux-ci incluent des bâtiments multifonctionnels pouvant accueillir aussi bien le culte que des activités communautaires dans des villages, Cressier par exemple, ou des quartiers, comme celui des Forges à La Chaux-de-Fonds, qui en étaient dépourvus. Un besoin aussi de bâtiments pour remplir de nouvelles missions: accueillir les étudiant·e·s étrangers - c'est la Maison de Champréveyres entre La Coudre et Hauterive - ou favoriser les débats et la formation - c'est Le Louverain dans le Val-de-Ruz.

À Genève, au printemps 1967, vingt-deux pasteurs non consacrés de l'Église protestante de Genève signent un manifeste, appelé justement le Manifeste des 22, dans lequel ils déclarent, en trois articles, que «tout chrétien est consacré par son baptême», que le ministère pastoral est une fonction, une fonction qui «n'est pas définitive» et qu'ils refusent «la consécration au ministère pastoral». Répondant positivement à l'interpellation, l'Église protestante de Genève renonce au caractère obligatoire de la consécration pastorale.

Durant les années 1990, les Églises réformées Berne-Jura réforment profondément la formation chrétienne qu'elles dispensent aux enfants et aux adolescents. Sous l'impulsion de Christiane Berthoud, de Pierre Paroz (1949-2010) et de Maurice Baumann (1949- ), elles créent ce qu'elles appellent «la nouvelle catéchèse». En 1994, elles publient des Directives pour la catéchèse qui «fixent de manière contraignante les 
structures de la catéchèse et les moyens de s'acquitter des tâches qui en découlent». Cette nouvelle catéchèse se donne deux buts: aider les enfants et les adolescent·e·s à répondre aux grandes questions de la vie - parfois aussi les aider à se les poser - et les «introduire à la vie de la communauté paroissiale»; concrètement, cette nouvelle catéchèse part du vécu des catéchumènes et leur propose de le réfléchir à la lumière de l'évangile. Elle est animée par des équipes composées de pasteur.e.s et de laïques.

L'Église réformée évangélique du canton de Vaud entame en 1995 un vaste processus de réorganisation, connu sous le titre «Église à venir» et qui prend effet le $1^{\text {er }}$ janvier 2000. L'annonce d'une restriction budgétaire fournit l'occasion de repenser l'Église: son organisation - 18 régions au lieu des anciens 8 arrondissements, 84 paroisses au lieu de 158 - et ses ministères, avec un renforcement des ministères régionaux consacrés à la coordination, à la jeunesse, à l'aumônerie dans les établissements médicaux sociaux, avec la création de ministères spécialisés à destination des toxicomanes, des personnes seules ou de l'accompagnement de la fin de vie, et avec le développement des aumôneries dans les institutions comme les hôpitaux, les écoles ou les prisons. Démarche peu usuelle, les 250 postes de ministres (diacres et pasteur.e.s) sont remis au concours. Les titulaires doivent démissionner et postuler au même poste ou à un nouveau; mais on a pris des précautions, et un arrêté prévoit que «tous les titulaires de postes reconnus par l'État ou financés par l'EERV [...] ont la garantie d'obtenir un poste à un taux d'activité semblable».

\section{ORIENTATION BIBLIOGRAPHIQUE}

CAmpiche Roland J., Croire en Suisse(s): analyse des résultats de l'enquête menée en 1988/1989 sur la religion des Suisses, Lausanne: L'Âge d'Homme, 1992.

Favre O., Les Églises évangéliques de Suisse: origines et identités, Genève: Labor et Fides, 2006.

Laufer H., Micheli G., Aux origines des «Dames de Morges» et des retraites de Grandchamp, 2012. 


\section{6 \\ XXI ${ }^{\mathrm{e}}$ SIÈCLE: UN PROTESTANTISME \\ QUI SE RENOUVELLE}

Celui ou celle qui s'est promené au bord du lac de Morat entre mai et octobre 2002 a pu voir sept cabanes en fer rouillé, posées sur des pilotis. Il s'agissait des sept «Ciels» d' «Un Ange passe », la contribution de quatorze Églises chrétiennes à l'Exposition nationale suisse Expo.02. Mobilisés par le théologien Gabriel de Montmollin (1959- ), sept artistes contemporains proposaient leurs points de vue sur sept thèmes spirituels : «Mystère», «Au-delà», «Bonne Nouvelle» où l'on pouvait répondre à la question «Qui suis-je pour Dieu?» et voir sa réponse affichée sur les murs, «Relations», «Parole», «Bénédiction» où celle-ci était dispensée par six paires de bras entre les mains desquelles coulaient des filets d'eau, et enfin «Création».

Le $\mathrm{XXI}^{\mathrm{e}}$ siècle est encore jeune et nous sommes bien incapables d'en faire l'histoire. Soulignons cependant deux aspects qui nous semblent particulièrement symptomatiques.

D'une part, les commémorations, notamment celles de deux grandes dates de l'histoire protestante: leur caractère événementiel et leur regard rétrospectif disent quelque chose du statut du protestantisme suisse romand au XXI ${ }^{\mathrm{e}}$ siècle.

D'autre part, la réorganisation de l'enseignement de la théologie protestante en Suisse romande: ensemble, la fermeture de la Faculté de théologie de l'Université de Neuchâtel 
et le développement d'une Haute École de théologie protestante disent quelque chose des évolutions au sein même du protestantisme.

Mais les Églises réformées de Suisse romande poursuivent leur vie quotidienne. Pour moins de paroissien.ne-s et avec moins de ressources, elles remplissent leurs tâches d'évangélisation, d'animation, de formation, d'information et d'accompagnement.

\section{I LES COMMÉMORATIONS}

Le début du $\mathrm{XXI}^{\mathrm{e}}$ siècle connaît deux anniversaires protestants importants qui sont largement célébrés.

En 2009, c'est le «Jubilé Calvin» marquant les 500 ans de la naissance du réformateur. Genève le fête en grand. L'Église protestante de Genève s'associe à la Conférence des Églises romandes et à la Fédération des Églises protestantes de la Suisse pour célébrer un culte dans la cathédrale Saint-Pierre le dimanche de Pentecôte. Retransmis par des chaînes de télévision en Europe, aux États-Unis et même en Corée, il accueille des représentants de l'Alliance réformée mondiale. Le Musée international de la Réforme, qui vient d'être créé en 2005, présente une exposition temporaire, en réalité virtuelle, consacrée à Une journée dans la vie de Calvin. On peut y découvrir la vie quotidienne de Jean Calvin de son lever, à 4 heures du matin, à son coucher, le soir à 21 heures. Les Éditions Labor et Fides publient des livres pour l'occasion, des plus sérieux, par exemple Calvin et le calvinisme. Cinq siècles d'influence sur l'Église et la Société, aux plus originaux comme ce Calvin sans trop se fatiguer ou ce Calvin World, qui offre les portraits de quarante personnes d'aujourd'hui dont le seul lien est de s'appeler Calvin.

De novembre 2016 à novembre 2017, comme l'ensemble du monde protestant, comme toute la Suisse protestante, la Suisse romande protestante vit au rythme des célébrations du 
$500^{\mathrm{e}}$ anniversaire de la Réforme. Commémorant l'affichage par Martin Luther de ses 95 thèses sur la porte du château de Wittenberg, il est marqué par de très nombreuses manifestations dans tous les cantons suisses romands. Témoignant d'une fierté d'être protestant·e et d'une volonté de le faire savoir, mais issues peut-être aussi du constat que le protestantisme n'est plus si connu en Suisse romande, les manifestations sont nombreuses et variées. La Fédération des Églises protestantes de la Suisse - sous l'appellation «Les Réformé·e·s en Suisse» - organisent une campagne d'affichage pour illustrer par l'image trois valeurs protestantes: «Pouvoir agir, aimer croire, oser penser». Elle met en place un site Internet particulier - www.ref-500.ch - pour faire la promotion de leurs activités et fait voyager une exposition itinérante qui part de Genève le 3 novembre 2016 et qui visite soixante-sept « cités de la Réforme» dans dix-neuf pays, dont Lausanne et Neuchâtel en Suisse romande.

En 2017, les Églises cantonales font preuve de créativité et d'originalité : la région Morges-Aubonne de l'Église évangélique réformée du canton de Vaud met en bouteille sa «cuvée de la Réforme»- un lot de six bouteilles de vin blanc et rouge dédiées à cinq réformateurs et à une réformatrice -, alors que la paroisse de Martigny-Saxon vendange le raisin d'une future «cuvée du $500^{\mathrm{e}}$ de la Réforme», un assemblage de trois cépages: Chardonnay, Païen - ça ne s'invente pas - et Marsanne. Dans l'Église réformée évangélique de Neuchâtel, on déguste un repas du $\mathrm{XVI}^{\mathrm{e}}$ siècle avec des lectures d'extrait des Propos de table de Martin Luther. L'Église réformée évangélique du Valais organise à Sion cinq rencontres de formation d'adulte, intitulées «CQFD (Croire-Questionner-Former-Débattre)».

À Genève se tient une exposition sur le quotidien des Genevois durant le premier siècle de la Réforme: "Côté chaire côté rue». La Réforme à Genève 1517-1617. L'Église évangélique réformée du canton de Fribourg fait sa fête à Morat. En novembre 2017, se tient à Genève le 


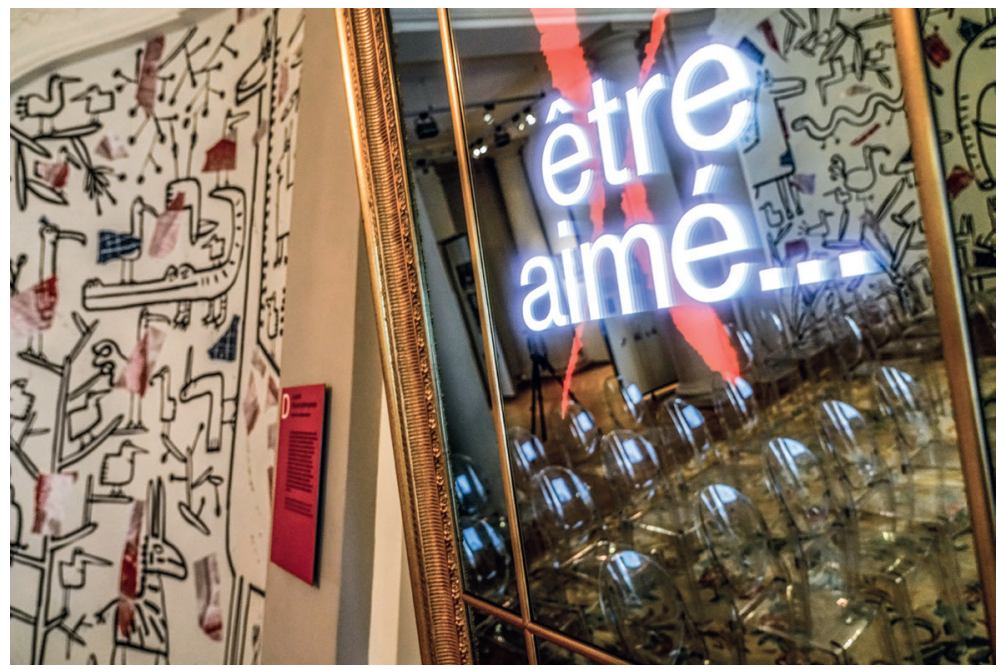

Nicolas Righetti, L'exposition Il était plusieurs fois au Musée International de la Réforme

Genève, 2019

(C) Nicolas Righetti - Lundi13

Le Musée international de la Réforme à Genève donne à voir le passé du protestantisme, mais aussi son présent et son avenir. En 2019, l'exposition Il était plusieurs fois actualise des idées fortes de la Bible.

festival Reform'Action, mélange de concerts, d'ateliers de réflexion et de célébration, qui rassemble presque cinq mille jeunes. Peut-être encore plus original, la Fédération des Églises protestantes n'hésite pas à lancer des produits dérivés : une tasse avec les logos de toutes les Églises cantonales, un jeu de jass où les réformateurs Martin Luther, Hudrich Zwingli, Jean Calvin et Johannes Oekolampad figurent sur les cartes des rois, tandis que leurs épouses, respectivement Katharina von Bora, Regula GwalitherZwingli, Idelette de Bure et Wibrandis Rosenblatt - cette 


\section{Pierre Paroz}

Il est difficile de choisir une forte personnalité pour un siècle qui n'en est encore qu'à ses débuts. Non pas qu'il en manque, mais parce qu'il y en aura forcément d'autres et peut-être de plus fortes encore. Ce qui n'est pas une raison pour ne pas choisir, au risque de froisser celles et ceux qui ne sont pas retenu.e.s.

Mais l'auteur de ce livre peut attester de la forte personnalité de Pierre Paroz et témoigner de l'impact qu'il a exercé sur lui et sur sa théologie. Dans de rares et brèves rencontres, mais surtout par lectures interposées.

Pierre Paroz (1949-2015), connu comme «le Piotr» dans son Jura natal, un surnom qui pourrait s'expliquer par sa ressemblance avec Alexandre Soljenitsyne, a été un mari, un père, un pasteur, un enseignant, un écrivain, entre autres choses et tout à la fois.

Né à Bienne en 1949, il suit des études de théologie dans les Universités de Lausanne et de Zurich, et devient, dès 1974, pasteur dans le Jura bernois: à Villeret pendant neuf ans, puis à Moutier pendant dixhuit ans.

En 1984, il obtient un doctorat en théologie de l'Université de Neuchâtel pour un travail de théologie fondamentale où il démontre que la foi chrétienne est une hypothèse qui peut être démentie par l'expérience, y compris les questions de Dieu et de la résurrection de Jésus.

Dès 1994, il participe à l'élaboration d'un nouveau catéchisme pour les enfants protestants dans les Églises réformées Berne-Jura-Soleure, une catéchèse à la fois communautaire, puisque c'est la communauté chrétienne qui démontre que le message biblique est vivant, et existentielle, puisque catéchètes et catéchumènes cherchent ensemble comment Dieu les rejoint dans leur existence. 
En 2001, il occupe deux postes d'enseignement à Bienne: la philosophie et les sciences des religions au Gymnase français, ainsi que la religion et l'éthique à la Haute École pédagogique.

Diagnostiqué de la maladie de Parkinson en 2003, il cesse son activité professionnelle en 2010. Intégrant sa maladie dans sa vie de foi et sa foi dans sa vie de malade, il demande à Dieu: «Prends soin de ma fin.» Il fait de cette expression, empruntée au Requiem de Mozart - «Gere curam mei finis»-, le titre d'un livre où il aborde de front la question du suicide assisté. Avec sa foi chrétienne, il y défend la dignité de la vie, de sa vie, de la vie bénie - en grec : zoé -, de la vie à qui Dieu donne un sens, de la seule vie vraiment humaine. Prendre soin de cette vie implique le droit de mettre fin à l'autre vie - en grec : bios - quand elle devient seulement végétative.

Pierre Paroz meurt en 2015, sans recourir à l'aide à mourir, en ayant combattu la maladie jusqu'au bout.

\section{Principaux ouvrages :}

Paroz Pierre, Prends soin de ma fin. Du devoir de vivre et du droit de mourir dans la dignité, Lyon: Éditions Olivétan, 2010.

Paroz Pierre, Parenthèse et Acolade, Contes de Noël, Bévilard: Éditions du ROC, 2005.

PAROZ Pierre, Le protestantisme vu par un adolescent. Itinéraire d'une protestation, Genève: Labor et Fides, 2001.

PAROz Pierre, Foi et raison. La foi chrétienne aux prises avec le rationalisme critique: Hans Albert et Gerhard Ebeling, Genève: Labor et Fides, 1985. 
dernière épouse de pas moins de trois réformateurs : Johannes Oekolampad, Wolfgang Capito et Martin Bucer - sont les reines et où Guillaume Farel n'est qu'un valet (mais il est susceptible de devenir le «bour» d'atout, la carte maîtresse). Enfin, le souvenir qui correspond sans doute le mieux aux stéréotypes sur le protestantisme, une pièce commémorative en argent de vingt francs émise par la Monnaie fédérale et ornée des portraits de Jean Calvin et de Huldrich Zwingli - honneur à Genève et à Zurich.

\subsection{LA FORMATION EN THÉOLOGIE}

Dès les années 2000, pour prendre en compte la diminution du nombre des étudiant·e·s, mais aussi pour répondre aux critiques sur la place de la théologie dans des universités publiques, les trois facultés de théologie protestante de Suisse romande, celles des Universités de Genève, de Lausanne et de Neuchâtel, se mettent à repenser leur fonctionnement et à intensifier leur collaboration. En 2004, elles créent une Fédération: l'enseignement de la théologie est dorénavant conçu sur le plan romand, chaque faculté offrant un enseignement dans une ou plusieurs spécialités, en y regroupant les professeur·e·s d'une même discipline. Lausanne continue d'offrir des programmes en sciences des religions, notamment l'histoire du judaïsme, les religions marginales, l'anthropologie, la psychologie et la sociologie de la religion, et renforce son offre en sciences bibliques. Genève reste un pôle d'excellence pour l'étude de l'histoire de la Réformation et élargit ses enseignements en théologie fondamentale, en philosophie et en éthique. Enfin, Neuchâtel change fondamentalement d'orientation en devenant une Faculté de théologie pratique. Désormais, ce sont les professeur·e·s et les étudiant·e·s en théologie qui se déplacent entre les trois cantons pour suivre leurs cours et poursuivre leurs études.

Le 31 juillet 2015, alors qu'elle ne compte plus qu'un seul professeur, la Faculté de théologie de l'Université de 
Neuchâtel ferme ses portes après cent quarante ans. Pour pallier cette disparition, les Universités de Genève et de Lausanne renforcent leur collaboration et créent un Collège de théologie protestante qui gère les formations en théologie. Elles mutualisent les enseignements - c'est-à-dire que les étudiant·e.s peuvent suivre indifféremment des cours sur l'un ou l'autre site -, créent chacune une chaire de théologie pratique et fondent un Institut lémanique de théologie pratique qui coordonne l'enseignement et la recherche en théologie pratique.

Dès les années 2010, les Églises évangéliques de Suisse romande décident de réorganiser la formation de leurs pasteur.e.s. En 2016, elles transforment l'Institut biblique et missionnaire Emmaüs à Saint-Légier (Vaud) en une Haute École spécialisée, nommée HET-PRO, «HET» valant pour «Haute École en Théologie» et «PRO» tout à la fois pour «protestante», pour «professante»-elle se réfère au Symbole de Nicée-Constantinople, à la Confession de foi du Réseau évangélique suisse et aux Confessions de foi du mouvement de Lausanne - et pour «professionnalisante». Ce nouveau lieu de formation en théologie a accueilli sa première volée d'étudiant·e.s en septembre 2017.

De leur côté, les Églises réformées de Suisse romande refondent l'ensemble de la formation professionnelle. En 2003, la Conférence des Églises réformées romande crée l'Office protestant de formation. Depuis 2014, cet office est responsable de la formation initiale et continue des diacres et des pasteur·e·s des Églises réformées de Suisse romande, ainsi que du Cours biblique par correspondance, un programme annuel d'étude de textes bibliques à destination des laïques. 


\section{LA BÉNÉDICTION DES COUPLES DE MÊME SEXE}

Dès la fin $\mathrm{du} \mathrm{Xx}^{\mathrm{e}}$ siècle, les Églises protestantes de Suisse se sont interrogées sur l'offre d'une bénédiction aux couples de même sexe. Première Église réformée romande à se prononcer, l'Église protestante de Genève la refuse en 1992. Et ce sont deux Églises réformées bilingues qui en sont les précurseures.

Celle de Berne, tout d'abord; en 1995, le règlement ecclésiastique indique: "L'accompagnement spirituel et diaconal vaut de manière identique pour des personnes seules, des couples mariés ou non mariés, des familles, des personnes ou des couples homosexuels, des divorcés ou des personnes vivant séparées, pour des personnes assumant seules l'éducation de leurs enfants ou des veufs. »

Celle de Fribourg ensuite, en 1998, dont le règlement ecclésiastique évoque «les cultes de bénédiction de couples non mariés » et cherche à «éviter toute confusion avec un culte de mariage».

Sur le plan civil, les initiatives sont d'abord cantonales. Le canton de Genève, en 2001, puis celui de Neuchâtel en 2004 introduisent un partenariat enregistré, qui vaut aussi bien pour les couples hétérosexuels - il peut pour eux «remplacer» le mariage - que pour les couples homosexuels - il représente pour eux la seule reconnaissance officielle. En 2005, le peuple suisse accepte avec une majorité de $58 \%$, l'introduction d'un partenariat enregistré pour toutes les formes de couple.

En 2002, la Commission de liturgie de l'Église réformée évangélique du canton de Neuchâtel entame une réflexion sur les «rites d'accompagnement» des couples homosexuels. En 2006, le Synode «charge le Conseil synodal d'élaborer un cadre pour une liturgie de bénédiction des couples liés par un partenariat». Mais quand le Conseil synodal dépose son rapport une année plus tard, le Synode refuse d'entrer en matière. 
La loi fédérale entre en vigueur le $1^{\text {er }}$ janvier 2007, et le grand public découvre que l'Église réformée en Suisse romande - au moins une Église réformée - bénit des couples de même sexe. Les médias rendent compte d'une célébration qui a lieu à Bienne, le 5 mai 2007, dans l'Église réformée Berne-Jura-Soleure. Elle est présidée par une pasteure, et l'un des deux conjoints est lui-même pasteur. Le Synode de l'Église évangélique réformée du canton de Vaud accepte en novembre 2012 ce qu'il avait refusé en 2008. Après des débats houleux, il décide, par 55 «oui » contre 31 «non» et une abstention, de célébrer les partenariats enregistrés. Il faut encore attendre une année pour que la forme liturgique en soit précisée : elle doit avoir lieu au cours d'un culte, comprendre une lecture biblique, un rappel du lien de partenariat et une prière pour le couple. Elle reconnaît aux paroisses et aux pasteur.e.s le droit à l'objection de conscience: elles et ils peuvent refuser d'accueillir ou d'officier pour des motifs théologiques. Au début de 2017, le Conseil synodal dresse un premier bilan. On y lit que les célébrations ont été peu nombreuses: une en 2013, deux en 2014, trois en 2015, une en 2016. Sur les sept célébrations, six concernaient des hommes et une des femmes.

En 2017, l'Église protestante de Genève décide d'entrer en matière. À l'unanimité moins cinq abstentions, les délégué.e.s des paroisses et des services acceptent de rouvrir et de discuter «la question d'une bénédiction et de gestes liturgiques pour les couples de même sexe reconnus civilement». En novembre 2019, le Consistoire accepte de donner la même bénédiction "pour les couples de même sexe que pour les couples de sexe différent».

Quant à l'Église réformée du Valais, elle n'a pas encore pris position, privant les couples de même sexe de toute reconnaissance liturgique. 


\subsection{L'AVENIR DES ÉGLISES RÉFORMÉES DE SUISSE}

Les délégué·e·s de la Fédération des Églises protestantes de Suisse ont décidé le 18 décembre 2018 de fonder «l'Église évangélique réformée de Suisse » qui réunira les vingt-quatre Églises protestantes cantonales en une seule Église fédérale. Le $1^{\text {er }}$ janvier 2020, quand entrera en vigueur la constitution de cette nouvelle Église, pourrait marquer le début d'une nouvelle époque pour le protestantisme suisse. Comme un clin d'œil aux transformations de la Suisse romande protestante, c'est le Valais qui accueillera son premier synode...

\section{QUELLE GRANDE HONTE? L'AVENIR LE DIRA}

Le $1^{\text {er }}$ avril 2118 à 22 h 30, Ibrahim fait apparaître l'hologramme de Marie NDongo, professeure de transmission des croyances marginales à la Faculté de religiologie de l'Université suisse. Il veut prolonger la réflexion proposée, il y a cent ans, par un professeur de «théologie pratique» de l'Université de Lausanne, un professeur depuis longtemps décédé. "OK Marie! Quelles sont les grandes hontes du christianisme "suisse romand" au XXI siècle?» Grâce à la réalité très augmentée, l'hologramme de Marie NDongo reçoit immédiatement dix téraoctets de données; en trois nanosecondes, il trie, hiérarchise et sélectionne les informations les plus pertinentes. Ibrahim choisit un sujet de honte qui l'intéresse et qu'il peut supporter.

«Aussi incroyable que cela puisse paraître, au XXI siècle, les Églises chrétiennes n'accueillaient pas encore largement et chaleureusement toutes les personnes qui voulaient les visiter, qui souhaitaient participer à leur vie ou qui désiraient en devenir membres. En Suisse romande, les Églises réformées - une appellation qui a perduré jusqu'au milieu du siècle - s'étaient montrées plutôt plus ouvertes que d'autres Églises, d'autres associations 
ou d'autres institutions. Mais il restait des exclus: certains pasteurs remettaient en cause l'aptitude des femmes à prêcher parce que certains hommes refusaient de les écouter. La publication d'une photo d'un couple gay avait suscité l'indignation de certaines lectrices et de certains lecteurs du magazine Réformés. On avait même proposé de célébrer des baptêmes en privé au prétexte que la présence d'enfants perturbait le culte paroissial. Les temples n'étaient pas toujours adaptés aux personnes en situation de handicap, et quand ils l'étaient, ils leur permettaient souvent d'être spectatrices, mais rarement actrices. L'aménagement des locaux paroissiaux ne convenait pas aux familles avec des bébés ou de jeunes enfants, car les toilettes et le mobilier étaient rarement adaptés: il n'y avait pas de table à langer; les endroits pour allaiter étaient rares. Avant l'apparition de la technologie de la T3I - traduction immédiate intérieure intégrée -, il n'était pas possible pour celles et ceux qui ne maîtrisaient pas le français de comprendre les paroles prononcées. Et quand elle a été largement implantée, on n'a pas toujours cherché à tenir compte des particularismes culturels. Faute de pain sans gluten, la cène était encore interdite aux malades coeliaques et les véganes devaient supporter un christianisme de l'agneau pascal, de l'agneau sacrifié, de l'agneau dont le sang lave les péchés.»

Que des chrétien.ne·s aient pu faire preuve d'aussi peu d'empathie laisse Ibrahim songeur. D'autant plus que cela ne date que d'à peine cent ans. Il se demande comment ces chrétien-ne·s n'ont pas compris qu'ils et elles allaient à l'encontre de l'évangile. En même temps, Ibrahim reste modeste. Il n'est pas sûr qu'il aurait fait mieux à leur place. Mais un autre aspect intrigue Ibrahim: comment un professeur de théologie pratique à l'Université de Lausanne a-t-il pu choisir en 2018 de donner un cours sur l'histoire spécifique des Églises réformées en Suisse romande, deux notions - «Églises réformées » et «Suisse romande»- qui ont depuis longtemps disparu? «Heureusement, se dit-il, ce fut un des derniers cours de théologie à ne pas intégrer une perspective interreligieuse et interculturelle.» 


\section{ORIENTATION BIBLIOGRAPHIQUE :}

Bourquin Y., Charras Sancho J., L'accueil radical: ressources pour une Église inclusive, Genève: Labor et Fides, 2015.

Chappuis J.-M., Ecclesiastic Park: histoire fantastique de William Bolomey, dernier pasteur chrétien, Genève: Labor et Fides, 1998.

Montmollin G. de, Jordan D., Un ange passe: 7 Räume des Glaubens $=7$ lieux spirituels, traduction de R. Schlegel, Genève: Labor et Fides, 2002.

Stolz J., Ballif E., Auberson L., L'avenir des réformés: les Églises face aux changements sociaux, Genève: Labor et Fides, 2011. 


\title{
BILAN
}

\author{
Presque 500 ANS DE PROTESTANTISME \\ EN SUISSE ROMANDE
}

Quel bilan tirer de presque 500 ans de protestantisme en Suisse romande? Quatre grandes périodes se détachent.

\section{Premier temps : L'ÉtABlisSement}

Il n'aura pas fallu plus de dix ans pour que la Réforme protestante s'impose en Suisse romande. Entre le premier culte à Aigle en 1526 et l'envahissement du pays de Vaud en 1536, les futurs cantons de Genève, de Neuchâtel et de Vaud ainsi que le Jura bernois et Morat deviennent protestants, tandis que Fribourg, le Jura et le Valais restent catholiques. À la fin du $\mathrm{XVI}^{\mathrm{e}}$ siècle, la carte confessionnelle de la Suisse romande est fixée, même s'il y a encore quelques évolutions dans le bailliage commun d'Échallens.

\section{DEUXIÈME TEMPS : LA FIXATION}

Pendant plus de deux cents ans, la situation du protestantisme ne va guère changer. Dans les territoires protestants, les Églises réformées fonctionnent comme des Églises d'État qui ne laissent pas, puis peu de place aux autres confessions. Au cours des $\mathrm{XVII}^{\mathrm{e}}$ et $\mathrm{XVIII}^{\mathrm{e}}$ siècles, on note cependant une lente ouverture de l'orthodoxie réformée à d'autres théologies protestantes, libérales et piétistes. 


\section{TROISIÈME TEMPS : LA LIBÉRALISATION}

Quand Bonaparte impose à la Suisse une République helvétique, quand le Congrès de Vienne modifie les frontières des cantons suisses, ils enclenchent un processus qui va conduire la Suisse - malgré la guerre du Sonderbund - vers la liberté religieuse. À la fin du XIX ${ }^{\mathrm{e}}$ siècle, catholiques et protestant.e.s exercent leur droit de s'installer dans n'importe quel canton. Mais le $\mathrm{XIX}^{\mathrm{e}}$ siècle connaît une autre évolution importante, celle-là interne au protestantisme. Il s'agit de l'émergence d'Églises protestantes évangéliques, indépendantes ou libres, qui toutes refusent d'être liées aux autorités politiques ou de dépendre d'elles.

\section{QUATRIÈME TEMPS: LA DIMINUTION}

En 2018, l'Office fédéral de la statistique publie les statistiques de la «Population résidante permanente de 15 ans et plus, selon l'appartenance religieuse et confessionnelle et le canton». Ces chiffres sont issus d'une observation réalisée en 2016. Ils sont éloquents.

Presque 500 ans après le début de la Réforme protestante en Suisse romande, deux siècles après la fin d'une hégémonie protestante dans les «cantons évangéliques», les réformé·e·s ne représentent plus qu'une minorité dans tous les cantons de la Suisse romande, à l'exception de Berne - on peut cependant se demander si cette majorité se retrouve encore dans la partie francophone.

Les réformé.e.s représentent $51 \%$ de la population du canton de Berne; $24 \%$ dans le canton de Vaud; $21 \%$ dans le canton de Neuchâtel; $12 \%$ dans le canton de Fribourg - francophones et germanophones confondus -, une part qui tend à croître. Il n'y a plus que $9 \%$ de réformé.e.s dans le canton de Genève; $8 \%$ dans le canton du Jura et $6 \%$ dans le canton du Valais - francophones et germanophones confondus, une population protestante qui croît ici aussi. 


\section{REGARD RÉTROSPECTIF}

Cet ouvrage est le fruit d'un cours intitulé « 491 ans de théologie pratique et de pratiques théologiques protestantes en Suisse romande » que j'ai donné à la Faculté de théologie et de sciences des religions de l'Université de Lausanne au printemps 2018.

J'ai choisi de donner ce cours - et d'écrire ce livre - d'abord pour apprendre d'où je viens. Comme Suisse romand, comme protestant et comme professeur de théologie pratique en Suisse romande protestante. Je voulais savoir comment la Suisse romande protestante avait fait ses pratiques et pensé sa théologie pratique pendant les presque 500 ans de son histoire. J'ai cherché à comprendre ce qui s'était pensé, écrit et fait dans les Églises protestantes d'hier pour aider à mieux penser, écrire et faire dans les Églises protestantes d'aujourd'hui.

Au commencement, je connaissais peu la matière que j'avais choisi d'enseigner. Bien moins que ce que je pensais savoir. J'ai donc beaucoup lu pour apprendre et comprendre. J'ai surtout lu des sources secondes, des ouvrages d'historien.ne-s qui ont identifié, dépouillé, lu, analysé, mis en perspective, commenté des sources premières. J'ai aussi lu quelques sources premières: des archives, des textes fondateurs, des journaux de pasteur.e.s ou de paroissien-ne-s. Je n'ai pas procédé de manière systématique mais j'ai lu ce que je connaissais, ce que l'on m'avait conseillé, ce que j'ai découvert par hasard, ce qui me paraissait pertinent. Il y a donc forcément des lacunes dans cet ouvrage. Et je suis convaincu que la lectrice ou le lecteur mettra le doigt sur des essentiels - ou sur ce qu'il ou elle juge essentiel - que j'aurai oubliés.

Pour ne pas retenir uniquement ce qui me plaît, ce que j'aime, ce qui me ressemble, j'ai tenté d'élargir mon horizon. J'ai donc traité de toute la Suisse romande, en rappelant ce qui est connu mais en présentant aussi des faits - ou ma 
représentation des faits -, des personnalités - des hommes et des femmes -, des gestes et des textes peu ou moins connus.

Pour ne pas idéaliser la Suisse romande protestante, j'ai aussi réfléchi aux plus grandes hontes qui jalonnent son histoire qui est la mienne aussi. J'en parle avec des regrets et des remords, mais aussi avec de l'empathie et de la sympathie pour mes devancières et mes devanciers, car je n'aurais certainement pas pensé, écrit, ni fait mieux.

Je mentionne encore une dernière limite: je suis tout à fait conscient des nouvelles orientations de l'historiographie de l'histoire du christianisme, notamment quant à la confessionnalisation - il faudrait et il faudra de plus en plus tenir également compte des religions non chrétiennes - ou relatives aux usages sociaux et politiques du religieux. Mais mon ouvrage se veut une première synthèse du protestantisme en Suisse romande. Et le format de la collection m'a contraint à faire des choix.

Je tiens à remercier les étudiant·e.s qui ont suivi mon cours. Ce livre leur doit beaucoup. Venant de toute la Suisse romande-et d' ailleurs !-elles et ils m'ont apporté leurs connaissances, générales et singulières; elles et ils m’ont fait découvrir en particulier des aspects très locaux du protestantisme suisse romand. Et comme étudiant·e·s en master de théologie, elles et ils m'ont obligé, par leurs questions, leurs remarques et leurs critiques, à travailler et retravailler ma matière. Merci donc à Nicole Awais, Maëlle Camille-Claire Bader, Abigaïl Bassac, Vincent Demaurex, Noémie Émery, Valérie Gafa, Calen Ebere Lee Gayle, Florence Hostettler, Julia Linder Simonin, Matthieu Mérillat, Pascal Pretot, Christine Rumpel et Carl-André Spillmann; ainsi qu'à Nathalie Monot-Senn et Philippe Zannelli, mes deux assistant.e.s pour ce cours.

Merci aussi à Jean-Pierre Curchod, Didier Halter, Lauriane Savoy et Alain Wimmer pour leurs précieux renseignements.

Et merci à Gabriel de Montmollin, directeur du Musée international de la Réforme pour m'avoir donné accès à ses archives et permis de reproduire des images de ses très riches collections. 


\section{TABLE DES MATIÈRES}

\section{INTRODUCTION}

LA SUISSE ROMANDE PROTESTANTE ................................... 7

La Suisse n'existe pas !........................................ 7

La Suisse romande n'existe pas !.......................... 8

La Suisse romande protestante n'existe pas !.......... 8

De quelle Suisse romande protestante est-il question ? ................................................... 9

Chapitre $1-\mathrm{XVI}^{\mathrm{e}}$ SIÈCle : LA RÉForme PRotestante..... 18

1.1 Dans le canton de Berne................................. 19

1.2 Pendant ce temps-là, dans la Principauté épiscopale de Bâle............................................... 22

1.3 Pendant ce temps-là, dans le Comté de Neuchâtel et la Seigneurie de Valangin............. 28

1.4 Pendant ce temps-là, dans la République de Genève.............................................................. 33

1.5 Pendant ce temps-là, dans le Pays de Vaud..... $\quad 38$

1.6 Pendant ce temps-là, dans le Valais assujetti... $\quad 40$

1.7 Pendant ce temps-là, dans le canton de Fribourg... 41

ChAPITRE $2-\mathrm{XVII}^{\mathrm{e}}$ SIÈCLE:

UNE ORTHODOXIE PROTESTANTE........................................ 44

2.1 Orthodoxie théologique ................................... 45

2.2 Discipline et indiscipline ................................. 50

2.3 Tolérance et intolérance................................... 53

2.4 Cultes et lieu de culte...................................... 55

2.5 Pendant ce temps-là, dans le Valais assujetti... 61 
Chapitre 3 - XVIII ${ }^{\mathrm{e}}$ SIÈCle :

UN PROTESTANTISME D'OUVERTURE

3.1 Dans la Principauté de Neuchâtel

et de Valangin

3.2 Pendant ce temps-là, dans les territoires

sous influence bernoise.

3.3 Pendant ce temps-là, dans la République

de Genève.

Chapitre 4 - XIX ${ }^{\mathrm{e}}$ SIÈCle :

DIVERSIFICATION DES ÉGLISES PROTESTANTES

4.1 Nationalisation des Églises réformées

4.2 Naissance des Églises libres

ou indépendantes

4.3 Pendant ce temps-là, dans le canton

de Fribourg. .

4.4 Pendant ce temps-là, dans le canton

du Valais

4.5 Pendant ce temps-là, d'autres formes

de protestantisme s'installent en Suisse romande...

Chapitre $5-\mathrm{XX}^{\mathrm{e}}$ SIÈCLE :

UN PROTESTANTISME RENOUVELÉ

5.1 Un protestantisme suisse romand

5.2 Un protestantisme intercantonal.

5.3 Un protestantisme fédéral

5.4 Un protestantisme international

5.5 Pendant ce temps-là, dans les Églises

protestantes de Suisse romande.

ChAPITRe 6 - XXI ${ }^{\mathrm{e}}$ SIÈCLE :

UN PROTESTANTISME QUI SE RENOUVELLE

6.1 Les commémorations.

6.2 La formation en théologie.

6.3 L'avenir des Églises réformées de Suisse. 
BILAN

PRESQUe 500 ANS DE PROTESTANTISME

EN SUISSE ROMANDE ................................................... 151

Premier temps : l'établissement ............................... 151

Deuxième temps : la fixation .................................. 151

Troisième temps : la libéralisation .......................... 152

Quatrième temps : la diminution............................ 152

REGARD RÉTROSPECTIF................................................... 153 


\section{DANS LA MÊME COLLECTION}

Histoire de la Suisse

1. Walter François, L'invention d'une Confédération, $X V^{e}-X V I^{e}$ siècles

2. WaLter François, L'âge classique (1600-1750)

3. WALter François, Le temps des révolutions (1750-1830)

4. WaLter François, La création de la Suisse moderne (1830-1930)

5. Walter François, Certitudes et incertitudes du temps présent (de 1930 à nos jours)

6. LüTHI Dave, La construction de l'architecte. Histoire d'une profession en Suisse romande (1800-1940)

\section{Histoire du canton de Neuchâtel}

7. Bujard Jacques, Morerod Jean-Daniel, Oguey Grégoire, de ReYNiER Christian, Le comté de Neuchâtel à l'époque médiévale

8. Henry Philippe, De la Réforme à la révolution radicale de 1848

9. BARRELET Jean-Marc, La création d'une république. De la révolution de 1848 à nos jours

10. Donzé Pierre-Yves, Histoire du Swatch Group

\section{Histoire de Genève}

11. Caesar Mathieu, La cité des évêques (IV -XVIe siècle)

12. Walker Corinne, De la cité de Calvin à la ville française (1530-1813)

13. Perroux Olivier, De la création du canton en 1814 à nos jours

14. Mach André, David Thomas, Ginalski Stéphanie, Bühlmann Felix, Les élites économiques suisses au $\mathrm{XX}^{e}$ siècle

15. Extermann Blaise, Histoire de l'enseignement des langues en Suisse romande, 1725-1945

16. DonzÉ Pierre-Yves, Histoire des politiques hospitalières en Suisse romande

17. LÉCHOt Pierre-Olivier, Une histoire de la Réforme protestante en Suisse (1520-1565)

18. Robert Michèle, Histoire de la Réforme dans le Pays de Neuchâtel 


\section{Histoire de Fribourg}

19. Utz Tremp Kathrin, La ville de Fribourg au Moyen Âge $\left(X I I^{e}-X V^{e}\right.$ siècle)

20. WALter François, Une ville-État pour l'éternité (XVI $-X V I I I^{e}$ siècle)

21. Python Francis, Ancrages traditionnels et renouveaux (XIX ${ }^{e}-$ $X X^{e}$ siècle)

22. Humair Cédric, La Suisse et les puissances européennes. Aux sources de l'indépendance (1813-1857)

23. Meuwly Olivier, Une histoire politique de la démocratie directe en Suisse

24. Willemin Nicolas, Médias suisses, le virage numérique

25. Rennwald Jean-Claude, Zimmermann Adrian, Andrey Laurent, REYNARD Mathias, Wicki Julien, La grève générale de 1918 en Suisse. Histoire et répercussions

26. Tinembart Sylviane, Pahud Edward, Une innovation pédagogique. Le cas de l'enseignement mutuel au XIX siècle

Série Rayons littéraires

27. CoRbellari Alain, Le Moyen Âge à travers les âges

28. JAQUier Claire, Par-delà le régionalisme. Roman contemporain et partage des lieux

29. Schuwey Christophe, Interfaces. L'apport des humanités numériques à la littérature

30. Marti Laurence, L'émergence du monde ouvrier en Suisse au XIX $X^{e}$ siècle

31. BAUER Olivier, 500 ans de Suisse romande protestante 
Achevé d'imprimer

en janvier 2020

pour le compte des Éditions Livreo-Alphil

Responsables de production: Marie Manzoni, Anne-Caroline Le Coultre 
D'où vient la frontière entre Jura sud et Jura nord? Pourquoi le train Yverdon-Sainte-Croix ne circulait-il pas le dimanche? Depuis quand le Conseil œcuménique des Églises est-il installé à Genève? Qu'est-ce qui lie les Dames de Morges à la communauté de Grandchamp? Pourquoi peut-on faire ses courses à Bulle le lundi du Jeûne? D'où venait le bois utilisé pour construire la chapelle des Mayens de Sion? Pourquoi Henri Druey, James Fazy et AlexisMarie Piaget ont-ils nationalisé les Églises réformées?

Cet ouvrage répond à ces questions, à d'autres que vous vous posez, à celles que vous n'osez pas imaginer. Il vous mène du premier culte célébré en 1526 par Farel jusqu'au synode de l'Église réformée évangélique de Suisse en 2020 . Il vous conduit d'Aigle à Porrentruy, à Saxon, à Morat, aux Ponts-de-Martel, à Corgémont ou à Genève.

Il offre une vision panoramique et détaillée de chacun des six siècles de l'histoire protestante dans les sept cantons suisses francophones ou bilingues. II met en lumière six fortes personnalités - trois hommes et trois femmes - , six beaux gestes, mais aussi six grandes hontes du protestantisme romand.

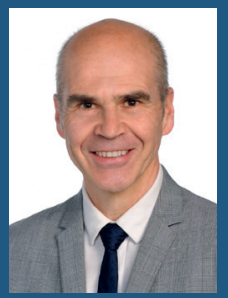

Olivier Bauer a grandi à Auvernier et vit à Lausanne. Entre le lac de Neuchâtel et le lac Léman, il est passé par Montpellier, Papeete, Washington et Montréal. Maintenant professeur de théologie pratique à l'Université de Lausanne, il combine un regard intérieur, celui d'un protestant romand, et un regard extérieur, celui que lui ont donné vingt années passées hors des frontières helvétiques, pour faire une synthèse de l'histoire du protestantisme suisse romand.

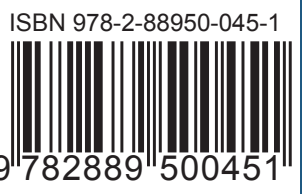

